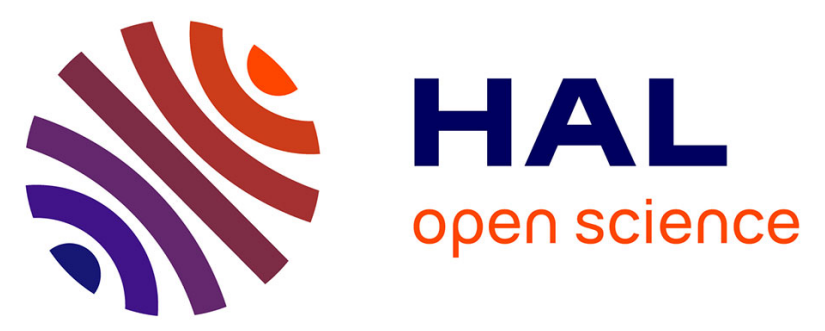

\title{
Correlations between broad-scale taxonomic and genetic differentiations suggest a dominant imprint of historical processes on beta diversities
}

\author{
Marine Robuchon, Boris Leroy, Céline Jézéquel, Bernard Hugueny
}

\section{To cite this version:}

Marine Robuchon, Boris Leroy, Céline Jézéquel, Bernard Hugueny. Correlations between broad-scale taxonomic and genetic differentiations suggest a dominant imprint of historical processes on beta diversities. Journal of Biogeography, 2019, 46 (5), pp.1083-1095. 10.1111/jbi.13559 . hal-02374621

\section{HAL Id: hal-02374621 \\ https: / hal.sorbonne-universite.fr/hal-02374621}

Submitted on 21 Nov 2019

HAL is a multi-disciplinary open access archive for the deposit and dissemination of scientific research documents, whether they are published or not. The documents may come from teaching and research institutions in France or abroad, or from public or private research centers.
L'archive ouverte pluridisciplinaire HAL, est destinée au dépôt et à la diffusion de documents scientifiques de niveau recherche, publiés ou non, émanant des établissements d'enseignement et de recherche français ou étrangers, des laboratoires publics ou privés. 
archives-ouvertes

\title{
Correlations between broad-scale taxonomic and genetic differentiations suggest a dominant imprint of historical processes on beta diversities
}

\author{
Marine Robuchon, Boris Leroy, Céline Jézéquel, Bernard Hugueny
}

\section{- To cite this version:}

Marine Robuchon, Boris Leroy, Céline Jézéquel, Bernard Hugueny. Correlations between broad-scale taxonomic and genetic differentiations suggest a dominant imprint of historical processes on beta diversities. Journal of Biogeography, Wiley, 2019, 46 (5), pp.1083-1095. 10.1111/jbi.13559 . hal02374621

\author{
HAL Id: hal-02374621 \\ https://hal.sorbonne-universite.fr/hal-02374621
}

Submitted on 21 Nov 2019

HAL is a multi-disciplinary open access archive for the deposit and dissemination of scientific research documents, whether they are published or not. The documents may come from teaching and research institutions in France or abroad, or from public or private research centers.
L'archive ouverte pluridisciplinaire HAL, est destinée au dépôt et à la diffusion de documents scientifiques de niveau recherche, publiés ou non, émanant des établissements d'enseignement et de recherche français ou étrangers, des laboratoires publics ou privés. 
1 Correlations between broad-scale taxonomic and genetic differentiations suggest a dominant imprint of historical processes on beta diversities

3 Running title: Broad-scale $\beta$-SGDCs in freshwater fishes

4 Marine Robuchon ${ }^{1,2 *}$, Boris Leroy ${ }^{1}$, Céline Jézéquel ${ }^{1,3}$ and Bernard Hugueny ${ }^{1,3}$

$5 \quad{ }^{1}$ Unité Biologie des organismes et écosystèmes aquatiques (BOREA), Muséum national

6 d'Histoire naturelle, Sorbonne Université, Université de Caen Normandie, Université des

7 Antilles, CNRS, IRD, CP 26, 57 rue Cuvier 75005 Paris, France

$8 \quad{ }^{2}$ Centre d'écologie et des sciences de la conservation (CESCO), Muséum national d'Histoire

9 naturelle, CNRS, Sorbonne Université, CP 135, 57 rue Cuvier 75005 Paris, France

$10 \quad{ }^{3}$ Laboratoire Évolution \& Diversité Biologique (EDB UMR 5174), Université de Toulouse

11 Midi-Pyrénées, CNRS, IRD, UPS, 118 route de Narbonne, Bat 4R1, 31062 Toulouse cedex 9,

12 France

* corresponding author: robuchon@mnhn.fr

\section{Acknowledgements}

This study was supported by the French State through the Research National Agency under the LabEx ANR-10-LABX-0003-BCDiv, within the framework of the program 'Investing for the future' (ANR-11-IDEX-0004-02). BH and CJ are supported by the French Laboratory of Excellence project "TULIP" (ANR-10-LABX-41; ANR-11-IDEX-0002-02). We thank Agnès

Dettaï and Gaël Denys for their valuable suggestions during the planning of this research work. We also thank Céline Bellard, Juliette Delavenne and Jean-Baptiste Mihoub for their relevant advice on figures and rewording that greatly improved the manuscript. We are grateful for the helpful comments of the associate editor and of two anonymous reviewers. 
- Aim: Dispersal limitation, environmental selection and drift are known to influence both taxonomic similarity between communities and genetic similarity between populations. However, disentangling the relative roles of these processes on spatial patterns of differentiation - whether regarding taxonomic differentiation between communities or genetic differentiation between populations - is challenging. Investigating whether spatial patterns of taxonomic differentiation and genetic differentiation are correlated ( $\beta$-SGDCs) is a promising approach to address this issue. Here, we investigated $\beta$-SGDCs over broad spatial scales and 22 freshwater fish species to elucidate the processes shaping taxonomic and genetic differentiations between drainage basins.

- Location: Global scope, data mainly from Europe and North America.

- Taxon: Actinopterygii and Petromyzontiformes (freshwater fishes).

- Methods: We used Mantel tests to investigate the raw correlation between taxonomic and genetic differentiations. We carried out multiple regressions to characterise the effects of geographic distance (proxy of dispersal limitation), environmental distance (proxy of environmental selection) and pairwise harmonic mean area between basins (proxy of drift) on taxonomic differentiation and genetic differentiation taken separately. We then analysed the correlation between the residuals of these two regressions with Mantel tests. Finally, we investigated whether the variation in $\beta$-SGDC between species was related to species traits.

- Results: We detected an overall positive $\beta$-SGDC, both for the raw and the residual correlations. This implies that, unmeasured effects, other than geographic distance, environmental distance and harmonic mean area, influence the $\beta$-SGDC observed. Values of $\beta$-SGDCs greatly varied between species, but this was not explained by any species traits. 


\section{Keywords}

54

$\beta$-SGDC, dispersal limitation, distance decay, drift, environmental selection, freshwater

fishes, historical processes, macrogenetics, Mantel tests, multiple regression of distance

- Main conclusions: Independently of the effects of geographic distance, environmental distance and harmonic mean area, the $\beta$-SGDC we observed suggests that historical processes strongly shaped the patterns of taxonomic and genetic differentiations between basins. Consequently, taxonomic differentiation may be an appropriate proxy to explain the influence of historical processes on genetic differentiation. matrices 
Understanding the mechanisms that shape taxonomic differentiation between spatially separated communities and those influencing genetic differentiation between spatially separated populations are long-standing issues in ecology and evolution (Wright, 1943, 1951; Whittaker, 1960, 1972; Preston, 1962; Mayr, 1963). More recently, these issues have been united (Vellend, 2003; Vellend \& Geber, 2005; Kahilainen, Puurtinen, \& Kotiaho, 2014), emphasising that drift, dispersal and selection influence both taxonomic differentiation between communities and genetic differentiation between populations. Drift and selection affect the species frequencies within communities and gene frequencies within populations, which tend to increase differentiation. Conversely, dispersal of individuals between populations and dispersal of species between communities will tend to decrease differentiation.

Among the factors that can affect both taxonomic and genetic differentiation, geographic distance is probably the most studied. The similarity in taxonomic composition between communities tends to decrease with the geographic distance that separates them; a pattern long-recognised in biogeography and formalised as the distance decay of similarity because the dispersal of organisms (i.e. their movement from a place to another) is limited by their intrinsic dispersal ability, which hence does not counteract anymore the differentiating 
similarity in spatially correlated environmental features; in such cases, the underlying explanation is environmental selection of different species (community differentiation) or genotypes (genetic differentiation) in distinct environments. However, differentiation between sites does not always increase with geographic distance. This is the case when the migrants are competitively excluded by already established communities (e.g. Almany, 2003) or populations (e.g. Fraser et al., 2018) at high densities, therefore counteracting the homogenising effect of dispersal whatever the intrinsic dispersal ability of the migrants. This may also happen when the environmental variation between sites displays no - or negative spatial autocorrelation (e.g. Derry et al., 2009).

Although spatial patterns of taxonomic and genetic differentiations can be explained by environmental selection independently of limited dispersal and vice-versa, disentangling the relative strengths of these mechanisms is challenging, as communities and populations that are geographically distant are also likely to inhabit different environments. Using modern spatial statistical methods, some recent studies have nonetheless taken up the challenge. In their study of global patterns of species turnover in terrestrial vertebrates, Qian \& Ricklefs (2012) have shown that both dispersal limitation and environmental selection have played important roles in determining the patterns they observed. Similarly, in their reinterpretation of 34 representative studies, Orsini et al. (2013) highlighted that patterns associated with dispersal limitation were as common as those associated with local genetic adaptation in structuring population genetic differentiation in the wild. However, the relative strength of dispersal limitation and environmental selection on differentiation patterns seems to vary according to the species and the spatial scale under consideration, both for taxonomic (Astorga et al., 2012; Moritz et al., 2013) and genetic (Orsini et al., 2013) differentiations. Comparative studies of multiple taxonomic groups suggest that the influence of dispersal limitation on taxonomic differentiation is stronger for species with low dispersal ability than 
for more effective dispersers, and this result holds true both at the broad-scale (e.g. Qian \& Ricklefs, 2012) and at the fine-scale (e.g. Astorga et al., 2012). Comparative studies of multiple species have also been identified as a promising avenue to reveal the factors influencing patterns of genetic differentiation (Wang et al., 2013). Yet, such studies are scarce and mainly carried out at relatively small spatial scales (e.g. Wang et al., 2013; Fourtune, PazVinas, Loot, Prunier, \& Blanchet, 2016) despite the increasing availability of broad-scale datasets in population genetics, suggesting that it is now time to embrace macrogenetics (Blanchet, Prunier, \& De Kort, 2017).

Theories in population genetics and community ecology acknowledge that dispersal, selection and drift together shape the differentiation between populations and between communities (see e.g. Vellend \& Orrock, 2009 for a review of processes in both disciplines). However, the contribution of drift to taxonomic or genetic differentiation has been the subject of few empirical investigations, in contrast with dispersal limitation and environmental selection (Gilbert \& Levine, 2017; Prunier, Dubut, Chikhi, \& Blanchet, 2017). Genetic drift is the evolutionary process of random fluctuations in allelic frequencies occurring naturally in all populations due to their finite size, although it is stronger in small ones (Allendorf, 1986). Similarly, ecological drift corresponds to the random fluctuations in species frequencies occurring naturally in all communities due to their finite size and this too is stronger in small ones. Drift is the result of random sampling during the processes of birth, death and reproduction and ultimately leads to the loss of genetic diversity within populations, and species diversity within communities. Therefore, drift increases the differentiation between populations and between communities depending on their respective sizes: the smaller they are, the more they will differentiate. Dispersal of organisms between populations and between communities counteracts the differentiating effect of drift while environmental selection can accelerate it. Attributing the observed spatial patterns of genetic or taxonomic differentiation 
to dispersal limitation or to environmental selection without accounting for drift may thus be misleading.

Most of the explanatory variables used in analyses to infer the role of dispersal limitation and environmental selection on differentiation patterns are proxies representing present-day conditions. Thus, using current explanatory variables to investigate dispersal limitation and environmental selection on differentiation patterns is only relevant if the contemporary geography and environment of the study area has not changed substantially since these patterns were established (Wang et al., 2013). Otherwise, the historical processes that may have shaped the observed differentiation patterns, including those explaining colonisation histories, may be overlooked. In addition, if dispersal is not continuous (as generally assumed) but rather intermittent because of landscape dynamics which have induced the appearance and disappearance of dispersal barriers, then two geographically close localities sharing a similar environment could, nevertheless, be dissimilar in terms of community composition and allele frequencies provided they have been isolated for a sufficiently long time (given their sizes) for drift to be effective. Nonetheless, examining which part of differentiation patterns is not explained by current explanatory variables may help to elucidate the influence of historical processes on those patterns.

In such complex contexts, understanding the rules that govern differentiation patterns (both taxonomic and genetic) may be enhanced by comparing taxonomic dissimilarities between communities and genetic dissimilarities between populations of a focal species (Lamy, Laroche, David, Massol, \& Jarne, 2017). The few empirical studies that have examined these correlations, called beta species-genetic diversity correlations ( $\beta$-SGDCs) (Kahilainen et al., 2014), revealed a majority of positive correlations (reviewed by Lamy et al., 2017). This suggests that the processes affecting taxonomic dissimilarity affect genetic dissimilarity of the species under study in the same way (Baselga et al., 2013; Baselga, 
158 Gómez-Rodríguez, \& Vogler, 2015). However, because the relative strength of processes shaping patterns of taxonomic and genetic differentiation is expected to vary according to the species and the spatial scale under consideration, so is the strength of the putative resulting $\beta$ SGDCs. Among the rare studies of $\beta$-SGDCs over multiple species, some have highlighted that positive $\beta$-SGDCs were stronger for focal species with low dispersive abilities (e.g. Papadoulou et al., 2011) while others did not find strong differences between species (e.g. Fourtune et al., 2016), and all were carried out at relatively small spatial scales. These contrasting results call for more studies of $\beta$-SGDCs for multiple species to gain a better understanding of whether and how variations in species traits lead to distinct patterns of $\beta$ SGDCs. In addition, $\beta$-SGDCs for multiple species have not been examined yet at broad spatial scales.

Freshwater fishes are a relevant model to start investigating this question for at least three reasons. First, as $\beta$-SGDCs for multiple freshwater fish species have been conducted at small scales within a single drainage basin (Fourtune et al., 2016), computing $\beta$-SGDCs for multiple freshwater fish species at broader scales will permit the comparison of $\beta$-SGDC variations across scales for the same biological model. Secondly, for strictly freshwater fishes, at present, almost no exchange of individuals occurs between drainage basins (hereafter "basins") because they are isolated from each other by land and/or sea (although dispersal may occasionally occur between adjacent basins). Therefore, if basins are isolated from each other independently of the geographic distance between them, we can expect dispersal limitation to play a minor role on the broad-scale between-basin patterns of taxonomic and genetic differentiations. On the contrary, if basins have been isolated from each other for a

180 long time, we can expect drift to play a significant role on the broad-scale between-basin 181 patterns of taxonomic and genetic differentiations, as dispersal no longer counteracts the effect of drift. This is particularly true if population sizes and community sizes are small: the 
larger they are, the longer it will take to observe differentiation. Finally, while several recent studies have tried to disentangle the role of dispersal limitation, environmental selection and historical processes on patterns of taxonomic differentiation between basins (Leprieur et al., 2009, 2011; Dias et al., 2014), the processes shaping genetic differentiation at such broad scales have rarely been examined together. Studying $\beta$-SGDCs may therefore reveal whether the processes influencing between-basin taxonomic differentiation, affect between-basin genetic differentiation in the same way.

In this meta-analysis of 22 freshwater fish species, our main goal was to elucidate the processes underlying $\beta$-SGDCs at broad spatial scales. In particular, we wanted to test whether $\beta$-SGDCs can be explained by the parallel action of measurable processes (dispersal limitation, environmental selection and drift) on taxonomic and genetic differentiation, or are due to other, non-measurable processes. To that end, we first computed measures of genetic differentiation between basins for each fish species. Then, for each species, we investigated i) the raw correlation between taxonomic and genetic differentiations, ii) the effects of geographic distance (as a proxy of dispersal limitation), environmental distance (as a proxy of environmental selection) and pairwise harmonic mean area between basins (as a proxy of drift) on taxonomic differentiation and genetic differentiation taken separately and iii) the correlation between taxonomic and genetic differentiations independent of the effects of geographic distance, environmental distance and harmonic mean area (Fig. 1). Such independent correlation integrates the effects of unmeasured processes, including the historical processes of dispersal, environmental selection and drift related to the historical connectivity of basins. This allowed us to characterise the overall (i.e. mean over the species) raw $\beta$-SGDC, the overall effects associated with each predictor for each response variable, and the overall independent $\beta$-SGDC. Finally, we tested whether the variation in $\beta$-SGDCs between species could be attributed to variations in species traits. 


\section{Materials and methods}

Genetic differentiation and geographic distribution of genetic data

211 As we wanted to investigate genetic differentiation at the broad scale, we restricted our analyses of spatial genetic differentiation to species exhibiting a wide distribution. We downloaded sequence records of the mitochondrial gene cytochrome c oxidase I (COI) from BOLD (www.boldsystems.org) in May 2017 for the following widespread taxa: Cyprinidae, Salmonidae, Lampetra, Petromyzon, Cobitis, Misgurnus, Barbatula, Silurus, Esox, Lota lota, Gymnocephalus and Sander. We first cleaned and aligned sequences by taxon and then realigned them together to keep the same fragment of 501 nucleotides for the analyses. Sequence records without sufficient geographic information to assign them to a drainage basin (hereafter "basin") or without a species name were discarded from our dataset. We defined a basin as the drainage area upstream from its mouth at the sea. According to this definition, a basin is isolated from other basins by barriers (sea or land) which are impassable for strictly freshwater fishes. The validity of species names was assessed using FishBase (Froese \& Pauly, 2017), resulting in a total of 6637 sequence records with a valid species names belonging to 716 distinct species distributed in 218 basins. We checked the environment (i.e. "freshwater", "brackish", "saltwater") of each species using FishBase (Froese \& Pauly, 2017), the status (i.e. "native", "exotic" or "unknown") of each species in each basin using the global database on freshwater fish species occurrence (Tedesco et al., 2017). We conserved only native records of strictly freshwater species, i.e. 4894 records, corresponding to a total of 509 species in 176 basins. 
three individuals per basin. To calculate such genetic differentiation, we converted single nucleotide polymorphisms (SNPs) of the sequence data into a table of individual genotypes and then calculated pairwise genetic distances for each pair of basins using G', ${ }_{\text {ST }}$ (Meirmans \& Hedrick, 2011), the corrected version of Hedrick's G' ${ }_{\text {ST }}$ (Hedrick, 2005). G' ${ }_{\text {ST }}$ is independent from within population diversity and does not underestimate genetic distance when the number of populations is small (Meirmans \& Hedrick, 2011). As G', st likely removes the effect of drift, we also calculated the pairwise genetic distances for each pair of basins using $\mathrm{F}_{\mathrm{ST}}(\mathrm{Nei}, 1973)$ for comparison purpose.

All these different selection filters drastically reduced the number of species we included in analyses: we finally focused our analyses of between-basin genetic differentiation on a total of 22 species in 38 basins (for more details about these basins, see Appendix S1 in Supporting Information). For instance, from all the species of Lampetra and Petromyzon we searched in BOLD, we conserved only L. planeri for the analyses. The number of species with analysed genetic data per basin varies from one (for 20 basins) to seventeen (for one basin, the basin "Odra"; Fig. 2; Appendix S1). The number of basins per species varies from four (our minimum threshold) to eleven (for the species Esox lucius) covering on average 76 $\%$ (standard deviation $(\mathrm{sd})=18 \%$ ) of their native range, with species exhibiting on average 11.0 individuals per basin $(\mathrm{sd}=11.0$; Appendix S2). Most records are located in Europe and North-America (Fig. 2).

\section{Taxonomic differentiation}

We calculated pairwise taxonomic differentiation between each pair of basins based on the list of native species per basin extracted from the global database on freshwater fish species occurrence (Tedesco et al., 2017). We used Simpson dissimilarity $\left(\beta_{\text {sim }}\right)$ - the turnover component of Sørensen dissimilarity (Sørensen, 1948) - which is independent from total 
taxonomic richness (see Baselga 2012 for review).

We computed between-basin geographic distance by calculating the distance between basin centroids. The average distance between basins was $5295 \mathrm{~km}(\mathrm{sd}=3920 \mathrm{~km})$. Measurements of geographic distance were then centred and scaled before further analyses. contemporary climate known to influence freshwater fish alpha diversity patterns at the global scale (e.g. Dias et al. 2014; Oberdorff et al. 2011; Tedesco et al. 2012; Tisseuil et al. 2013) i.e. mean annual temperature and precipitation (http://www.worldclim.org/), mean annual surface runoff (http://www.grdc.sr.unh.edu/) and mean annual actual and potential evapotranspiration (http://csi.cgiar.org/Aridity/). The mean values of all the variables were computed for each basin. To compute pairwise environmental distances between each pair of basins, we performed a principal component analysis (PCA) on these environmental variables (previously centred and scaled) and calculated the Euclidean distance between basins based on the first three PCA axes.

Finally, we calculated the pairwise harmonic mean area between each pair of basins. Indeed, the harmonic mean population size between pairs allows the role of drift on genetic differentiation (Serrouya et al., 2012) to be taken into account and can be computed using environmental proxies for local carrying capacities (Prunier et al., 2017). In our case, we used

275 the surface area of the basin as a raw environmental proxy for local carrying capacity. The 276 basins studied had an average surface area of $257589 \mathrm{~km}^{2}\left(\mathrm{sd}=584803 \mathrm{~km}^{2}\right)$. Measurements

277 of harmonic mean area were centred and scaled before further analyses. 
First, we investigated the raw correlation between taxonomic differentiation and genetic differentiation for each species individually using a Mantel correlation test with 999 permutations. To test the null hypothesis that there is no relationship between taxonomic differentiation and genetic differentiation using the information provided by all the species examined, we considered that this hypothesis has been tested independently $n$ times, with $n$ being the number of species included in the analyses. To combine the results from several independent tests bearing upon the same overall hypothesis, we used a modification of the Fisher's combined probability test. Under the null hypothesis that taxonomic and genetic differentiations are unrelated, observed p-values associated with the Mantel's test of each species are expected to be distributed according to a uniform distribution in $[0,1]$. We therefore compared the observed mean p-value over the species to a null distribution of mean p-values obtained by sampling randomly 10000 times one p-value by species in a uniform distribution in $[0,1]$. We calculated the p-value associated with the combined test as the frequency at which null mean p-values were below the observed mean p-value. This procedure avoids some problems identified by the use of a chi-2 test (e.g. Whitlock, 2005) which was the method initially proposed by Fisher.

To investigate the putative roles of dispersal limitation, environmental selection and drift on taxonomic and genetic differentiations, for each species we built multiple regressions of geographic distance $\left(D_{\text {geo }}\right)$, environmental distance $\left(D_{\text {env }}\right)$ and harmonic mean area $\left(D_{\text {area }}\right)$ on taxonomic differentiation (TD) and genetic differentiation (GD) taken separately (Fig. 1) as follows: TD $=\alpha_{0}+\alpha_{1} *$ Dgeo $+\alpha_{2} * \mathrm{D}_{\text {env }}+\alpha_{3} * \mathrm{D}_{\text {area }}$ and GD $=\beta_{0}+\beta_{1} *$ Dgeo $+\beta_{2} * \mathrm{D}_{\mathrm{env}}+$ $\beta_{3} * D_{\text {area. }}$ Our approach is very similar to multiple regressions on distance matrices (MRM; Lichstein 2007) except in the way we calculated p-values associated with partial regression coefficients. As in MRM, we permuted the rows and associated columns of the response distance matrix simultaneously. We repeated this operation 1999 times while holding the 
explanatory distance matrices constant to generate null distributions for partial regression coefficients. Then, in MRM, the p-value associated with a partial regression coefficient is calculated with a two-sided permutation test using the pseudo-t of Legendre et al. (1994), i.e. it tests whether the t-statistic associated with each regression coefficient is lower or higher than expected under a null distribution of pseudo-t obtained by permutation. In our approach, we hypothesised that geographic distance and environmental distance have a positive effect on both taxonomic and genetic differentiations (dispersal limitation and environmental selection enhance differentiation and are positively related to geographic and environmental distances respectively) while harmonic mean area has a negative effect on taxonomic and genetic differentiations (drift enhances differentiation and is negatively related to the harmonic mean area). To increase the statistical power of the tests, we therefore carried out one-sided tests for calculating the p-values associated with each partial regression coefficient. We tested the overall (i.e. over the species) effects of geographic distance, environmental distance and harmonic mean area on taxonomic and genetic differentiations by performing a combined probability test as described for the raw correlation between taxonomic and genetic differentiations, but this time considering probabilities associated with partial regression coefficients.

To examine whether taxonomic and genetic differentiations were still correlated once the effects of geographic distance and environmental distance had been taken into account, we then performed a Mantel correlation test between the residuals of the multiple regression on taxonomic differentiation and the residuals of the multiple regression on genetic differentiation with 999 permutations for each species. We tested this overall (i.e. over the species) residual correlation using a combined probability test as described for the raw correlation between taxonomic and genetic differentiations. 
Finally, we examined the heterogeneity between species regarding the residual

correlation between taxonomic and genetic differentiations and tested whether some species traits could explain such heterogeneity. The species traits initially considered were body aquarium, habitat, migratory behaviour and dispersal ability - which was calculated using a formula giving dispersal distance as a function of body size and caudal fin aspect ratio

334 (Radinger \& Wolter, 2014). However, as migratory behaviour was 'potamodromous' for 16 out of the 22 species, 'non-migratory' for one species and the information was not available for the 5 species left, we excluded this non-informative trait from our analyses. Species traits were directly extracted from FishBase (Froese \& Pauly, 2017). All the analyses and the corresponding figures were realised with R 3.5.1 (R Core Team 2018) using the packages 'ade4' (Dray \& Dufour, 2007), 'ape' (Paradis, Claude, \& Strimmer, 2004), 'betapart'

(Baselga, Orme, Villeger, De Bortoli, \& Leprieur, 2018), 'Biostrings' (Pagès, Aboyoun,

Gentleman, \& DebRoy, 2018), 'broom' (Robinson \& Hayes, 2018), 'ggplot2' (Wickham,

2016), 'ggthemes' (Arnold, 2018), 'hierfstat' (Goudet \& Jombart, 2015), 'maptools' (Bivand $\underline{\text { \& Lewin-Koh, 2018), 'mmod' (Winter, 2012), 'RColorBrewer' (Neuwirth, 2014), 'rgdal' }}$

(Bivand, Keitt, \& Rowlingson, 2018), 'rgeos' (Bivand \& Rundel, 2018), 'reshape2'

(Wickham, 2007), 'seriation' (Hahsler, Buchta, \& Hornik, 2018) and 'vegan' (Oksanen et al., 2018).

\section{Results}

We detected an overall positive correlation between taxonomic and genetic differentiations, significantly different from 0 . This result holds true both for the raw correlation between taxonomic and genetic differentiations $\left(\mathrm{r}_{\text {mean } \pm \mathrm{sd}}=0.433 \pm 0.420\right.$; Fig. 3a; Appendices S3, S4) 
and for the residual correlation, i.e. the correlation between taxonomic and genetic differentiations independent of the effects of geographic distance, environmental distance and harmonic mean area $\left(r_{\text {mean } \pm \text { sd }}=0.379 \pm 0.641\right.$; Fig. 3b; Appendices S3, S4).

There was almost no overall effect of geographic distance on taxonomic differentiation $\left(\alpha_{1 \text { mean } \pm \text { sd }}=0.032 \pm 1.051\right)$ or on genetic differentiation $\left(\beta_{1 \text { mean } \pm \text { sd }}=-0.011 \pm 1.060\right)$, and these overall effects did not differ significantly from 0 (Fig. 4; Appendices S5, S6, S7). In contrast, we detected an overall positive effect of environmental distance on both taxonomic differentiation $\left(\alpha_{2 \text { mean } \pm \text { sd }}=0.405 \pm 0.956\right)$ and genetic differentiation $\left(\beta_{2 \text { mean } \pm \text { sd }}=0.229 \pm\right.$ 0.865), although it was only significantly different from 0 for taxonomic differentiation (Fig. 4; Appendices S5, S6, S7). There was an overall negative effect of harmonic mean area on both taxonomic differentiation $\left(\alpha_{3 \text { mean } \pm \text { sd }}=-0.178 \pm 0.617\right)$ and genetic differentiation $\left(\beta_{3 \text { mean }}\right.$ \pm sd $=-0.092 \pm 0.713)$, but it was only significantly different from 0 for taxonomic differentiation (Fig. 4; Appendices S5, S6, S7). Using $\mathrm{F}_{\mathrm{ST}}$ as a measure of genetic differentiation did not change the trend we observed: there was an overall negative but not significant effect of harmonic area on $\mathrm{F}_{\mathrm{ST}}$ (Appendices S6, S7).

The results of these multiple regressions as well as the residual correlations between taxonomic and genetic differentiations are summarised in Fig. 5. Overall, they suggest that the effect of geographic distance, environmental distance and harmonic mean area only explain a small part of the correlation between taxonomic and genetic differentiations.

Despite this strong overall independent correlation between taxonomic differentiation of freshwater fish communities and genetic differentiation of freshwater fish populations, the correlation between taxonomic and genetic differentiations varied greatly between species (Fig. 3b; Appendix S3). For some species, such as the common roach Rutilus rutilus (Fig. 6a, b), there was a sound correlation between taxonomic differentiation and genetic 
differentiation, whether we considered the raw or residual correlation. In other species, such as the common chub Squalius cephalus, taxonomic differentiation and genetic differentiation were not correlated (Fig. 6c, d). In this species, genetic differentiation was better predicted by geographic distance and harmonic mean area (Appendix S5). However, none of the species traits examined explained this heterogeneity of responses between species (Appendix S8).

\section{Discussion}

Our analyses indicated that taxonomic and genetic differentiations are strongly correlated overall, and independently of the parallel effects of geographic distance, environmental distance and harmonic mean area on taxonomic and genetic differentiations. This suggests that the parallel influence of dispersal limitation, environmental selection and drift on taxonomic and genetic differentiations only partially explains the overall $\beta$-SGDC we observed. This independent, unexplained correlation between taxonomic and genetic differentiations thus probably results from processes that we did not explicitly consider in our study. The most probable explanation is that the independent $\beta$-SGDC we observed is due to the parallel action of historical processes, which occurred when the basins were still connected, on taxonomic and genetic differentiations. These historical processes include all the different processes that explain the colonisation history of basins (Orsini et al., 2013): i) the dispersal of individuals between previously connected basins in interaction with environmental and/or biotic selection on their dispersal route and ii) environmental and/or biotic selection in interaction with drift within their place of arrival and/or origin that may have led to extinction. This explanation is supported by previous studies on the influence of historical processes on broad-scale taxonomic differentiation between freshwater fish communities on the one hand and on broad-scale genetic differentiation between freshwater 
fish populations on the other hand. Two recent studies on global freshwater fish biodiversity have shown that present-day patterns of taxonomic dissimilarity across basins are well explained by the historical connectivity of basins (Dias et al., 2014) and also historical climatic oscillations that took place during the Quaternary and the Holocene (Leprieur et al., 2011). For fish species, it is well known that historical dispersal influences genetic structure across basins (Carvalho, 1993), especially for zones that were subject to intense post-glacial recolonisation such as our study area. Multispecies comparisons at large spatial scales in Europe (Seifertová, Bryja, Vyskočilová, Martínková, \& Šimková, 2012) and in North America (April, Hanner, Mayden, \& Bernatchez, 2013) have shown that the climatic fluctuations that caused glacial cycles during the Pleistocene had a generalised effect on the patterns of fish genetic divergence. In addition, three other, non-exclusive hypotheses may explain the independent $\beta$-SGDC we observed. First, the proxies we used to account for dispersal limitation, environmental selection and drift may not fully represent these processes. For instance, we may have overlooked some environmental variables that are important in driving environmental selection. Alternatively, we may have poorly estimated the role of drift, either because the area of the basin we used to account for drift may be too approximate to accurately represent the carrying capacities of populations and communities or because we did not consider that the influence of drift within a basin increases with its age of isolation. Secondly, the sequence data we used to calculate genetic differentiation may not detect dispersal limitation and/or environmental selection properly, either because they did not cover the entire native ranges of species (see possible consequences of such sampling bias in e.g. Meirmans, 2015), or because the mitochondrial gene COI is not directly under environmental selection. Finally, the proposed frameworks to interpret SGDCs (Vellend \& Geber, 2005; Lamy et al., 2017) suggest that correlations between species diversity and genetic diversity may also result from a causal action of species diversity on genetic diversity or vice-versa. 
For instance, if the focal species (i.e. the species for which we studied genetic diversity) is a facilitator for the other component species of the community, we would expect their populations sizes to co-vary positively, resulting in a positive $\alpha$-SGDC; the converse is expected if the focal species is a competitor. If the nature of the interaction between the focal species and the other species of the community is generally the same within each basin, such causal effect is not expected to influence the $\beta$-SGDC we observed. However, if the focal species is facilitator in one basin and competitor in another, we would expect the population sizes of the other component species of the community to increase in the first case and decrease in the second case. This would result in more ecological drift within the community where the focal species is competitor, and therefore more taxonomic differentiation between basins than would be expected without this causal effect. In the end, such causal effect would tend to reduce $\beta$-SGDC because it would increase taxonomic differentiation between basins without influencing genetic differentiation.

Moreover, our results contribute new insights into the study of $\beta$-SGDCs. With the study of 22 new $\beta$-SGDCs, we increased the number of $\beta$-SGDCs (43) previously reported in the literature by more than $50 \%$ (see Lamy et al., 2017 for the most recent review). We found an average raw correlation between taxonomic and genetic differentiations of 0.433 , and an independent correlation (i.e. independent from the parallel effects of geographic distance, environmental distance and harmonic mean area on taxonomic and genetic differentiations) of 0.379. Both of these values are superior to the average value of 0.221 reported by Lamy et al. (2017). They are also around three times superior to the average value of 0.139 found by Fourtune et al. (2016) in their study of four freshwater fish species at a smaller scale, within

447 one drainage basin. This suggests that the strong correlations we found are probably more 448 related to the size and/or the isolation of the habitats we studied (i.e. large drainage basins isolated from each other) rather than our biological model. Previous syntheses have reported 
that $\alpha$-SGDCs (i.e. correlations between genetic diversity within populations and species diversity within communities) are stronger and more often positive in island-like habitats (Vellend \& Geber, 2005; Vellend et al., 2014), in agreement with the predictions of theoretical models (Laroche et al., 2015). As drainage basins are typically island-like habitats (Sepkoski \& Rex, 1974; Hugueny, 1989), our findings suggest that this explanation may hold true for $\beta$-SGDCs as well. The observed differences also suggest that for a system without present-day dispersal the $\beta$-SGDC is stronger than in systems with present-day dispersal. Actually, the opposite could have been expected (i.e. weaker $\beta$-SGDCs for systems without present-day dispersal than for systems with present-day dispersal) if the genetic similarity between two previously connected populations had been erased by genetic drift occurring after their isolation without changes in species composition (i.e. no species extinction). However, our results suggest that drift did not influence significantly the patterns of genetic differentiation we observed. As this result holds true both for $\mathrm{G}^{\prime}{ }_{\mathrm{ST}}$ and $\mathrm{F}_{\mathrm{ST}}$, this is probably because we mainly focused on large drainage basins and consequently large population sizes. between the different species we examined. We provided two examples. On the one hand, we showed that the $\beta$-SGDC was strong for Rutilus rutilus, suggesting that historical processes largely shaped the patterns of genetic differentiation observed in this species. This is consistent with a previous study indicating that $R$. rutilus is composed of two historically isolated, independently evolving sets of populations (Larmuseau et al., 2009). On the other hand, our results indicate that genetic differentiation in Squalius cephalus was not correlated to taxonomic differentiation, but was well explained by geographic distance. This suggests that dispersal limitation has a more important effect than any other processes on broad-scale genetic differentiation in S. cephalus. This might seem surprising, since previous analyses of the mitochondrial gene cytochrome $b$ in that species indicated four main lineages originating 
from multiple glacial refugia (Durand, Persat, \& Bouvet, 1999; Seifertová et al., 2012).

However, the use of a combination of both mitochondrial and nuclear DNA, Seifertová et al. (2012) also suggested that genetic differentiation in $S$. cephalus resulted from a combination of different factors, i.e. post-glacial colonisation from different refugia or recent evolutionary processes such as drift or dispersal limitation. Our results based on the analysis of the mitochondrial gene COI strongly support the dispersal limitation hypothesis although, as we did not design the sampling, but analysed existing data, we might not have captured the whole picture. As $R$. rutilus and $S$. cephalus have similar dispersal abilities, this difference of $\beta$ SGDC between the two species does not seem to be related to their difference in dispersal abilities. Beyond these two species and this single trait, our analyses did not permit us to uncover any trait that could explain the variability of $\beta$-SGDC over the 22 species we examined. This is surprising because life-history traits of species are known to shape spatial patterns of genetic differentiation (e.g. Duminil et al., 2007; Kelly \& Palumbi, 2010), and therefore $\beta$-SGDC. This unexpected finding may be due to different reasons. First, the variability of $\beta$-SGDC may be due to species traits that we did not consider. Secondly, the $\beta$ SGDC at the specific scale was sometimes examined for a small number of basins, which may result in wide variations in the estimated correlation coefficients. Therefore, single species outcomes should be interpreted with great caution.

To conclude, this study of broad-scale $\beta$-SGDC for multiple freshwater fish species suggests that historical processes greatly contributed to the shape of present-day patterns of taxonomic and genetic differentiations, independently of contemporary processes. This implies that taxonomic differentiation may be an appropriate proxy to explain the role of historical processes on patterns of genetic differentiation, which remains a challenging issue in landscape genetics (Dyer, Nason, \& Garrick, 2010). We believe that further studies of broad-scale $\beta$-SGDCs comparing organisms whose dispersal is limited within habitat patches 
500 with organisms that are able to disperse across habitat patches, will help to investigate the 501 extent to which our findings can be generalised. 


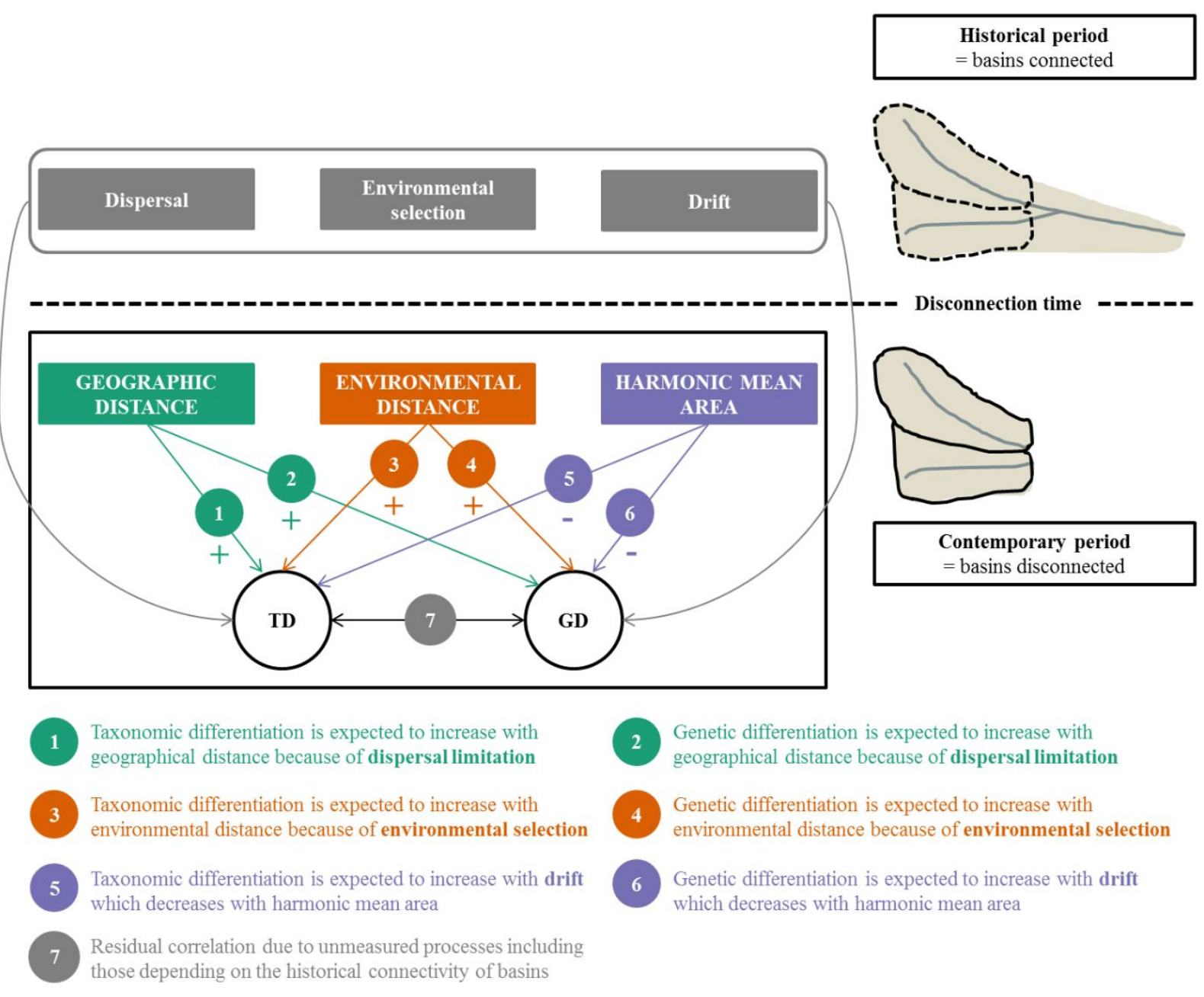

Figure 1. Illustration of the different processes expected to act in parallel on between-basin taxonomic differentiation of freshwater fish communities (TD) and on between-basin genetic differentiation of freshwater fish populations (GD) at different periods and the proxies used in this study to infer those processes. The black frame encompasses the causal diagram depicting the relationships that we actually tested in this study, i.e. the effects of geographic distance (proxy of contemporary dispersal limitation), environmental distance (proxy of contemporary

511 environmental selection) and pairwise harmonic mean area between basins (proxy of

512 contemporary drift) on TD and GD. The double arrow between TD and GD represent the

513 residual correlation, i.e. the correlation between TD and GD which is not explained by the parallel influence of contemporary dispersal limitation, contemporary environmental selection 
515 and contemporary drift on TD and GD. The numbers on the arrows and the signs below them

516 correspond to our theoretical expectations regarding the different effects which are detailed in

517 the text below the black frame. The grey arrows represent the putative effects of historical

518 dispersal limitation, historical environmental selection and historical drift on TD and GD that

519 we did not directly test in our statistical approach. The grey polygons on the right side

520 represent the evolution of the basin configuration through time from one unique basin to two

521 distinct and disconnected basins, with almost no contemporary dispersal of individuals

522 between them (dispersal may occasionally occur between adjacent basins). 


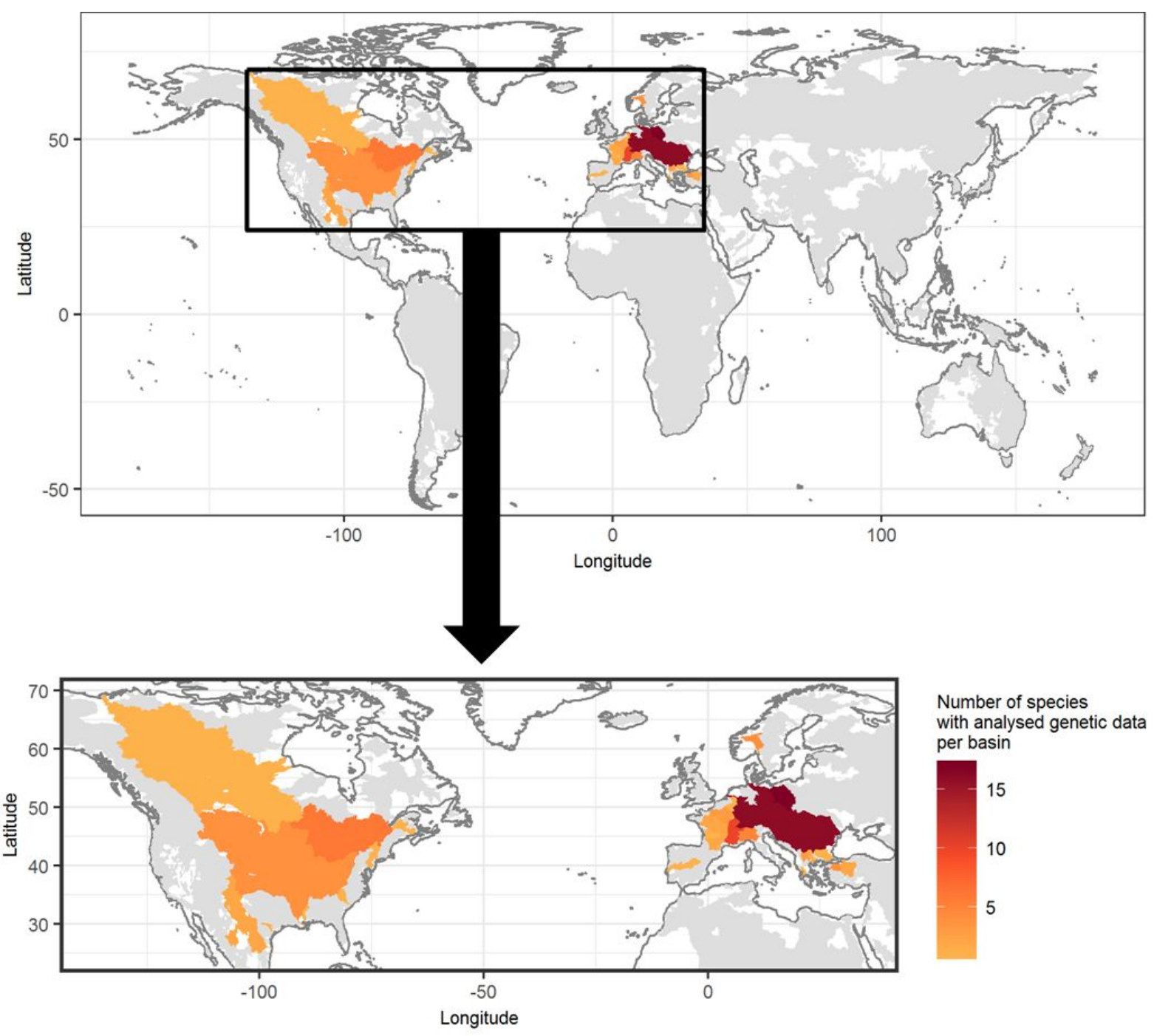

525 Figure 2. Spatial distribution of the number of species with analysed genetic data per basin

526 studied in our analyses at the global scale. Top: the rectangle indicates the location of the

527 enlarged area. Bottom: enlarged area including Europe and North America. In total, our study encompasses 22 species with analysed genetic data in 38 basins. 
(a) Raw correlations between

taxonomic differentiation and genetic differentiation

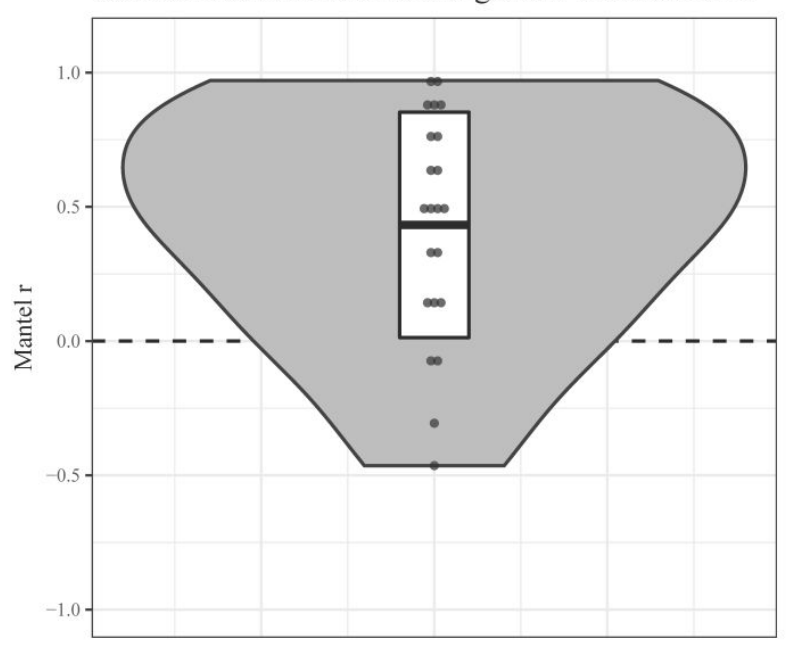

(b) Residual correlations between

taxonomic differentiation and genetic differentiation

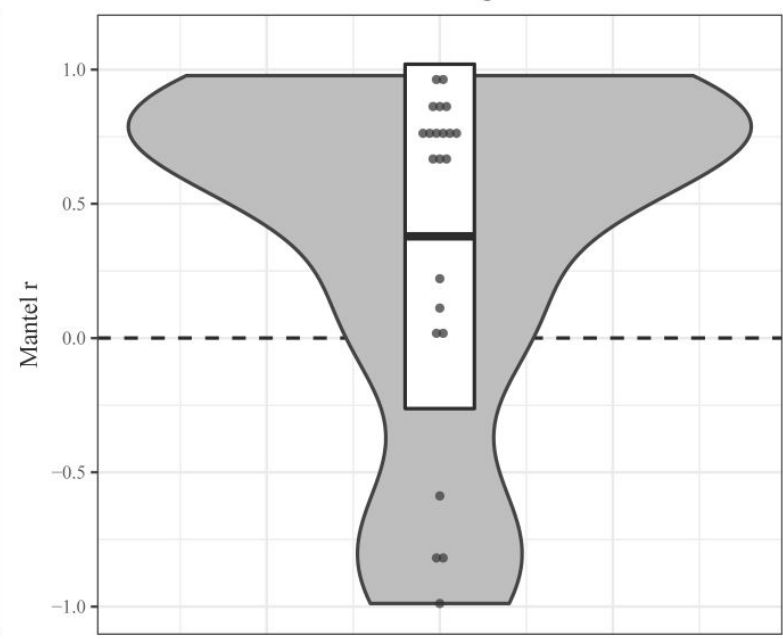

530

531 Figure 3. Violin plots showing the distribution and the probability density of (a) raw

532 correlations coefficients and (b) residual correlation coefficients between taxonomic

533 differentiation and genetic differentiation for the 22 fish species examined at global scale.

534 Crossbars indicate mean \pm standard deviation. 
(a) Multiple regressions on taxonomic differentiation

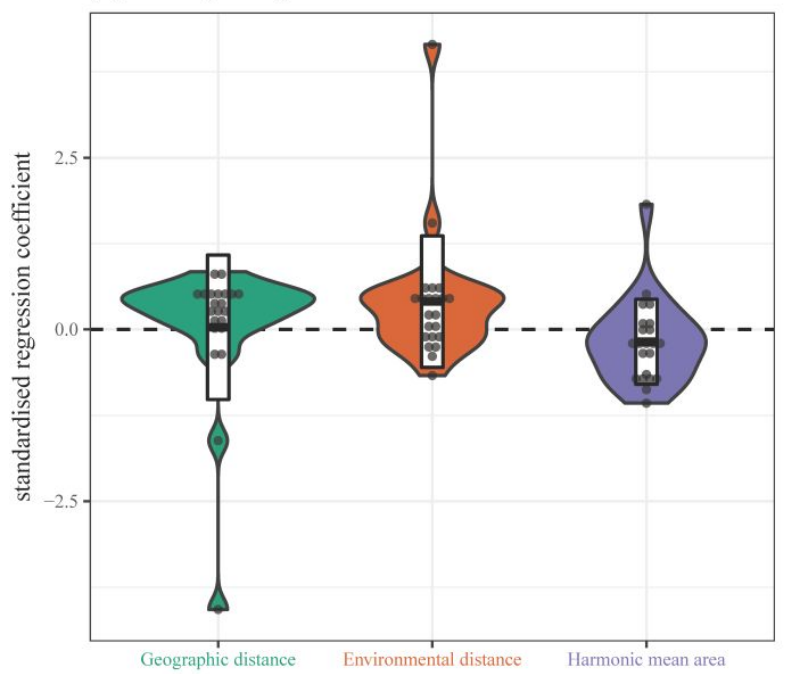

(b) Multiple regressions on genetic differentiation

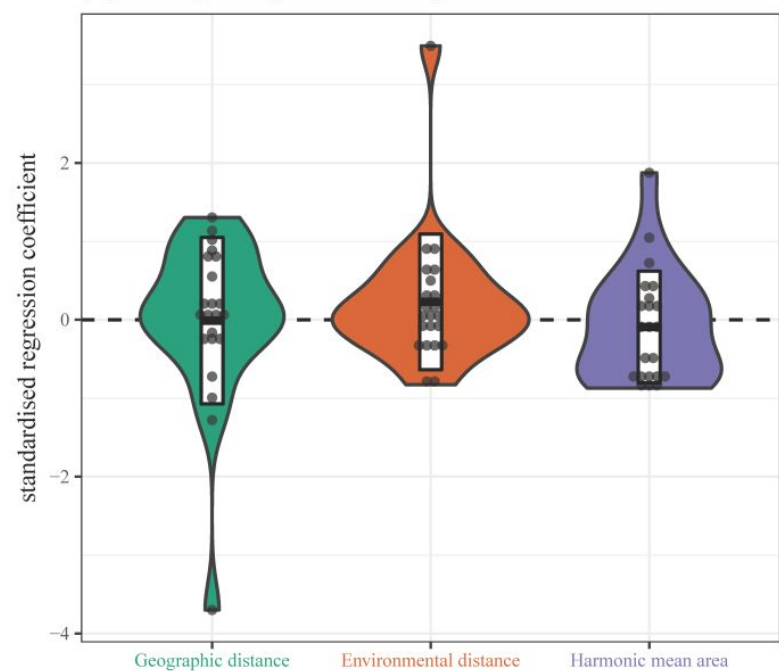

537 Figure 4. Violin plots showing the distribution and the probability density of the effect of 538 geographic distance, environmental distance and harmonic mean area (as standardised 539 regression coefficients) for the 22 fish species examined at global scale on (a) taxonomic 540 differentiation and (b) genetic differentiation. Crossbars indicate mean \pm standard deviation. 


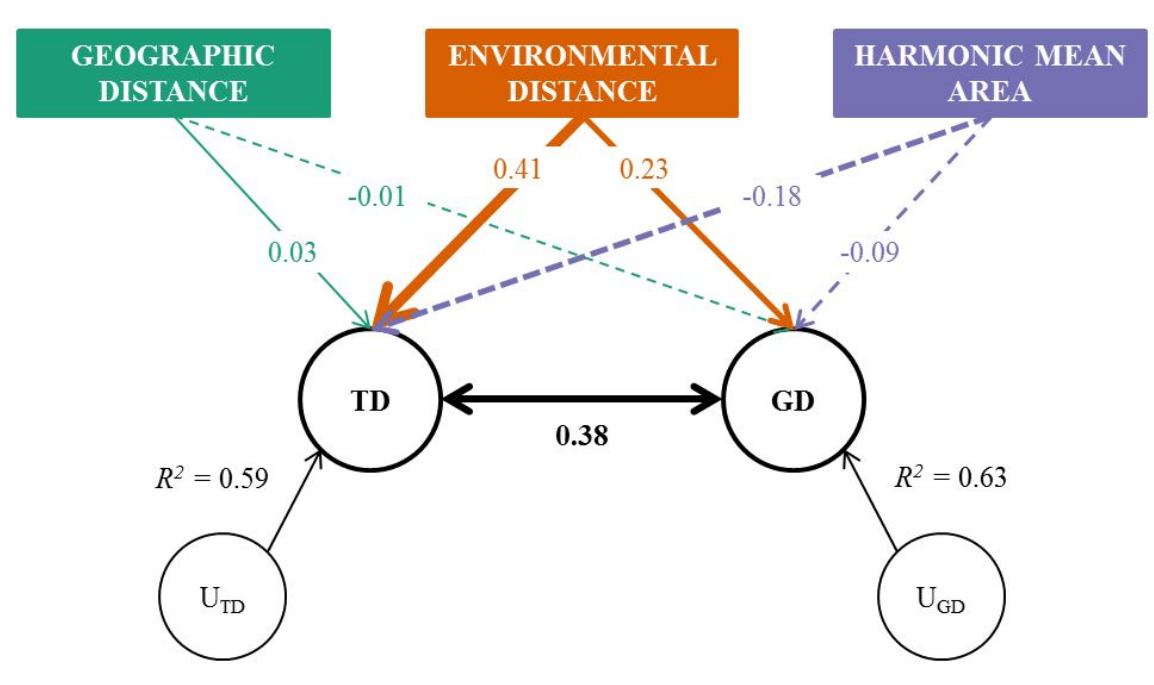

543 Figure 5. Causal diagram depicting the results of multiple regressions of geographic distance,

544 environmental distance and harmonic mean area on TD and GD (taken separately). Arrows

545 represent putative causal effects through the standardised regression coefficients (positive

546 values: solid arrows; negative values: dotted arrows; arrow width is proportional to coefficient

547 value). The $\mathrm{R}^{2}$ represent the part of variance explained by the multiple regressions on TD

548 (left) and GD (right). $\mathrm{U}_{\mathrm{TD}}$ and $\mathrm{U}_{\mathrm{GD}}$ represent unspecified factors influencing TD and GD

549 respectively. The double arrow between SD and GD corresponds to the residual correlation.

550 All numerical values represent means for the 22 fish species examined at global scale. 
(a) Raw correlations

Rutilus rutilus

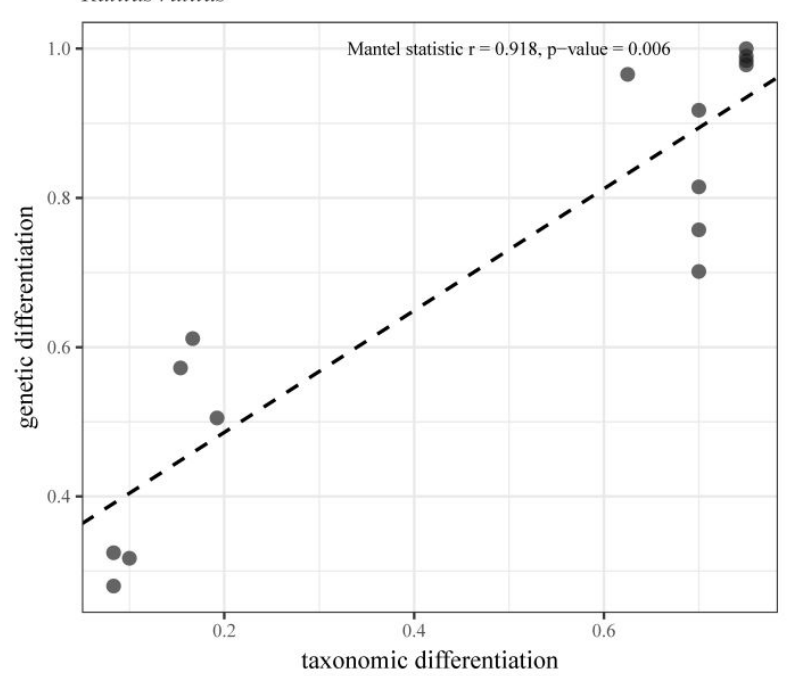

(c) Raw correlations

Squalius cephalus

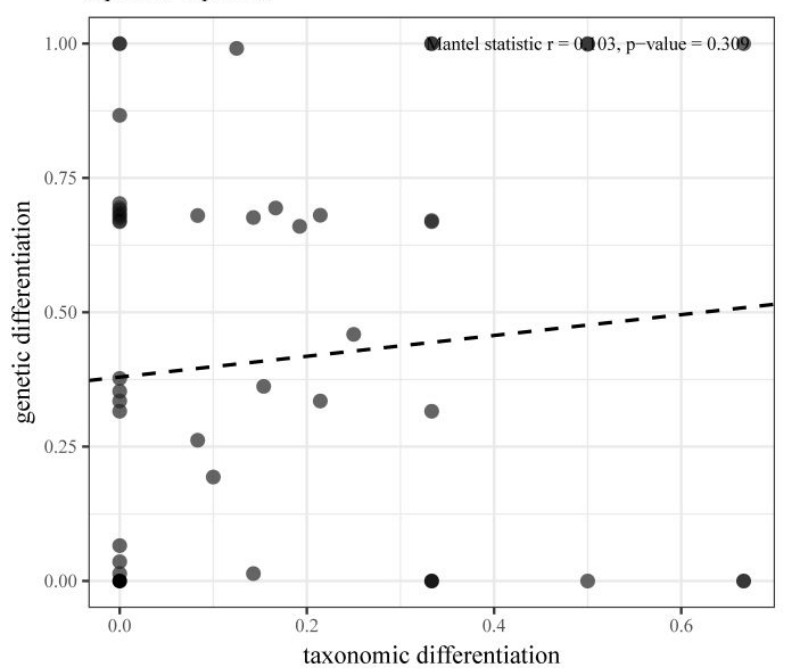

(b) Residual correlations

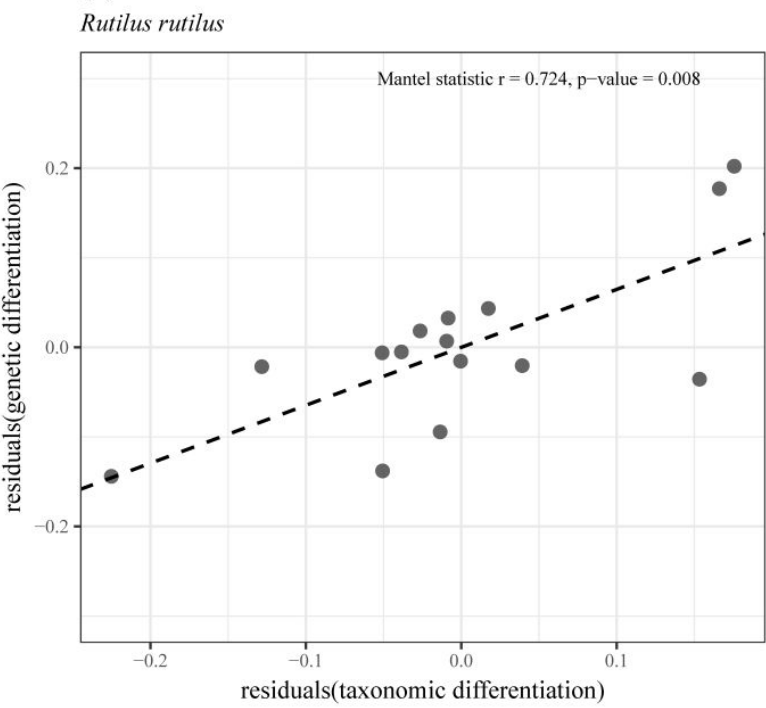

(d) Residual correlations

Squalius cephalus

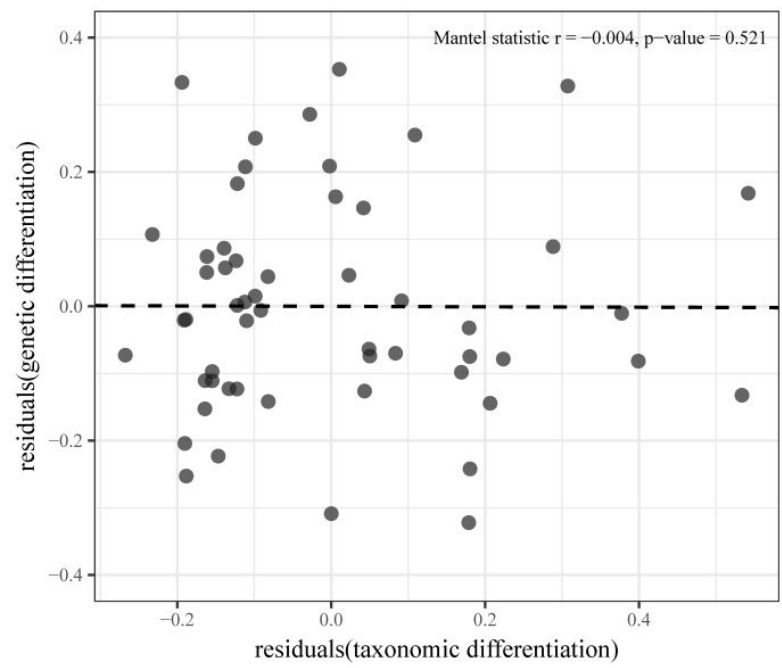

552 Figure 6. Observed (dots) and predicted (dashed line) raw values (a, c) and residual values

553 from the multiple regressions (b, d) of genetic differentiation as a function of taxonomic

554 differentiation for the two fish species (a, b) Rutilus rutilus and (c, d) Squalius cephalus. 


\section{References}

557 Allendorf, F. W. (1986). Genetic drift and the loss of alleles versus heterozygosity. Zoobiology, 5(2), 181-190.

Almany, G. R. (2003). Priority effects in coral reef fish communities. Ecology, 84(7), 19201935.

April, J., Hanner, R. H., Mayden, R. L., \& Bernatchez, L. (2013). Metabolic rate and climatic fluctuations shape continental wide pattern of genetic divergence and biodiversity in fishes. PLoS ONE, 8(7), e 70296.

Arnold, J.B. (2018). ggthemes: Extra Themes, Scales and Geoms for 'ggplot2'. R package version 4.0.1. Retrieved from https://CRAN.R-project.org/package=ggthemes.

Astorga, A., Oksanen, J., Luoto, M., Soininen, J., Virtanen, R., \& Muotka, T. (2012). Distance decay of similarity in freshwater communities: do macro-and microorganisms follow the same rules?. Global Ecology and Biogeography, 21(3), 365-375.

Baselga, A. (2012). The relationship between species replacement, dissimilarity derived from nestedness, and nestedness. Global Ecology and Biogeography, 21(12), 1223-1232.

Baselga, A., Fujisawa, T., Crampton-Platt, A., Bergsten, J., Foster, P. G., Monaghan, M. T., \& Vogler, A. P. (2013). Whole-community DNA barcoding reveals a spatio-temporal continuum of biodiversity at species and genetic levels. Nature Communications, 4(1892).

Baselga, A., Gómez-Rodríguez, C., \& Vogler, A. P. (2015). Multi-hierarchical macroecology at species and genetic levels to discern neutral and non-neutral processes. Global Ecology and Biogeography, 24(8), 873-882. 
Baselga, A., Orme, D., Villeger, S., De Bortoli, J., \& Leprieur, F. (2018). betapart:

$\underline{\text { Partitioning Beta Diversity into Turnover and Nestedness Components. R package }}$ version 1.5.0. Retrieved from https://CRAN.R-project.org/package=betapart.

Bivand, R., \& Lewin-Koh, N. (2018). maptools: Tools for Reading and Handling Spatial Objects. R package version 0.9-3. Retrieved from https://CRAN.Rproject.org/package $=$ maptools.

Bivand, R., Keitt, T., \& Rowlingson, B. (2018). rgdal: Bindings for the 'Geospatial' Data Abstraction Library. R package version 1.3-4. Retrieved from https://CRAN.Rproject.org/package $=$ rgdal .

Bivand, R., \& Rundel, C. (2018). rgeos: Interface to Geometry Engine - Open Source ('GEOS'). R package version 0.3-28. Retrieved from https://CRAN.Rproject.org/package $=$ rgeos.

Blanchet, S., Prunier, J. G., \& De Kort, H. (2017). Time to go bigger: emerging patterns in macrogenetics. Trends in Genetics, 33(9), 579-580.

Carvalho, G. R. (1993). Evolutionary aspects of fish distribution: genetic variability and adaptation. Journal of Fish Biology, 43(Supplement A), 53-73.

Derry, A. M., Arnott, S. E., Shead, J. A., Hebert, P. D., \& Boag, P. T. (2009). Ecological linkages between community and genetic diversity in zooplankton among boreal shield lakes. Ecology, 90(8), 2275-2286.

Dias, M. S., Oberdorff, T., Hugueny, B., Leprieur, F., Jézéquel, C., Cornu, J. F., ... Tedesco, P. A. (2014). Global imprint of historical connectivity on freshwater fish biodiversity. Ecology Letters, 17(9), 1130-1140. 
600 Dray, S., \& Dufour, A. (2007). The ade4 package: Implementing the Duality Diagram for Ecologists. Journal of Statistical Software, 22(4), 1-20.

Duminil, J., Fineschi, S., Hampe, A., Jordano, P., Salvini, D., Vendramin, G. G., \& Petit, R. J. (2007). Can population genetic structure be predicted from life-history traits?. The American Naturalist, 169(5), 662-672.

Durand, J. D., Persat, H., \& Bouvet, Y. (1999). Phylogeography and postglacial dispersion of the chub (Leuciscus cephalus) in Europe. Molecular Ecology, 8(6), 989-997.

Dyer, R. J., Nason, J. D., \& Garrick, R. C. (2010). Landscape modelling of gene flow: improved power using conditional genetic distance derived from the topology of population networks. Molecular Ecology, 19(17), 3746-3759.

Fourtune, L., Paz-Vinas, I., Loot, G., Prunier, J. G., \& Blanchet, S. (2016). Lessons from the fish: a multi-species analysis reveals common processes underlying similar speciesgenetic diversity correlations. Freshwater Biology, 61(11), 1830-1845.

Fraser, C. I., Davies, I. D., Bryant, D., Waters, J. M. (2018). How disturbance and dispersal influence intraspecific structure. Journal of Ecology, 106,1298-1306.

Froese, R., \& Pauly, D. (2017). FishBase. World Wide Web electronic publication. www.fishbase.org, version (06/2017).

Gilbert, B., \& Levine, J. M. (2017). Ecological drift and the distribution of species diversity. Proceedings of the Royal Society B: Biological Sciences, , R. Søc. B, 284(1855), 20170507.

Goudet, J., \& Jombart, T. (2015). hierfstat: Estimation and Tests of Hierarchical F-Statistics. 
project.org/package=hierfstat

Hahsler, M., Buchta, C., \& Hornik, K. (2018). seriation: Infrastructure for Ordering Objects Using Seriation. R package version 1.2-3.Retrieved from https://CRAN.Rproject.org/package $=$ seriation.

Hedrick, P. W. (2005). A standardized genetic differentiation measure. Evolution, 59(8), $1633-1638$.

Hugueny, B. (1989). West African rivers as biogeographic islands: species richness of fish communities. Oecologia, 79, 236-243.

Kahilainen, A., Puurtinen, M., \& Kotiaho, J. S. (2014). Conservation implications of speciesgenetic diversity correlations. Global Ecology and Conservation, 2, 315-323.

Kelly, R. P., \& Palumbi, S. R. (2010). Genetic structure among 50 species of the northeastern Pacific rocky intertidal community. PLoS ONEPLoS One, 5(1), e8594.

Lamy, T., Laroche, F., David, P., Massol, F., \& Jarne, P. (2017). The contribution of speciesgenetic diversity correlations to the understanding of community assembly rules. Oikos, 126(6), 759-771.

Larmuseau, M. H. D., Freyhof, J., Volckaert, F. A. M., \& Van Houdt, J. K. J. (2009). Matrilinear phylogeography and demographical patterns of Rutilus rutilus: implications for taxonomy and conservation. Journal of Fish Biology, 75(2), 332-353.

Laroche, F., Jarne, P., Lamy, T., David, P., \& Massol, F. (2014). A neutral theory for interpreting correlations between species and genetic diversity in communities. The American Naturalist, 185(1), 59-69.

Legendre, P., Lapointe, F.-J., \& Casgrain, P. (1994). Modeling brain evolution from behavior: 
a permutational regression approach. Evolution, 48(5), 1487-1499.

Leprieur, F., Olden, J. D., Lek, S., \& Brosse, S. (2009). Contrasting patterns and mechanisms of spatial turnover for native and exotic freshwater fish in Europe. Journal of Biogeography, 36(10), 1899-1912.

Leprieur, F., Tedesco, P. A., Hugueny, B., Beauchard, O., Dürr, H. H., Brosse, S., \& Oberdorff, T. (2011). Partitioning global patterns of freshwater fish beta diversity reveals contrasting signatures of past climate changes. Ecology Letters, 14(4), 325-334.

Lichstein, J. W. (2007). Multiple regression on distance matrices: a multivariate spatial analysis tool. Plant Ecology, 188(2), 117-131.

Mayr, E. (1963). Animal species and evolution. Cambridge, MA: Harvard University Press.

Meirmans, P. G. (2015). Seven common mistakes in population genetics and how to avoid them. Molecular Ecology, 24, 3223-3231.

Meirmans, P. G., \& Hedrick, P. W. (2011). Assessing population structure: $\mathrm{F}_{\mathrm{ST}}$ and related measures. Molecular Ecology Resources, 11(1), 5-18.

Moritz, C., Meynard, C. N., Devictor, V., Guizien, K., Labrune, C., Guarini, J. M., \& Mouquet, N. (2013). Disentangling the role of connectivity, environmental filtering, and spatial structure on metacommunity dynamics. Oikos, 122(10), 1401-1410.

Oberdorff, T., Tedesco, P. A., Hugueny, B., Leprieur, F., Beauchard, O., Brosse, S., \& Dürr, H. H. (2011). Global and regional patterns in riverine fish species richness: a review. International Journal of Ecology, 201(967631).

Oksanen, J., Blanchet, G., Friendly, M., Kindt, R., Legendre, P., McGlinn, D., ...Wagner, H. (2018). vegan: Community Ecology Package. R package version 2.5-2. Retrieved from 
https://CRAN.R-project.org/package=vegan.

Orsini, L., Vanoverbeke, J., Swillen, I., Mergeay, J., \& De Meester, L. (2013). Drivers of population genetic differentiation in the wild: isolation by dispersal limitation, isolation by adaptation and isolation by colonization. Molecular Ecology, 22(24), 5983-5999.

Nei, M. (1973). Analysis of gene diversity in subdivided populations. Proceedings of the National Academy of Sciences, 70(12), 3321-3323.

Nekola, J. C., \& White, P. S. (1999). The distance decay of similarity in biogeography and ecology. Journal of Biogeography, 26(4), 867-878.

Neuwirth, E. (2014). RColorBrewer: ColorBrewer Palettes. R package version 1.1-2. Retrieved from https://CRAN.R-project.org/package=RColorBrewer.

Pagès, H., Aboyoun, P., Gentleman, R., \& DebRoy, S. (2018). Biostrings: Efficient manipulation of biological strings. R package version 2.48.0.

Papadopoulou, A., Anastasiou, I., Spagopoulou, F., Stalimerou, M., Terzopoulou, S., Legakis, A., \& Vogler, A. P. (2011). Testing the species-genetic diversity correlation in the Aegean Archipelago: toward a haplotype-based macroecology? The American Naturalist, 178(2), 241-255.

Paradis, E., Claude, J., \& Strimmer, K. (2004). APE: analyses of phylogenetics and evolution in R language. Bioinformatics, 20, 289-290.

Preston, F. W. (1962). The canonical distribution of commonness and rarity: Part II. Ecology, 43(3), 410-432.

Prunier, J. G., Dubut, V., Chikhi, L., \& Blanchet, S. (2017). Contribution of spatial heterogeneity in effective population sizes to the variance in pairwise measures of 

genetic differentiation. Methods in Ecology and Evolution, 8(12), 1866-1877.

Qian, H., \& Ricklefs, R. E. (2012). Disentangling the effects of geographic distance and environmental dissimilarity on global patterns of species turnover. Global ecology and Biogeography, 21(3), 341-351.

$\underline{\text { R Core Team. (2018). R: A language and environment for statistical computing. Vienna, }}$ Austria: R Foundation for Statistical Computing. Retrieved from https://www.Rproject.org/.

Radinger, J., \& Wolter, C. (2014). Patterns and predictors of fish dispersal in rivers. Fish and fisheries, 15(3), 456-473.

Robinson, D., \& Hayes, A. (2018). broom: Convert Statistical Analysis Objects into Tidy Tibbles. R package version 0.5.0. Retrieved from https://CRAN.Rproject.org/package $=$ broom .

Rosenzweig, M. L. (1995). Species diversity in space and time. Cambridge, UK: Cambridge

Rousset, F. (1997). Genetic differentiation and estimation of gene flow from F-statistics under isolation by distance. Genetics, 145(4), 1219--1228.

Seifertová, M., Bryja, J., Vyskočilová, M., Martínková, N., \& Šimková, A. (2012). Multiple Pleistocene refugia and post-glacial colonization in the European chub (Squalius cephalus) revealed by combined use of nuclear and mitochondrial markers. Journal of Biogeography, 39(6), 1024-1040.

Sepkoski, J. J., \& Rex, M. A. (1974). Distribution of freshwater mussels: coastal rivers as biogeographic islands. Systematic Zoology, 23(2), 165-188. 
Serrouya, R., Paetkau, D., McLellan, B. N., Boutin, S., Campbell, M., \& Jenkins, D. A. (2012). Population size and major valleys explain microsatellite variation better than taxonomic units for caribou in western Canada. Molecular Ecology, 21(11), 2588-2601.

Soininen, J., McDonald, R., \& Hillebrand, H. (2007). The distance decay of similarity in ecological communities. Ecography, 30(1), 3-12.

Sørensen, T. J. (1948). A method of establishing groups of equal amplitude in plant sociology based on similarity of species content, and its application to analyses of the vegetation on Danish commons. Kongelige Danske Videnskabernes Selskabs Biologiske Skrifter, 5, 134.

Tedesco, P. A., Beauchard, O., Bigorne, R., Blanchet, S., Buisson, L., Conti, L., ... Oberdorff, T. (2017). A global database on freshwater fish species occurrence in drainage basins. Scientific Data, 4(170141).

Tedesco, P. A., Leprieur, F., Hugueny, B., Brosse, S., Dürr, H. H., Beauchard, O., ... Oberdorff, T. (2012). Patterns and processes of global riverine fish endemism. Global Ecology and Biogeography, 21(10), 977-987.

Tisseuil, C., Cornu, J. F., Beauchard, O., Brosse, S., Darwall, W., Holland, R., ... Oberdorff, T. (2013). Global diversity patterns and cross-taxa convergence in freshwater systems. Journal of Animal Ecology, 82(2), 365-376.

Vellend, M. (2003). Island biogeography of genes and species. The American Naturalist, $162(3), 358-365$.

Vellend, M., \& Geber, M. A. (2005). Connections between species diversity and genetic diversity. Ecology Letters, 8(7), 767-781. 
Vellend, M., \& Orrock, J. L. (2009). Ecological and genetic models of diversity. The theory of Island biogeography revisited. Princeton Univ. Press, Princeton, NJ, 439-462.

Vellend, M., Lajoie, G., Bourret, A., Múrria, C., Kembel, S. W., \& Garant, D. (2014). Drawing ecological inferences from coincident patterns of population- and communitylevel biodiversity. Molecular Ecology, 23(12), 2890-2901.

Wang, I. J., Glor, R. E., \& Losos, J. B. (2013). Quantifying the roles of ecology and geography in spatial genetic divergence. Ecology Letters, 16(2), 175-182.

Whittaker, R. H. (1960). Vegetation of the Siskiyou mountains, Oregon and California. Ecological monographs, 30(3), 279-338.

$\underline{\text { Wickham, H. (2007). Reshaping Data with the reshape Package. Journal of Statistical }}$ Software, 21(12), 1-20.

Wickham, H. (2016). ggplot2: Elegant Graphics for Data Analysis. New-York, NY: SpringerVerlag.

Winter, D. J. (2012). mmod: an R library for the calculation of population differentiation statistics. Molecular Ecology Resources, 12(6), 1158-1160.

Wright, S. (1943). Isolation by distance. Genetics, 28(March), 114-138.

Wright, S. (1951). The genetical structure of natural populations. Annals of Eugenics, 15(4), 323-354. 


\section{Biosketch}

756 The authors are particularly interested in documenting and explaining spatial patterns of

757 biodiversity at large spatial scales. They try to disentangle the interplay between historical and 758 contemporary factors (including anthropogenic pressures) in shaping patterns of alpha and

759 beta diversities in aquatic populations and communities and value this knowledge to guide

760 conservation strategies of aquatic ecosystems.

\section{Supporting information}

762 Supporting information for this article may be found online.

\section{Data availability}

764 The data and the scriptUpon acceptance of this manuscript, all data and scripts used for the

765 analyses are available from the Dryad Digital Repository:

766 https://doi.org/10.5061/dryad.8vb6160.will be uploaded in a Dryad repository. 
1 Correlations between broad-scale taxonomic and genetic differentiations suggest a dominant imprint of historical processes on beta diversities

3 Running title: Broad-scale $\beta$-SGDCs in freshwater fishes

4 Marine Robuchon ${ }^{1,2 *}$, Boris Leroy ${ }^{1}$, Céline Jézéquel ${ }^{1,3}$ and Bernard Hugueny ${ }^{1,3}$

$5 \quad{ }^{1}$ Unité Biologie des organismes et écosystèmes aquatiques (BOREA), Muséum national

6 d'Histoire naturelle, Sorbonne Université, Université de Caen Normandie, Université des

$7 \quad$ Antilles, CNRS, IRD, CP 26, 57 rue Cuvier 75005 Paris, France

$8 \quad{ }^{2}$ Centre d'écologie et des sciences de la conservation (CESCO), Muséum national d'Histoire

9 naturelle, CNRS, Sorbonne Université, CP 135, 57 rue Cuvier 75005 Paris, France

$10 \quad{ }^{3}$ Laboratoire Évolution \& Diversité Biologique (EDB UMR 5174), Université de Toulouse

11 Midi-Pyrénées, CNRS, IRD, UPS, 118 route de Narbonne, Bat 4R1, 31062 Toulouse cedex 9,

12 France

* corresponding author: robuchon@mnhn.fr

\section{Acknowledgements}

This study was supported by the French State through the Research National Agency under the LabEx ANR-10-LABX-0003-BCDiv, within the framework of the program 'Investing for the future' (ANR-11-IDEX-0004-02). BH and CJ are supported by the French Laboratory of Excellence project "TULIP" (ANR-10-LABX-41; ANR-11-IDEX-0002-02). We thank Agnès

Dettaï and Gaël Denys for their valuable suggestions during the planning of this research work. We also thank Céline Bellard, Juliette Delavenne and Jean-Baptiste Mihoub for their relevant advice on figures and rewording that greatly improved the manuscript. We are grateful for the helpful comments of the associate editor and of two anonymous reviewers. 


\section{Abstract}

- Aim: Dispersal limitation, environmental selection and drift are known to influence both taxonomic similarity between communities and genetic similarity between populations. However, disentangling the relative roles of these processes on spatial patterns of differentiation - whether regarding taxonomic differentiation between communities or genetic differentiation between populations - is challenging. Investigating whether spatial patterns of taxonomic differentiation and genetic differentiation are correlated ( $\beta$-SGDCs) is a promising approach to address this issue. Here, we investigated $\beta$-SGDCs over broad spatial scales and 22 freshwater fish species to elucidate the processes shaping taxonomic and genetic differentiations between drainage basins.

- Location: Global scope, data mainly from Europe and North America.

- Taxon: Actinopterygii and Petromyzontiformes (freshwater fishes).

- Methods: We used Mantel tests to investigate the raw correlation between taxonomic and genetic differentiations. We carried out multiple regressions to characterise the effects of geographic distance (proxy of dispersal limitation), environmental distance (proxy of environmental selection) and pairwise harmonic mean area between basins (proxy of drift) on taxonomic differentiation and genetic differentiation taken separately. We then analysed the correlation between the residuals of these two regressions with Mantel tests. Finally, we investigated whether the variation in $\beta$-SGDC between species was related to species traits.

- Results: We detected an overall positive $\beta$-SGDC, both for the raw and the residual correlations. This implies that, unmeasured effects, other than geographic distance, environmental distance and harmonic mean area, influence the $\beta$-SGDC observed. Values of $\beta$-SGDCs greatly varied between species, but this was not explained by any species traits. 


\section{Keywords}

54

$\beta$-SGDC, dispersal limitation, distance decay, drift, environmental selection, freshwater

fishes, historical processes, macrogenetics, Mantel tests, multiple regression of distance

- Main conclusions: Independently of the effects of geographic distance, environmental distance and harmonic mean area, the $\beta$-SGDC we observed suggests that historical processes strongly shaped the patterns of taxonomic and genetic differentiations between basins. Consequently, taxonomic differentiation may be an appropriate proxy to explain the influence of historical processes on genetic differentiation. matrices 


\section{Introduction}

Understanding the mechanisms that shape taxonomic differentiation between spatially separated communities and those influencing genetic differentiation between spatially separated populations are long-standing issues in ecology and evolution (Wright, 1943, 1951; Whittaker, 1960, 1972; Preston, 1962; Mayr, 1963). More recently, these issues have been united (Vellend, 2003; Vellend \& Geber, 2005; Kahilainen, Puurtinen, \& Kotiaho, 2014), emphasising that drift, dispersal and selection influence both taxonomic differentiation between communities and genetic differentiation between populations. Drift and selection affect the species frequencies within communities and gene frequencies within populations, which tend to increase differentiation. Conversely, dispersal of individuals between populations and dispersal of species between communities will tend to decrease differentiation.

Among the factors that can affect both taxonomic and genetic differentiation, geographic distance is probably the most studied. The similarity in taxonomic composition between communities tends to decrease with the geographic distance that separates them; a pattern long-recognised in biogeography and formalised as the distance decay of similarity (Nekola \& White, 1999; Soininen, McDonald, \& Hillebrand, 2007). Similarly, the genetic similarity between populations tends to decrease with the geographic distance separating them; a pattern long-recognised in population genetics and referred to as isolation-by-distance (IBD; Wright, 1943; Rousset, 1997). Two main non-mutually exclusive explanations can account for the distance decay of taxonomic and genetic similarity (see Soininen et al., 2007 and Orsini et al., 2013 for reviews). First, similarity decreases with geographic distance because the dispersal of organisms (i.e. their movement from a place to another) is limited by their intrinsic dispersal ability, which hence does not counteract anymore the differentiating effect of drift. Secondly, similarity decays with geographic distance because of decreasing 
similarity in spatially correlated environmental features; in such cases, the underlying explanation is environmental selection of different species (community differentiation) or genotypes (genetic differentiation) in distinct environments. However, differentiation between sites does not always increase with geographic distance. This is the case when the migrants are competitively excluded by already established communities (e.g. Almany, 2003) or populations (e.g. Fraser et al., 2018) at high densities, therefore counteracting the homogenising effect of dispersal whatever the intrinsic dispersal ability of the migrants. This may also happen when the environmental variation between sites displays no - or negative spatial autocorrelation (e.g. Derry et al., 2009).

Although spatial patterns of taxonomic and genetic differentiations can be explained by environmental selection independently of limited dispersal and vice-versa, disentangling the relative strengths of these mechanisms is challenging, as communities and populations that are geographically distant are also likely to inhabit different environments. Using modern spatial statistical methods, some recent studies have nonetheless taken up the challenge. In their study of global patterns of species turnover in terrestrial vertebrates, Qian \& Ricklefs (2012) have shown that both dispersal limitation and environmental selection have played important roles in determining the patterns they observed. Similarly, in their reinterpretation of 34 representative studies, Orsini et al. (2013) highlighted that patterns associated with dispersal limitation were as common as those associated with local genetic adaptation in structuring population genetic differentiation in the wild. However, the relative strength of dispersal limitation and environmental selection on differentiation patterns seems to vary according to the species and the spatial scale under consideration, both for taxonomic (Astorga et al., 2012; Moritz et al., 2013) and genetic (Orsini et al., 2013) differentiations. Comparative studies of multiple taxonomic groups suggest that the influence of dispersal limitation on taxonomic differentiation is stronger for species with low dispersal ability than 
for more effective dispersers, and this result holds true both at the broad-scale (e.g. Qian \& Ricklefs, 2012) and at the fine-scale (e.g. Astorga et al., 2012). Comparative studies of multiple species have also been identified as a promising avenue to reveal the factors influencing patterns of genetic differentiation (Wang et al., 2013). Yet, such studies are scarce and mainly carried out at relatively small spatial scales (e.g. Wang et al., 2013; Fourtune, PazVinas, Loot, Prunier, \& Blanchet, 2016) despite the increasing availability of broad-scale datasets in population genetics, suggesting that it is now time to embrace macrogenetics (Blanchet, Prunier, \& De Kort, 2017).

Theories in population genetics and community ecology acknowledge that dispersal, selection and drift together shape the differentiation between populations and between communities (see e.g. Vellend \& Orrock, 2009 for a review of processes in both disciplines). However, the contribution of drift to taxonomic or genetic differentiation has been the subject of few empirical investigations, in contrast with dispersal limitation and environmental selection (Gilbert \& Levine, 2017; Prunier, Dubut, Chikhi, \& Blanchet, 2017). Genetic drift is the evolutionary process of random fluctuations in allelic frequencies occurring naturally in all populations due to their finite size, although it is stronger in small ones (Allendorf, 1986). Similarly, ecological drift corresponds to the random fluctuations in species frequencies occurring naturally in all communities due to their finite size and this too is stronger in small ones. Drift is the result of random sampling during the processes of birth, death and reproduction and ultimately leads to the loss of genetic diversity within populations, and species diversity within communities. Therefore, drift increases the differentiation between populations and between communities depending on their respective sizes: the smaller they are, the more they will differentiate. Dispersal of organisms between populations and between communities counteracts the differentiating effect of drift while environmental selection can accelerate it. Attributing the observed spatial patterns of genetic or taxonomic differentiation 
to dispersal limitation or to environmental selection without accounting for drift may thus be misleading.

Most of the explanatory variables used in analyses to infer the role of dispersal limitation and environmental selection on differentiation patterns are proxies representing present-day conditions. Thus, using current explanatory variables to investigate dispersal limitation and environmental selection on differentiation patterns is only relevant if the contemporary geography and environment of the study area has not changed substantially since these patterns were established (Wang et al., 2013). Otherwise, the historical processes that may have shaped the observed differentiation patterns, including those explaining colonisation histories, may be overlooked. In addition, if dispersal is not continuous (as generally assumed) but rather intermittent because of landscape dynamics which have induced the appearance and disappearance of dispersal barriers, then two geographically close localities sharing a similar environment could, nevertheless, be dissimilar in terms of community composition and allele frequencies provided they have been isolated for a sufficiently long time (given their sizes) for drift to be effective. Nonetheless, examining which part of differentiation patterns is not explained by current explanatory variables may help to elucidate the influence of historical processes on those patterns.

In such complex contexts, understanding the rules that govern differentiation patterns (both taxonomic and genetic) may be enhanced by comparing taxonomic dissimilarities between communities and genetic dissimilarities between populations of a focal species (Lamy, Laroche, David, Massol, \& Jarne, 2017). The few empirical studies that have examined these correlations, called beta species-genetic diversity correlations ( $\beta$-SGDCs) (Kahilainen et al., 2014), revealed a majority of positive correlations (reviewed by Lamy et al., 2017). This suggests that the processes affecting taxonomic dissimilarity affect genetic dissimilarity of the species under study in the same way (Baselga et al., 2013; Baselga, 
158 Gómez-Rodríguez, \& Vogler, 2015). However, because the relative strength of processes shaping patterns of taxonomic and genetic differentiation is expected to vary according to the species and the spatial scale under consideration, so is the strength of the putative resulting $\beta$ SGDCs. Among the rare studies of $\beta$-SGDCs over multiple species, some have highlighted that positive $\beta$-SGDCs were stronger for focal species with low dispersive abilities (e.g. Papadoulou et al., 2011) while others did not find strong differences between species (e.g. Fourtune et al., 2016), and all were carried out at relatively small spatial scales. These contrasting results call for more studies of $\beta$-SGDCs for multiple species to gain a better understanding of whether and how variations in species traits lead to distinct patterns of $\beta$ SGDCs. In addition, $\beta$-SGDCs for multiple species have not been examined yet at broad spatial scales.

Freshwater fishes are a relevant model to start investigating this question for at least three reasons. First, as $\beta$-SGDCs for multiple freshwater fish species have been conducted at small scales within a single drainage basin (Fourtune et al., 2016), computing $\beta$-SGDCs for multiple freshwater fish species at broader scales will permit the comparison of $\beta$-SGDC variations across scales for the same biological model. Secondly, for strictly freshwater fishes, at present, almost no exchange of individuals occurs between drainage basins (hereafter "basins") because they are isolated from each other by land and/or sea (although dispersal may occasionally occur between adjacent basins). Therefore, if basins are isolated from each other independently of the geographic distance between them, we can expect dispersal limitation to play a minor role on the broad-scale between-basin patterns of taxonomic and genetic differentiations. On the contrary, if basins have been isolated from each other for a

180 long time, we can expect drift to play a significant role on the broad-scale between-basin 181 patterns of taxonomic and genetic differentiations, as dispersal no longer counteracts the effect of drift. This is particularly true if population sizes and community sizes are small: the 
larger they are, the longer it will take to observe differentiation. Finally, while several recent studies have tried to disentangle the role of dispersal limitation, environmental selection and historical processes on patterns of taxonomic differentiation between basins (Leprieur et al., 2009, 2011; Dias et al., 2014), the processes shaping genetic differentiation at such broad scales have rarely been examined together. Studying $\beta$-SGDCs may therefore reveal whether the processes influencing between-basin taxonomic differentiation, affect between-basin genetic differentiation in the same way.

In this meta-analysis of 22 freshwater fish species, our main goal was to elucidate the processes underlying $\beta$-SGDCs at broad spatial scales. In particular, we wanted to test whether $\beta$-SGDCs can be explained by the parallel action of measurable processes (dispersal limitation, environmental selection and drift) on taxonomic and genetic differentiation, or are due to other, non-measurable processes. To that end, we first computed measures of genetic differentiation between basins for each fish species. Then, for each species, we investigated i) the raw correlation between taxonomic and genetic differentiations, ii) the effects of geographic distance (as a proxy of dispersal limitation), environmental distance (as a proxy of environmental selection) and pairwise harmonic mean area between basins (as a proxy of drift) on taxonomic differentiation and genetic differentiation taken separately and iii) the correlation between taxonomic and genetic differentiations independent of the effects of geographic distance, environmental distance and harmonic mean area (Fig. 1). Such independent correlation integrates the effects of unmeasured processes, including the historical processes of dispersal, environmental selection and drift related to the historical connectivity of basins. This allowed us to characterise the overall (i.e. mean over the species) raw $\beta$-SGDC, the overall effects associated with each predictor for each response variable, and the overall independent $\beta$-SGDC. Finally, we tested whether the variation in $\beta$-SGDCs between species could be attributed to variations in species traits. 


\section{Materials and methods}

211 As we wanted to investigate genetic differentiation at the broad scale, we restricted our analyses of spatial genetic differentiation to species exhibiting a wide distribution. We downloaded sequence records of the mitochondrial gene cytochrome c oxidase I (COI) from BOLD (www.boldsystems.org) in May 2017 for the following widespread taxa: Cyprinidae, Salmonidae, Lampetra, Petromyzon, Cobitis, Misgurnus, Barbatula, Silurus, Esox, Lota lota, Gymnocephalus and Sander. We first cleaned and aligned sequences by taxon and then realigned them together to keep the same fragment of 501 nucleotides for the analyses. Sequence records without sufficient geographic information to assign them to a drainage basin (hereafter "basin") or without a species name were discarded from our dataset. We defined a basin as the drainage area upstream from its mouth at the sea. According to this definition, a basin is isolated from other basins by barriers (sea or land) which are impassable for strictly freshwater fishes. The validity of species names was assessed using FishBase (Froese \& Pauly, 2017), resulting in a total of 6637 sequence records with a valid species names belonging to 716 distinct species distributed in 218 basins. We checked the environment (i.e. "freshwater", "brackish", "saltwater") of each species using FishBase (Froese \& Pauly, 2017), the status (i.e. "native", "exotic" or "unknown") of each species in each basin using the global database on freshwater fish species occurrence (Tedesco et al., 2017). We conserved only native records of strictly freshwater species, i.e. 4894 records, corresponding to a total of 509 species in 176 basins. 
three individuals per basin. To calculate such genetic differentiation, we converted single nucleotide polymorphisms (SNPs) of the sequence data into a table of individual genotypes and then calculated pairwise genetic distances for each pair of basins using G', ${ }_{\text {ST }}$ (Meirmans \& Hedrick, 2011), the corrected version of Hedrick's G' ${ }_{\text {ST }}$ (Hedrick, 2005). G' ${ }_{\text {ST }}$ is independent from within population diversity and does not underestimate genetic distance when the number of populations is small (Meirmans \& Hedrick, 2011). As G', st likely removes the effect of drift, we also calculated the pairwise genetic distances for each pair of basins using $\mathrm{F}_{\mathrm{ST}}(\mathrm{Nei}, 1973)$ for comparison purpose.

All these different selection filters drastically reduced the number of species we included in analyses: we finally focused our analyses of between-basin genetic differentiation on a total of 22 species in 38 basins (for more details about these basins, see Appendix S1 in Supporting Information). For instance, from all the species of Lampetra and Petromyzon we searched in BOLD, we conserved only L. planeri for the analyses. The number of species with analysed genetic data per basin varies from one (for 20 basins) to seventeen (for one basin, the basin "Odra"; Fig. 2; Appendix S1). The number of basins per species varies from four (our minimum threshold) to eleven (for the species Esox lucius) covering on average 76 $\%$ (standard deviation $(\mathrm{sd})=18 \%$ ) of their native range, with species exhibiting on average 11.0 individuals per basin $(\mathrm{sd}=11.0$; Appendix S2). Most records are located in Europe and North-America (Fig. 2).

\section{Taxonomic differentiation}

We calculated pairwise taxonomic differentiation between each pair of basins based on the list of native species per basin extracted from the global database on freshwater fish species occurrence (Tedesco et al., 2017). We used Simpson dissimilarity $\left(\beta_{\text {sim }}\right)$ - the turnover component of Sørensen dissimilarity (Sørensen, 1948) - which is independent from total 
taxonomic richness (see Baselga 2012 for review).

We computed between-basin geographic distance by calculating the distance between basin centroids. The average distance between basins was $5295 \mathrm{~km}(\mathrm{sd}=3920 \mathrm{~km})$. Measurements of geographic distance were then centred and scaled before further analyses. contemporary climate known to influence freshwater fish alpha diversity patterns at the global scale (e.g. Dias et al. 2014; Oberdorff et al. 2011; Tedesco et al. 2012; Tisseuil et al. 2013) i.e. mean annual temperature and precipitation (http://www.worldclim.org/), mean annual surface runoff (http://www.grdc.sr.unh.edu/) and mean annual actual and potential evapotranspiration (http://csi.cgiar.org/Aridity/). The mean values of all the variables were computed for each basin. To compute pairwise environmental distances between each pair of basins, we performed a principal component analysis (PCA) on these environmental variables (previously centred and scaled) and calculated the Euclidean distance between basins based on the first three PCA axes.

Finally, we calculated the pairwise harmonic mean area between each pair of basins. Indeed, the harmonic mean population size between pairs allows the role of drift on genetic differentiation (Serrouya et al., 2012) to be taken into account and can be computed using environmental proxies for local carrying capacities (Prunier et al., 2017). In our case, we used

275 the surface area of the basin as a raw environmental proxy for local carrying capacity. The 276 basins studied had an average surface area of $257589 \mathrm{~km}^{2}\left(\mathrm{sd}=584803 \mathrm{~km}^{2}\right)$. Measurements 277 of harmonic mean area were centred and scaled before further analyses. 
First, we investigated the raw correlation between taxonomic differentiation and genetic differentiation for each species individually using a Mantel correlation test with 999 permutations. To test the null hypothesis that there is no relationship between taxonomic differentiation and genetic differentiation using the information provided by all the species examined, we considered that this hypothesis has been tested independently $n$ times, with $n$ being the number of species included in the analyses. To combine the results from several independent tests bearing upon the same overall hypothesis, we used a modification of the Fisher's combined probability test. Under the null hypothesis that taxonomic and genetic differentiations are unrelated, observed p-values associated with the Mantel's test of each species are expected to be distributed according to a uniform distribution in $[0,1]$. We therefore compared the observed mean p-value over the species to a null distribution of mean p-values obtained by sampling randomly 10000 times one p-value by species in a uniform distribution in $[0,1]$. We calculated the p-value associated with the combined test as the frequency at which null mean p-values were below the observed mean p-value. This procedure avoids some problems identified by the use of a chi-2 test (e.g. Whitlock, 2005) which was the method initially proposed by Fisher.

To investigate the putative roles of dispersal limitation, environmental selection and drift on taxonomic and genetic differentiations, for each species we built multiple regressions of geographic distance $\left(D_{\text {geo }}\right)$, environmental distance $\left(D_{\text {env }}\right)$ and harmonic mean area $\left(D_{\text {area }}\right)$ on taxonomic differentiation (TD) and genetic differentiation (GD) taken separately (Fig. 1) as follows: TD $=\alpha_{0}+\alpha_{1} *$ Dgeo $+\alpha_{2} * \mathrm{D}_{\text {env }}+\alpha_{3} * \mathrm{D}_{\text {area }}$ and GD $=\beta_{0}+\beta_{1} *$ Dgeo $+\beta_{2} * \mathrm{D}_{\mathrm{env}}+$ $\beta_{3} * D_{\text {area. }}$ Our approach is very similar to multiple regressions on distance matrices (MRM; Lichstein 2007) except in the way we calculated p-values associated with partial regression coefficients. As in MRM, we permuted the rows and associated columns of the response distance matrix simultaneously. We repeated this operation 1999 times while holding the 
explanatory distance matrices constant to generate null distributions for partial regression coefficients. Then, in MRM, the p-value associated with a partial regression coefficient is calculated with a two-sided permutation test using the pseudo-t of Legendre et al. (1994), i.e. it tests whether the t-statistic associated with each regression coefficient is lower or higher than expected under a null distribution of pseudo-t obtained by permutation. In our approach, we hypothesised that geographic distance and environmental distance have a positive effect on both taxonomic and genetic differentiations (dispersal limitation and environmental selection enhance differentiation and are positively related to geographic and environmental distances respectively) while harmonic mean area has a negative effect on taxonomic and genetic differentiations (drift enhances differentiation and is negatively related to the harmonic mean area). To increase the statistical power of the tests, we therefore carried out one-sided tests for calculating the p-values associated with each partial regression coefficient. We tested the overall (i.e. over the species) effects of geographic distance, environmental distance and harmonic mean area on taxonomic and genetic differentiations by performing a combined probability test as described for the raw correlation between taxonomic and genetic differentiations, but this time considering probabilities associated with partial regression coefficients.

To examine whether taxonomic and genetic differentiations were still correlated once the effects of geographic distance and environmental distance had been taken into account, we then performed a Mantel correlation test between the residuals of the multiple regression on taxonomic differentiation and the residuals of the multiple regression on genetic differentiation with 999 permutations for each species. We tested this overall (i.e. over the species) residual correlation using a combined probability test as described for the raw correlation between taxonomic and genetic differentiations. 
Finally, we examined the heterogeneity between species regarding the residual

correlation between taxonomic and genetic differentiations and tested whether some species traits could explain such heterogeneity. The species traits initially considered were body length, longevity in the wild, vulnerability, used in aquaculture, use as bait, use in the aquarium, habitat, migratory behaviour and dispersal ability - which was calculated using a formula giving dispersal distance as a function of body size and caudal fin aspect ratio (Radinger \& Wolter, 2014). However, as migratory behaviour was 'potamodromous' for 16 out of the 22 species, 'non-migratory' for one species and the information was not available for the 5 species left, we excluded this non-informative trait from our analyses. Species traits were directly extracted from FishBase (Froese \& Pauly, 2017). All the analyses and the corresponding figures were realised with R 3.5.1 (R Core Team 2018) using the packages 'ade4' (Dray \& Dufour, 2007), 'ape' (Paradis, Claude, \& Strimmer, 2004), 'betapart' (Baselga, Orme, Villeger, De Bortoli, \& Leprieur, 2018), 'Biostrings' (Pagès, Aboyoun, Gentleman, \& DebRoy, 2018), ‘broom' (Robinson \& Hayes, 2018), 'ggplot2' (Wickham, 2016), 'ggthemes' (Arnold, 2018), 'hierfstat' (Goudet \& Jombart, 2015), 'maptools' (Bivand \& Lewin-Koh, 2018), 'mmod' (Winter, 2012), 'RColorBrewer' (Neuwirth, 2014), 'rgdal' (Bivand, Keitt, \& Rowlingson, 2018), 'rgeos' (Bivand \& Rundel, 2018), 'reshape2' (Wickham, 2007), ‘seriation' (Hahsler, Buchta, \& Hornik, 2018) and 'vegan’ (Oksanen et al., 2018).

\section{Results}

We detected an overall positive correlation between taxonomic and genetic differentiations, significantly different from 0 . This result holds true both for the raw correlation between taxonomic and genetic differentiations $\left(\mathrm{r}_{\text {mean } \pm s d}=0.433 \pm 0.420\right.$; Fig. 3a; Appendices S3, S4) 
and for the residual correlation, i.e. the correlation between taxonomic and genetic differentiations independent of the effects of geographic distance, environmental distance and harmonic mean area $\left(r_{\text {mean } \pm \text { sd }}=0.379 \pm 0.641\right.$; Fig. 3b; Appendices S3, S4).

There was almost no overall effect of geographic distance on taxonomic differentiation $\left(\alpha_{1 \text { mean } \pm \text { sd }}=0.032 \pm 1.051\right)$ or on genetic differentiation $\left(\beta_{1 \text { mean } \pm \text { sd }}=-0.011 \pm 1.060\right)$, and these overall effects did not differ significantly from 0 (Fig. 4; Appendices S5, S6, S7). In contrast, we detected an overall positive effect of environmental distance on both taxonomic differentiation $\left(\alpha_{2 \text { mean } \pm \text { sd }}=0.405 \pm 0.956\right)$ and genetic differentiation $\left(\beta_{2 \text { mean } \pm \text { sd }}=0.229 \pm\right.$ 0.865), although it was only significantly different from 0 for taxonomic differentiation (Fig. 4; Appendices S5, S6, S7). There was an overall negative effect of harmonic mean area on both taxonomic differentiation $\left(\alpha_{3 \text { mean } \pm \text { sd }}=-0.178 \pm 0.617\right)$ and genetic differentiation $\left(\beta_{3 \text { mean }}\right.$ \pm sd $=-0.092 \pm 0.713)$, but it was only significantly different from 0 for taxonomic differentiation (Fig. 4; Appendices S5, S6, S7). Using F $_{\text {ST }}$ as a measure of genetic differentiation did not change the trend we observed: there was an overall negative but not significant effect of harmonic area on $\mathrm{F}_{\mathrm{ST}}$ (Appendices S6, S7).

The results of these multiple regressions as well as the residual correlations between taxonomic and genetic differentiations are summarised in Fig. 5. Overall, they suggest that the effect of geographic distance, environmental distance and harmonic mean area only explain a small part of the correlation between taxonomic and genetic differentiations.

Despite this strong overall independent correlation between taxonomic differentiation of freshwater fish communities and genetic differentiation of freshwater fish populations, the correlation between taxonomic and genetic differentiations varied greatly between species (Fig. 3b; Appendix S3). For some species, such as the common roach Rutilus rutilus (Fig. 6a, b), there was a sound correlation between taxonomic differentiation and genetic 
differentiation, whether we considered the raw or residual correlation. In other species, such as the common chub Squalius cephalus, taxonomic differentiation and genetic differentiation were not correlated (Fig. 6c, d). In this species, genetic differentiation was better predicted by geographic distance and harmonic mean area (Appendix S5). However, none of the species traits examined explained this heterogeneity of responses between species (Appendix S8).

\section{Discussion}

Our analyses indicated that taxonomic and genetic differentiations are strongly correlated overall, and independently of the parallel effects of geographic distance, environmental distance and harmonic mean area on taxonomic and genetic differentiations. This suggests that the parallel influence of dispersal limitation, environmental selection and drift on taxonomic and genetic differentiations only partially explains the overall $\beta$-SGDC we observed. This independent, unexplained correlation between taxonomic and genetic differentiations thus probably results from processes that we did not explicitly consider in our study. The most probable explanation is that the independent $\beta$-SGDC we observed is due to the parallel action of historical processes, which occurred when the basins were still connected, on taxonomic and genetic differentiations. These historical processes include all the different processes that explain the colonisation history of basins (Orsini et al., 2013): i) the dispersal of individuals between previously connected basins in interaction with environmental and/or biotic selection on their dispersal route and ii) environmental and/or biotic selection in interaction with drift within their place of arrival and/or origin that may have led to extinction. This explanation is supported by previous studies on the influence of historical processes on broad-scale taxonomic differentiation between freshwater fish communities on the one hand and on broad-scale genetic differentiation between freshwater 
fish populations on the other hand. Two recent studies on global freshwater fish biodiversity have shown that present-day patterns of taxonomic dissimilarity across basins are well explained by the historical connectivity of basins (Dias et al., 2014) and also historical climatic oscillations that took place during the Quaternary and the Holocene (Leprieur et al., 2011). For fish species, it is well known that historical dispersal influences genetic structure across basins (Carvalho, 1993), especially for zones that were subject to intense post-glacial recolonisation such as our study area. Multispecies comparisons at large spatial scales in Europe (Seifertová, Bryja, Vyskočilová, Martínková, \& Šimková, 2012) and in North America (April, Hanner, Mayden, \& Bernatchez, 2013) have shown that the climatic fluctuations that caused glacial cycles during the Pleistocene had a generalised effect on the patterns of fish genetic divergence. In addition, three other, non-exclusive hypotheses may explain the independent $\beta$-SGDC we observed. First, the proxies we used to account for dispersal limitation, environmental selection and drift may not fully represent these processes. For instance, we may have overlooked some environmental variables that are important in driving environmental selection. Alternatively, we may have poorly estimated the role of drift, either because the area of the basin we used to account for drift may be too approximate to accurately represent the carrying capacities of populations and communities or because we did not consider that the influence of drift within a basin increases with its age of isolation. Secondly, the sequence data we used to calculate genetic differentiation may not detect dispersal limitation and/or environmental selection properly, either because they did not cover the entire native ranges of species (see possible consequences of such sampling bias in e.g. Meirmans, 2015), or because the mitochondrial gene COI is not directly under environmental selection. Finally, the proposed frameworks to interpret SGDCs (Vellend \& Geber, 2005; Lamy et al., 2017) suggest that correlations between species diversity and genetic diversity may also result from a causal action of species diversity on genetic diversity or vice-versa. 
For instance, if the focal species (i.e. the species for which we studied genetic diversity) is a facilitator for the other component species of the community, we would expect their populations sizes to co-vary positively, resulting in a positive $\alpha$-SGDC; the converse is expected if the focal species is a competitor. If the nature of the interaction between the focal species and the other species of the community is generally the same within each basin, such causal effect is not expected to influence the $\beta$-SGDC we observed. However, if the focal species is facilitator in one basin and competitor in another, we would expect the population sizes of the other component species of the community to increase in the first case and decrease in the second case. This would result in more ecological drift within the community where the focal species is competitor, and therefore more taxonomic differentiation between basins than would be expected without this causal effect. In the end, such causal effect would tend to reduce $\beta$-SGDC because it would increase taxonomic differentiation between basins without influencing genetic differentiation.

Moreover, our results contribute new insights into the study of $\beta$-SGDCs. With the study of 22 new $\beta$-SGDCs, we increased the number of $\beta$-SGDCs (43) previously reported in the literature by more than $50 \%$ (see Lamy et al., 2017 for the most recent review). We found an average raw correlation between taxonomic and genetic differentiations of 0.433 , and an independent correlation (i.e. independent from the parallel effects of geographic distance, environmental distance and harmonic mean area on taxonomic and genetic differentiations) of 0.379. Both of these values are superior to the average value of 0.221 reported by Lamy et al. (2017). They are also around three times superior to the average value of 0.139 found by Fourtune et al. (2016) in their study of four freshwater fish species at a smaller scale, within

447 one drainage basin. This suggests that the strong correlations we found are probably more 448 related to the size and/or the isolation of the habitats we studied (i.e. large drainage basins isolated from each other) rather than our biological model. Previous syntheses have reported 
that $\alpha$-SGDCs (i.e. correlations between genetic diversity within populations and species diversity within communities) are stronger and more often positive in island-like habitats (Vellend \& Geber, 2005; Vellend et al., 2014), in agreement with the predictions of theoretical models (Laroche et al., 2015). As drainage basins are typically island-like habitats (Sepkoski \& Rex, 1974; Hugueny, 1989), our findings suggest that this explanation may hold true for $\beta$-SGDCs as well. The observed differences also suggest that for a system without present-day dispersal the $\beta$-SGDC is stronger than in systems with present-day dispersal. Actually, the opposite could have been expected (i.e. weaker $\beta$-SGDCs for systems without present-day dispersal than for systems with present-day dispersal) if the genetic similarity between two previously connected populations had been erased by genetic drift occurring after their isolation without changes in species composition (i.e. no species extinction). However, our results suggest that drift did not influence significantly the patterns of genetic differentiation we observed. As this result holds true both for $\mathrm{G}^{\prime}{ }_{\mathrm{ST}}$ and $\mathrm{F}_{\mathrm{ST}}$, this is probably because we mainly focused on large drainage basins and consequently large population sizes. between the different species we examined. We provided two examples. On the one hand, we showed that the $\beta$-SGDC was strong for Rutilus rutilus, suggesting that historical processes largely shaped the patterns of genetic differentiation observed in this species. This is consistent with a previous study indicating that $R$. rutilus is composed of two historically isolated, independently evolving sets of populations (Larmuseau et al., 2009). On the other hand, our results indicate that genetic differentiation in Squalius cephalus was not correlated to taxonomic differentiation, but was well explained by geographic distance. This suggests that dispersal limitation has a more important effect than any other processes on broad-scale genetic differentiation in S. cephalus. This might seem surprising, since previous analyses of the mitochondrial gene cytochrome $b$ in that species indicated four main lineages originating 
from multiple glacial refugia (Durand, Persat, \& Bouvet, 1999; Seifertová et al., 2012).

However, the use of a combination of both mitochondrial and nuclear DNA, Seifertová et al. (2012) also suggested that genetic differentiation in $S$. cephalus resulted from a combination of different factors, i.e. post-glacial colonisation from different refugia or recent evolutionary processes such as drift or dispersal limitation. Our results based on the analysis of the mitochondrial gene COI strongly support the dispersal limitation hypothesis although, as we did not design the sampling, but analysed existing data, we might not have captured the whole picture. As $R$. rutilus and $S$. cephalus have similar dispersal abilities, this difference of $\beta$ SGDC between the two species does not seem to be related to their difference in dispersal abilities. Beyond these two species and this single trait, our analyses did not permit us to uncover any trait that could explain the variability of $\beta$-SGDC over the 22 species we examined. This is surprising because life-history traits of species are known to shape spatial patterns of genetic differentiation (e.g. Duminil et al., 2007; Kelly \& Palumbi, 2010), and therefore $\beta$-SGDC. This unexpected finding may be due to different reasons. First, the variability of $\beta$-SGDC may be due to species traits that we did not consider. Secondly, the $\beta$ SGDC at the specific scale was sometimes examined for a small number of basins, which may result in wide variations in the estimated correlation coefficients. Therefore, single species outcomes should be interpreted with great caution.

To conclude, this study of broad-scale $\beta$-SGDC for multiple freshwater fish species suggests that historical processes greatly contributed to the shape of present-day patterns of taxonomic and genetic differentiations, independently of contemporary processes. This implies that taxonomic differentiation may be an appropriate proxy to explain the role of historical processes on patterns of genetic differentiation, which remains a challenging issue in landscape genetics (Dyer, Nason, \& Garrick, 2010). We believe that further studies of broad-scale $\beta$-SGDCs comparing organisms whose dispersal is limited within habitat patches 
500 with organisms that are able to disperse across habitat patches, will help to investigate the 501 extent to which our findings can be generalised. 


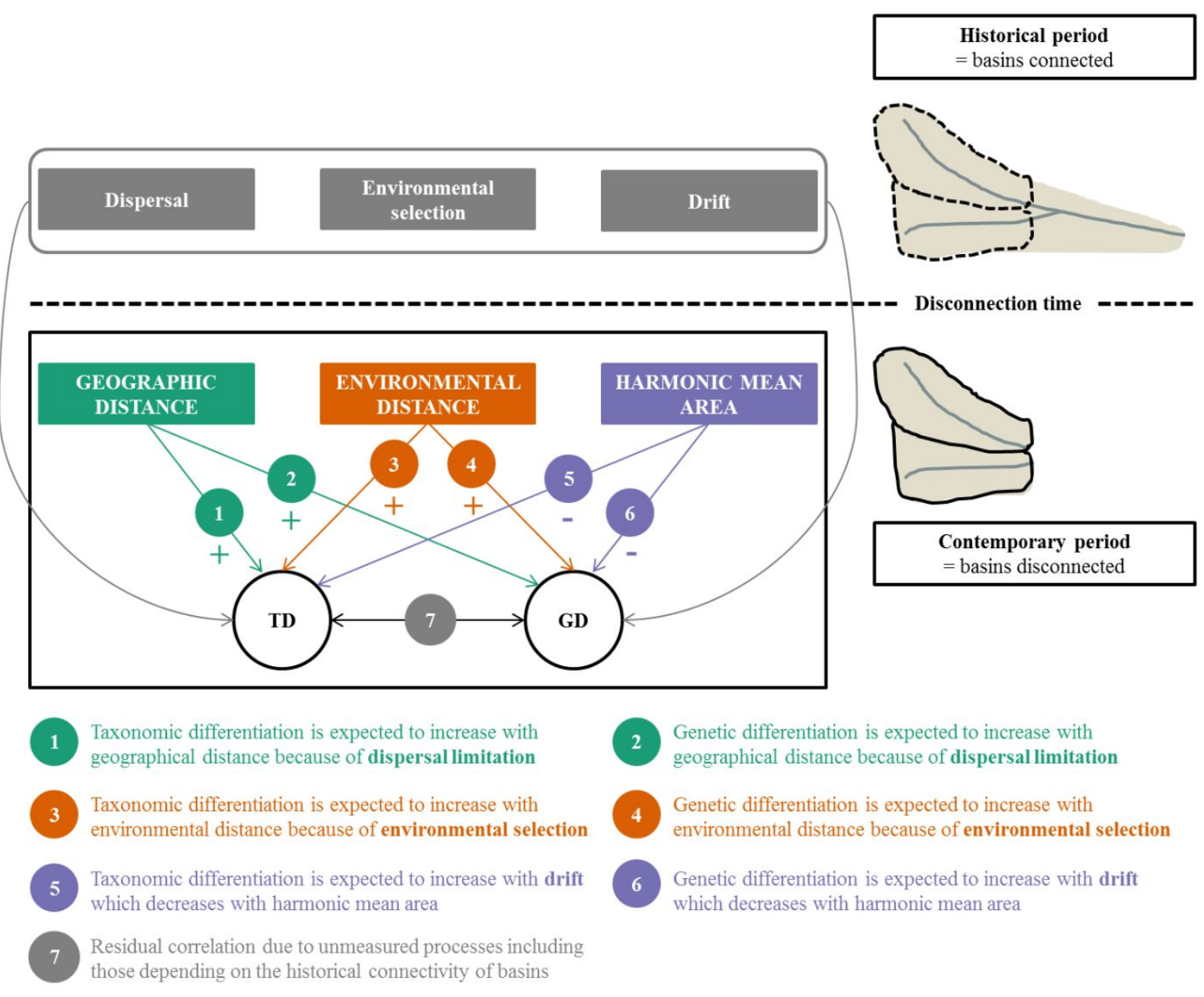

Figure 1. Illustration of the different processes expected to act in parallel on between-basin taxonomic differentiation of freshwater fish communities (TD) and on between-basin genetic differentiation of freshwater fish populations (GD) at different periods and the proxies used in this study to infer those processes. The black frame encompasses the causal diagram depicting the relationships that we actually tested in this study, i.e. the effects of geographic distance (proxy of contemporary dispersal limitation), environmental distance (proxy of contemporary

511 environmental selection) and pairwise harmonic mean area between basins (proxy of

512 contemporary drift) on TD and GD. The double arrow between TD and GD represent the

513 residual correlation, i.e. the correlation between TD and GD which is not explained by the parallel influence of contemporary dispersal limitation, contemporary environmental selection 
515 and contemporary drift on TD and GD. The numbers on the arrows and the signs below them

516 correspond to our theoretical expectations regarding the different effects which are detailed in

517 the text below the black frame. The grey arrows represent the putative effects of historical

518 dispersal limitation, historical environmental selection and historical drift on TD and GD that

519 we did not directly test in our statistical approach. The grey polygons on the right side

520 represent the evolution of the basin configuration through time from one unique basin to two

521 distinct and disconnected basins, with almost no contemporary dispersal of individuals

522 between them (dispersal may occasionally occur between adjacent basins). 


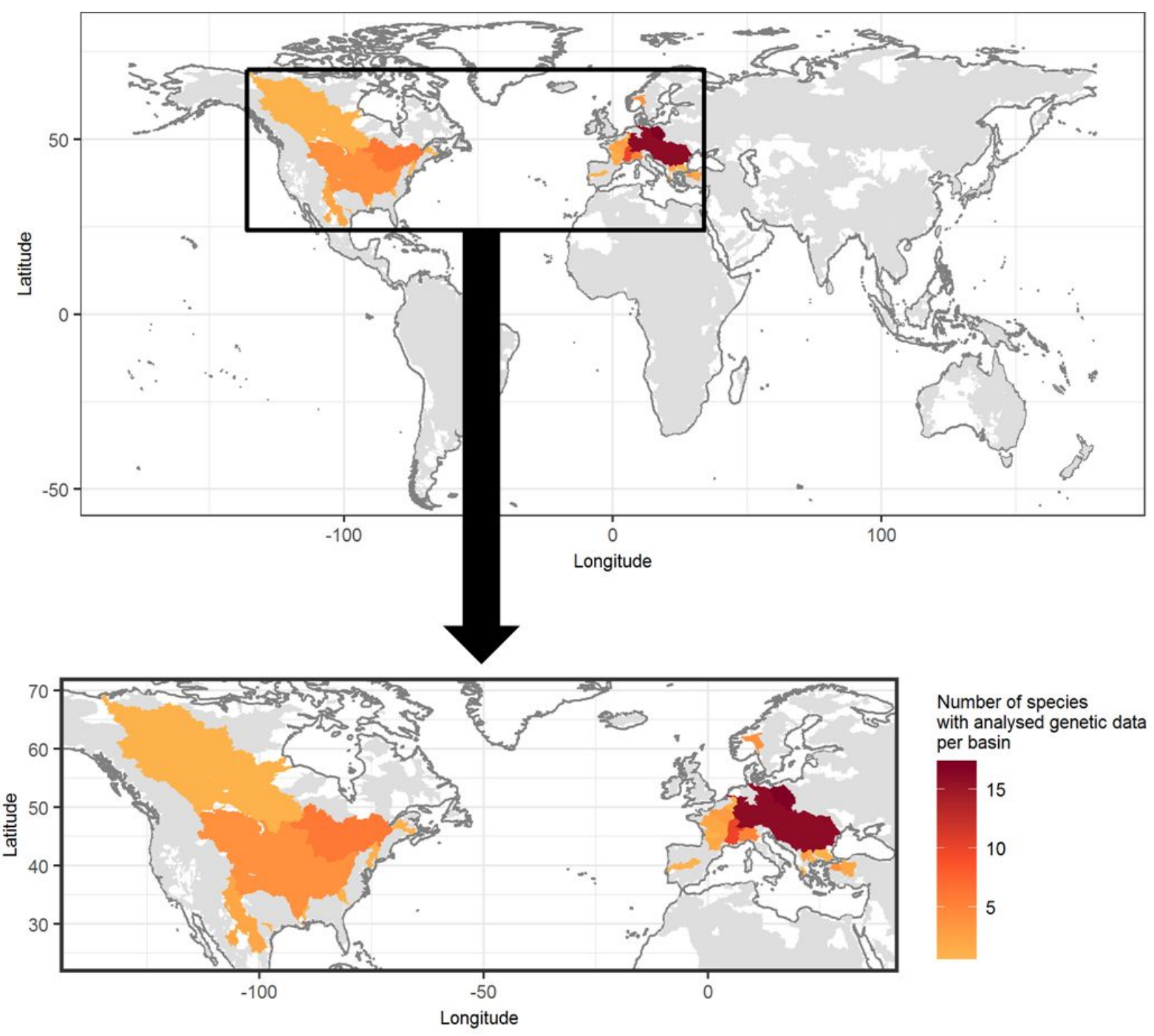

525 Figure 2. Spatial distribution of the number of species with analysed genetic data per basin

526 studied in our analyses at the global scale. Top: the rectangle indicates the location of the

527 enlarged area. Bottom: enlarged area including Europe and North America. In total, our study encompasses 22 species with analysed genetic data in 38 basins. 
(a) Raw correlations between

taxonomic differentiation and genetic differentiation

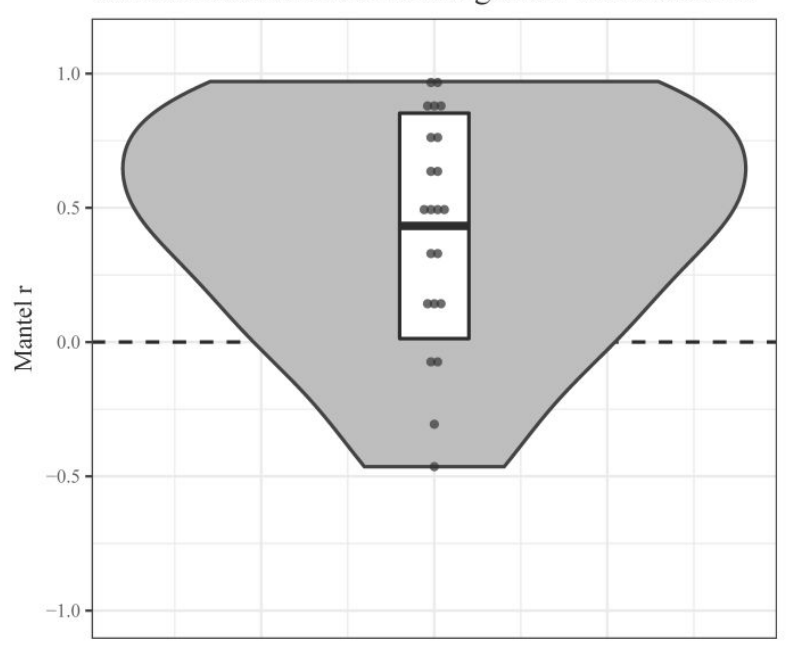

(b) Residual correlations between

taxonomic differentiation and genetic differentiation

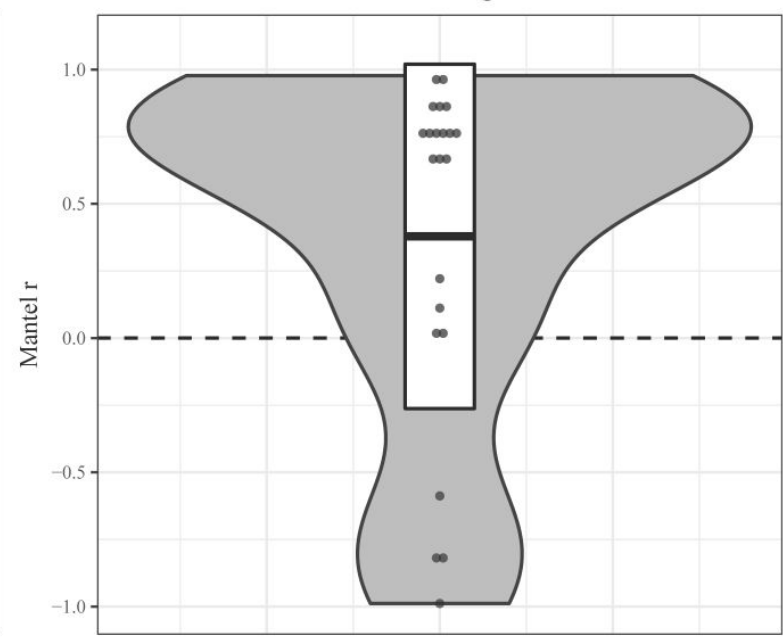

531 Figure 3. Violin plots showing the distribution and the probability density of (a) raw

532 correlations coefficients and (b) residual correlation coefficients between taxonomic

533 differentiation and genetic differentiation for the 22 fish species examined at global scale.

534 Crossbars indicate mean \pm standard deviation. 
(a) Multiple regressions on taxonomic differentiation

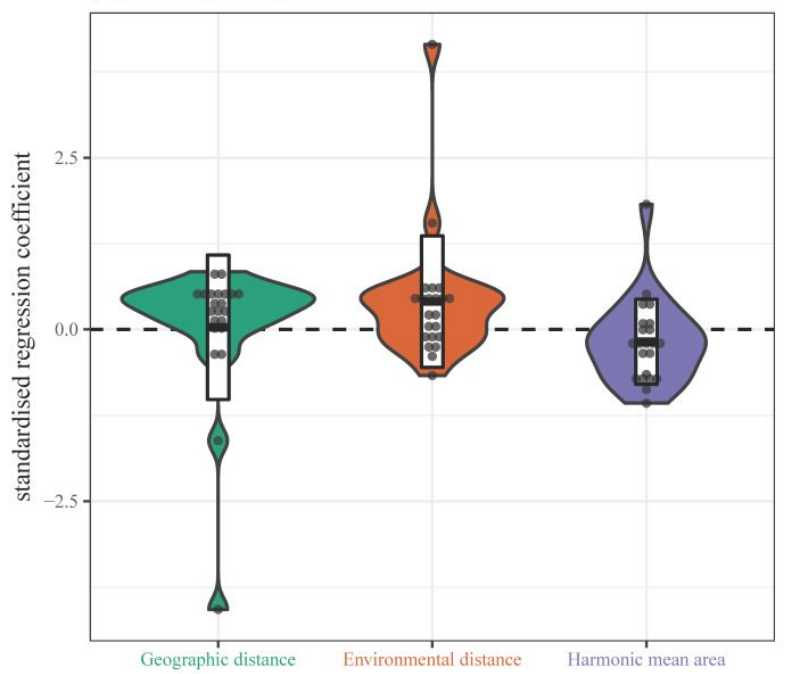

(b) Multiple regressions on genetic differentiation

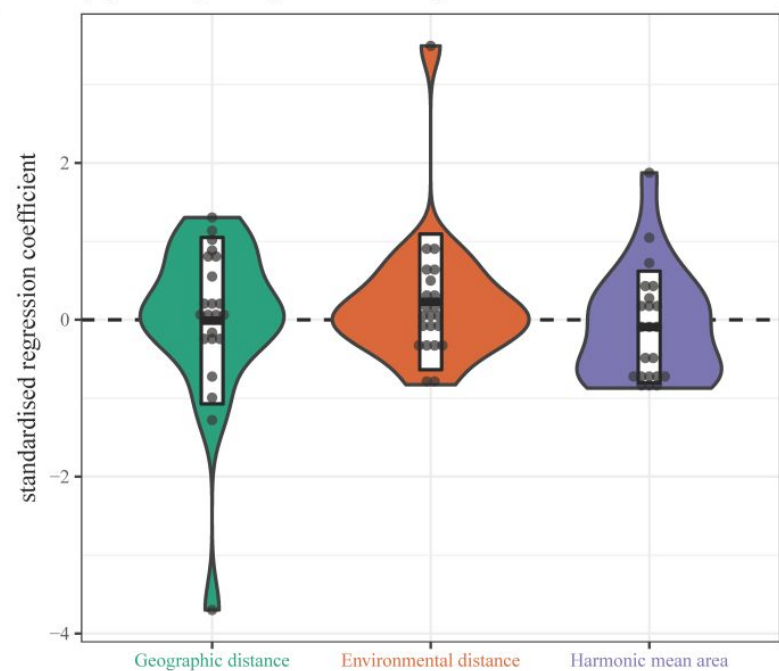

537 Figure 4. Violin plots showing the distribution and the probability density of the effect of

538 geographic distance, environmental distance and harmonic mean area (as standardised regression coefficients) for the 22 fish species examined at global scale on (a) taxonomic differentiation and (b) genetic differentiation. Crossbars indicate mean \pm standard deviation. 


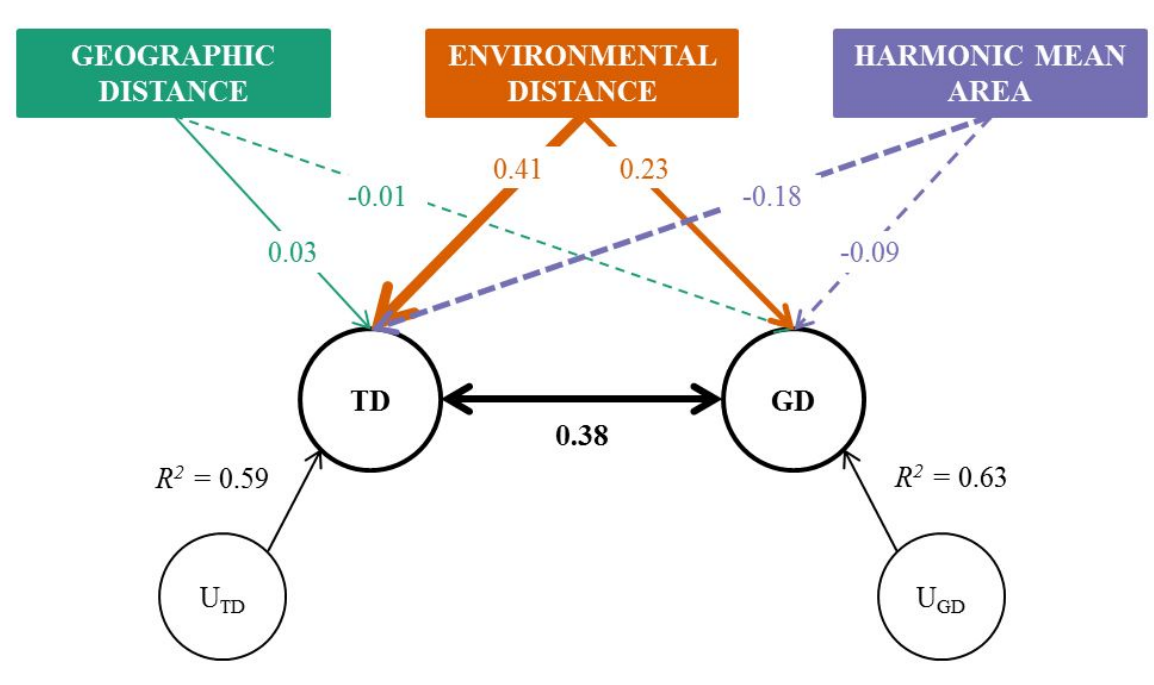

543 Figure 5. Causal diagram depicting the results of multiple regressions of geographic distance,

544 environmental distance and harmonic mean area on TD and GD (taken separately). Arrows

545 represent putative causal effects through the standardised regression coefficients (positive

546 values: solid arrows; negative values: dotted arrows; arrow width is proportional to coefficient

547 value). The $\mathrm{R}^{2}$ represent the part of variance explained by the multiple regressions on TD

548 (left) and GD (right). $\mathrm{U}_{\mathrm{TD}}$ and $\mathrm{U}_{\mathrm{GD}}$ represent unspecified factors influencing TD and GD

549 respectively. The double arrow between SD and GD corresponds to the residual correlation.

550 All numerical values represent means for the 22 fish species examined at global scale. 
(a) Raw correlations

Rutilus rutilus

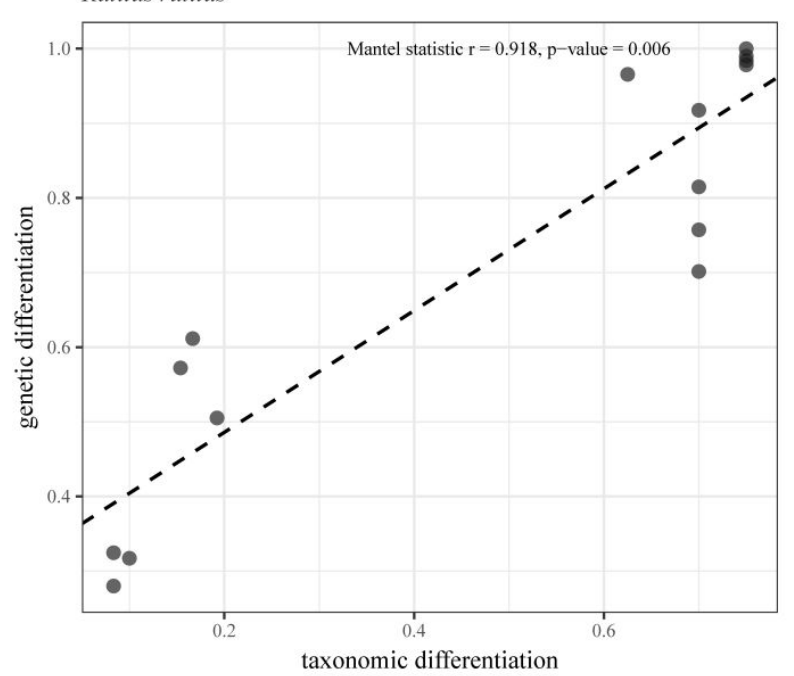

(c) Raw correlations

Squalius cephalus

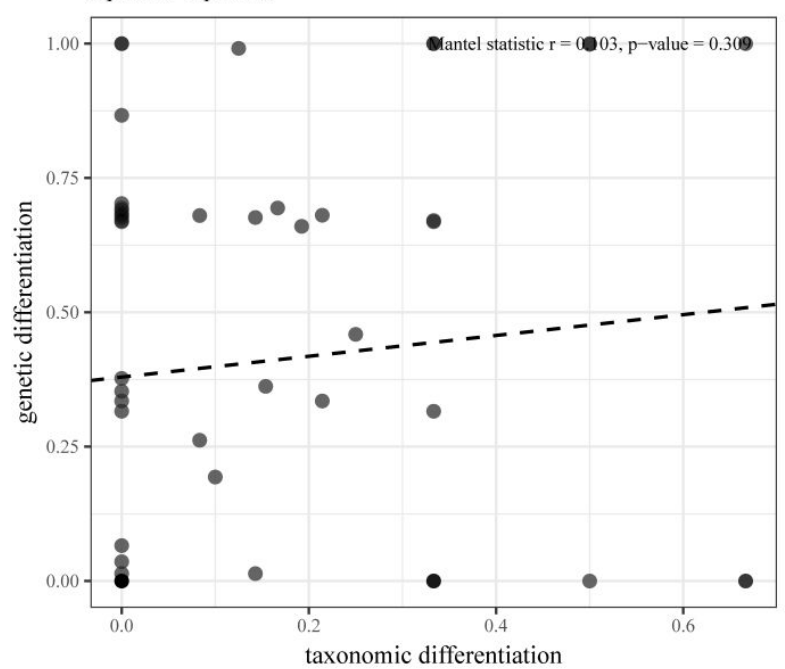

(b) Residual correlations

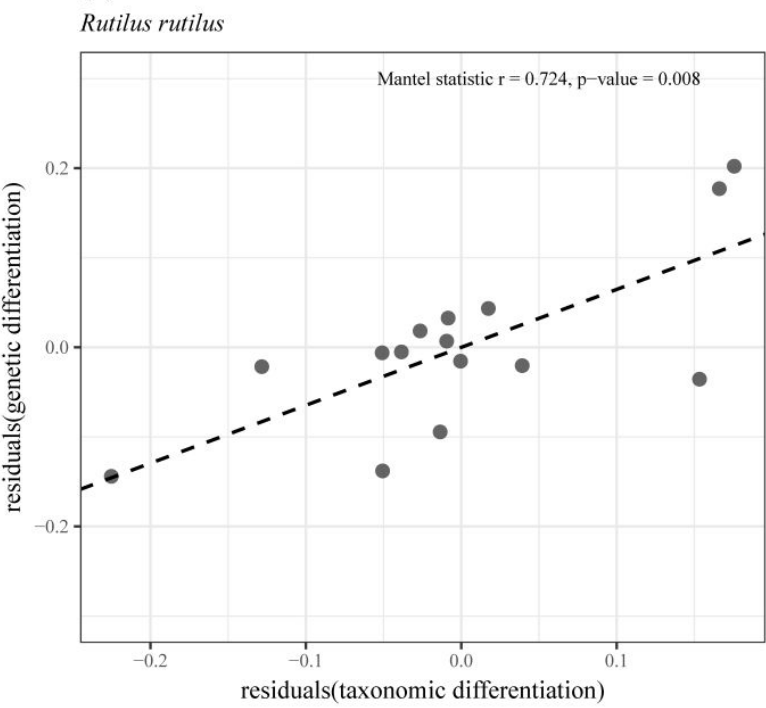

(d) Residual correlations

Squalius cephalus

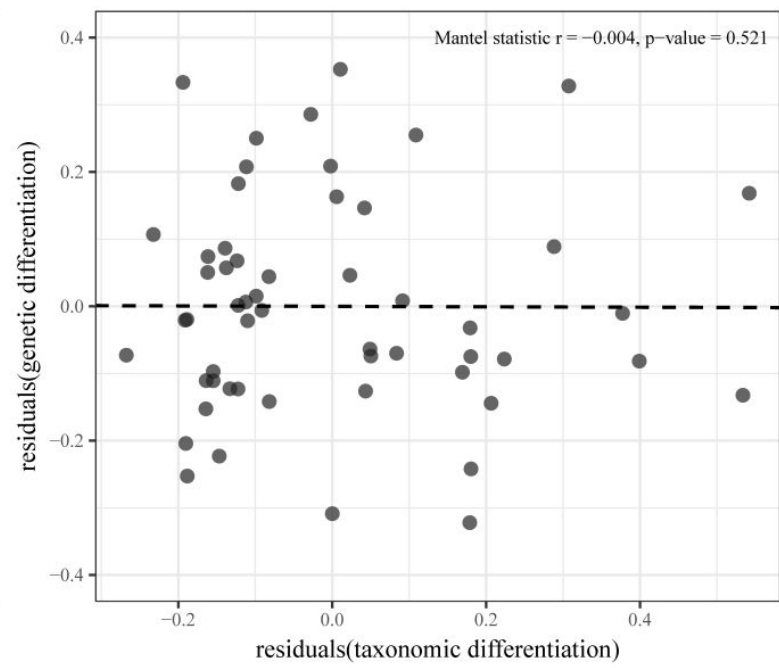

552 Figure 6. Observed (dots) and predicted (dashed line) raw values (a, c) and residual values

553 from the multiple regressions (b, d) of genetic differentiation as a function of taxonomic

554 differentiation for the two fish species (a, b) Rutilus rutilus and (c, d) Squalius cephalus. 


\section{References}

Allendorf, F. W. (1986). Genetic drift and the loss of alleles versus heterozygosity. Zoobiology, 5(2), 181-190.

Almany, G. R. (2003). Priority effects in coral reef fish communities. Ecology, 84(7), 19201935.

April, J., Hanner, R. H., Mayden, R. L., \& Bernatchez, L. (2013). Metabolic rate and climatic fluctuations shape continental wide pattern of genetic divergence and biodiversity in fishes. PLoS ONE, 8(7), e70296.

Arnold, J.B. (2018). ggthemes: Extra Themes, Scales and Geoms for 'ggplot2'. R package version 4.0.1. Retrieved from https://CRAN.R-project.org/package=ggthemes.

Astorga, A., Oksanen, J., Luoto, M., Soininen, J., Virtanen, R., \& Muotka, T. (2012). Distance decay of similarity in freshwater communities: do macro-and microorganisms follow the same rules?. Global Ecology and Biogeography, 21(3), 365-375.

Baselga, A. (2012). The relationship between species replacement, dissimilarity derived from nestedness, and nestedness. Global Ecology and Biogeography, 21(12), 1223-1232.

Baselga, A., Fujisawa, T., Crampton-Platt, A., Bergsten, J., Foster, P. G., Monaghan, M. T., \& Vogler, A. P. (2013). Whole-community DNA barcoding reveals a spatio-temporal continuum of biodiversity at species and genetic levels. Nature Communications, 4(1892).

Baselga, A., Gómez-Rodríguez, C., \& Vogler, A. P. (2015). Multi-hierarchical macroecology at species and genetic levels to discern neutral and non-neutral processes. Global Ecology and Biogeography, 24(8), 873-882. 
578 Baselga, A., Orme, D., Villeger, S., De Bortoli, J., \& Leprieur, F. (2018). betapart:

579

580

581

582

583

584

585

586

587

588

589

590

591

592

593

594

595

596 Partitioning Beta Diversity into Turnover and Nestedness Components. R package version 1.5.0. Retrieved from https://CRAN.R-project.org/package=betapart.

Bivand, R., \& Lewin-Koh, N. (2018). maptools: Tools for Reading and Handling Spatial Objects. R package version 0.9-3. Retrieved from https://CRAN.Rproject.org/package $=$ maptools.

Bivand, R., Keitt, T., \& Rowlingson, B. (2018). rgdal: Bindings for the 'Geospatial' Data Abstraction Library. R package version 1.3-4. Retrieved from https://CRAN.Rproject.org/package $=$ rgdal.

Bivand, R., \& Rundel, C. (2018). rgeos: Interface to Geometry Engine - Open Source ('GEOS'). R package version 0.3-28. Retrieved from https://CRAN.Rproject.org/package $=$ rgeos .

Blanchet, S., Prunier, J. G., \& De Kort, H. (2017). Time to go bigger: emerging patterns in macrogenetics. Trends in Genetics, 33(9), 579-580.

Carvalho, G. R. (1993). Evolutionary aspects of fish distribution: genetic variability and adaptation. Journal of Fish Biology, 43(Supplement A), 53-73.

Derry, A. M., Arnott, S. E., Shead, J. A., Hebert, P. D., \& Boag, P. T. (2009). Ecological linkages between community and genetic diversity in zooplankton among boreal shield lakes. Ecology, 90(8), 2275-2286.

Dias, M. S., Oberdorff, T., Hugueny, B., Leprieur, F., Jézéquel, C., Cornu, J. F., ... Tedesco, P. A. (2014). Global imprint of historical connectivity on freshwater fish biodiversity. Ecology Letters, 17(9), 1130-1140. 
600 Dray, S., \& Dufour, A. (2007). The ade4 package: Implementing the Duality Diagram for 601 Ecologists. Journal of Statistical Software, 22(4), 1-20.

602

603

604

605

606

607

608

609

610

611

612

613

614

615

616

Duminil, J., Fineschi, S., Hampe, A., Jordano, P., Salvini, D., Vendramin, G. G., \& Petit, R. J. (2007). Can population genetic structure be predicted from life-history traits?. The American Naturalist, 169(5), 662-672.

Durand, J. D., Persat, H., \& Bouvet, Y. (1999). Phylogeography and postglacial dispersion of the chub (Leuciscus cephalus) in Europe. Molecular Ecology, 8(6), 989-997.

Dyer, R. J., Nason, J. D., \& Garrick, R. C. (2010). Landscape modelling of gene flow: improved power using conditional genetic distance derived from the topology of population networks. Molecular Ecology, 19(17), 3746-3759.

Fourtune, L., Paz-Vinas, I., Loot, G., Prunier, J. G., \& Blanchet, S. (2016). Lessons from the fish: a multi-species analysis reveals common processes underlying similar speciesgenetic diversity correlations. Freshwater Biology, 61(11), 1830-1845.

Fraser, C. I., Davies, I. D., Bryant, D., Waters, J. M. (2018). How disturbance and dispersal influence intraspecific structure. Journal of Ecology, 106,1298-1306.

Froese, R., \& Pauly, D. (2017). FishBase. World Wide Web electronic publication. www.fishbase.org, version (06/2017).

Gilbert, B., \& Levine, J. M. (2017). Ecological drift and the distribution of species diversity. Proceedings of the Royal Society B: Biological Sciences, 284(1855), 20170507.

Goudet, J., \& Jombart, T. (2015). hierfstat: Estimation and Tests of Hierarchical F-Statistics. R package version 0.04-22. Retrieved from https://CRAN.Rproject.org/package $=$ hierfstat 
Hahsler, M., Buchta, C., \& Hornik, K. (2018). seriation: Infrastructure for Ordering Objects Using Seriation. R package version 1.2-3.Retrieved from https:/CRAN.Rproject.org/package $=$ seriation.

Hedrick, P. W. (2005). A standardized genetic differentiation measure. Evolution, 59(8), $1633-1638$.

Hugueny, B. (1989). West African rivers as biogeographic islands: species richness of fish communities. Oecologia, 79, 236-243.

Kahilainen, A., Puurtinen, M., \& Kotiaho, J. S. (2014). Conservation implications of speciesgenetic diversity correlations. Global Ecology and Conservation, 2, 315-323.

Kelly, R. P., \& Palumbi, S. R. (2010). Genetic structure among 50 species of the northeastern Pacific rocky intertidal community. PLoS ONE, 5(1), e8594.

Lamy, T., Laroche, F., David, P., Massol, F., \& Jarne, P. (2017). The contribution of speciesgenetic diversity correlations to the understanding of community assembly rules. Oikos, 126(6), 759-771.

Larmuseau, M. H. D., Freyhof, J., Volckaert, F. A. M., \& Van Houdt, J. K. J. (2009). Matrilinear phylogeography and demographical patterns of Rutilus rutilus: implications for taxonomy and conservation. Journal of Fish Biology, 75(2), 332-353.

Laroche, F., Jarne, P., Lamy, T., David, P., \& Massol, F. (2014). A neutral theory for interpreting correlations between species and genetic diversity in communities. The American Naturalist, 185(1), 59-69.

Legendre, P., Lapointe, F.-J., \& Casgrain, P. (1994). Modeling brain evolution from behavior: a permutational regression approach. Evolution, 48(5), 1487-1499. 
Leprieur, F., Olden, J. D., Lek, S., \& Brosse, S. (2009). Contrasting patterns and mechanisms of spatial turnover for native and exotic freshwater fish in Europe. Journal of Biogeography, 36(10), 1899-1912.

Leprieur, F., Tedesco, P. A., Hugueny, B., Beauchard, O., Dürr, H. H., Brosse, S., \& Oberdorff, T. (2011). Partitioning global patterns of freshwater fish beta diversity reveals contrasting signatures of past climate changes. Ecology Letters, 14(4), 325-334.

Lichstein, J. W. (2007). Multiple regression on distance matrices: a multivariate spatial analysis tool. Plant Ecology, 188(2), 117-131.

Mayr, E. (1963). Animal species and evolution. Cambridge, MA: Harvard University Press.

Meirmans, P. G. (2015). Seven common mistakes in population genetics and how to avoid them. Molecular Ecology, 24, 3223-3231.

Meirmans, P. G., \& Hedrick, P. W. (2011). Assessing population structure: $F_{\text {ST }}$ and related measures. Molecular Ecology Resources, 11(1), 5-18.

Moritz, C., Meynard, C. N., Devictor, V., Guizien, K., Labrune, C., Guarini, J. M., \& Mouquet, N. (2013). Disentangling the role of connectivity, environmental filtering, and spatial structure on metacommunity dynamics. Oikos, 122(10), 1401-1410.

Oberdorff, T., Tedesco, P. A., Hugueny, B., Leprieur, F., Beauchard, O., Brosse, S., \& Dürr, H. H. (2011). Global and regional patterns in riverine fish species richness: a review. International Journal of Ecology, 201(967631).

Oksanen, J., Blanchet, G., Friendly, M., Kindt, R., Legendre, P., McGlinn, D., ...Wagner, H. (2018). vegan: Community Ecology Package. R package version 2.5-2. Retrieved from https://CRAN.R-project.org/package=vegan. 
666

667

668

669

670

671

672

673

674

675

676

677

678

679

680

681

682

683

684

685

686

687

Orsini, L., Vanoverbeke, J., Swillen, I., Mergeay, J., \& De Meester, L. (2013). Drivers of population genetic differentiation in the wild: isolation by dispersal limitation, isolation by adaptation and isolation by colonization. Molecular Ecology, 22(24), 5983-5999.

Nei, M. (1973). Analysis of gene diversity in subdivided populations. Proceedings of the National Academy of Sciences, 70(12), 3321-3323.

Nekola, J. C., \& White, P. S. (1999). The distance decay of similarity in biogeography and ecology. Journal of Biogeography, 26(4), 867-878.

Neuwirth, E. (2014). RColorBrewer: ColorBrewer Palettes. R package version 1.1-2. Retrieved from https://CRAN.R-project.org/package=RColorBrewer.

Pagès, H., Aboyoun, P., Gentleman, R., \& DebRoy, S. (2018). Biostrings: Efficient manipulation of biological strings. R package version 2.48.0.

Papadopoulou, A., Anastasiou, I., Spagopoulou, F., Stalimerou, M., Terzopoulou, S., Legakis, A., \& Vogler, A. P. (2011). Testing the species-genetic diversity correlation in the Aegean Archipelago: toward a haplotype-based macroecology? The American Naturalist, 178(2), 241-255.

Paradis, E., Claude, J., \& Strimmer, K. (2004). APE: analyses of phylogenetics and evolution in R language. Bioinformatics, 20, 289-290.

Preston, F. W. (1962). The canonical distribution of commonness and rarity: Part II. Ecology, 43(3), 410-432.

Prunier, J. G., Dubut, V., Chikhi, L., \& Blanchet, S. (2017). Contribution of spatial heterogeneity in effective population sizes to the variance in pairwise measures of genetic differentiation. Methods in Ecology and Evolution, 8(12), 1866-1877. 
688 Qian, H., \& Ricklefs, R. E. (2012). Disentangling the effects of geographic distance and 689 environmental dissimilarity on global patterns of species turnover. Global ecology and Biogeography, 21(3), 341-351.

691

R Core Team. (2018). R: A language and environment for statistical computing. Vienna, 692 Austria: R Foundation for Statistical Computing. Retrieved from https://www.R-

693 project.org/.

694

695

696

697

698

699

700

701

702

703

704

705

706

707

708

709

Radinger, J., \& Wolter, C. (2014). Patterns and predictors of fish dispersal in rivers. Fish and fisheries, 15(3), 456-473.

Robinson, D., \& Hayes, A. (2018). broom: Convert Statistical Analysis Objects into Tidy Tibbles. R package version 0.5.0. Retrieved from https://CRAN.Rproject.org/package=broom .

Rosenzweig, M. L. (1995). Species diversity in space and time. Cambridge, UK: Cambridge University Press.

Rousset, F. (1997). Genetic differentiation and estimation of gene flow from F-statistics under isolation by distance. Genetics, 145(4), 1219--1228.

Seifertová, M., Bryja, J., Vyskočilová, M., Martínková, N., \& Šimková, A. (2012). Multiple Pleistocene refugia and post-glacial colonization in the European chub (Squalius cephalus) revealed by combined use of nuclear and mitochondrial markers. Journal of Biogeography, 39(6), 1024-1040.

Sepkoski, J. J., \& Rex, M. A. (1974). Distribution of freshwater mussels: coastal rivers as biogeographic islands. Systematic Zoology, 23(2), 165-188.

Serrouya, R., Paetkau, D., McLellan, B. N., Boutin, S., Campbell, M., \& Jenkins, D. A. 

(2012). Population size and major valleys explain microsatellite variation better than taxonomic units for caribou in western Canada. Molecular Ecology, 21(11), 2588-2601.

Soininen, J., McDonald, R., \& Hillebrand, H. (2007). The distance decay of similarity in ecological communities. Ecography, 30(1), 3-12.

Sørensen, T. J. (1948). A method of establishing groups of equal amplitude in plant sociology based on similarity of species content, and its application to analyses of the vegetation on Danish commons. Kongelige Danske Videnskabernes Selskabs Biologiske Skrifter, 5, 134.

Tedesco, P. A., Beauchard, O., Bigorne, R., Blanchet, S., Buisson, L., Conti, L., ... Oberdorff, T. (2017). A global database on freshwater fish species occurrence in drainage basins. Scientific Data, 4(170141).

Tedesco, P. A., Leprieur, F., Hugueny, B., Brosse, S., Dürr, H. H., Beauchard, O., ... Oberdorff, T. (2012). Patterns and processes of global riverine fish endemism. Global Ecology and Biogeography, 21(10), 977-987.

Tisseuil, C., Cornu, J. F., Beauchard, O., Brosse, S., Darwall, W., Holland, R., ... Oberdorff, T. (2013). Global diversity patterns and cross-taxa convergence in freshwater systems. Journal of Animal Ecology, 82(2), 365-376.

Vellend, M. (2003). Island biogeography of genes and species. The American Naturalist, $162(3), 358-365$.

Vellend, M., \& Geber, M. A. (2005). Connections between species diversity and genetic diversity. Ecology Letters, 8(7), 767-781.

Vellend, M., \& Orrock, J. L. (2009). Ecological and genetic models of diversity. The theory of 
Vellend, M., Lajoie, G., Bourret, A., Múrria, C., Kembel, S. W., \& Garant, D. (2014). Drawing ecological inferences from coincident patterns of population- and communitylevel biodiversity. Molecular Ecology, 23(12), 2890-2901.

Wang, I. J., Glor, R. E., \& Losos, J. B. (2013). Quantifying the roles of ecology and geography in spatial genetic divergence. Ecology Letters, 16(2), 175-182.

Whitlock, M. C. (2005). Combining probability from independent tests: the weighted Zmethod is superior to Fisher's approach. Journal of Evolutionary Biology, 18(5), 1368 1373.

Whittaker, R. H. (1960). Vegetation of the Siskiyou mountains, Oregon and California. Ecological monographs, 30(3), 279-338.

Whittaker, R. H. (1972). Evolution and measurement of species diversity. Taxon, 213-251.

Wickham, H. (2007). Reshaping Data with the reshape Package. Journal of Statistical Software, 21(12), 1-20.

Wickham, H. (2016). ggplot2: Elegant Graphics for Data Analysis. New-York, NY: SpringerVerlag.

Winter, D. J. (2012). mmod: an R library for the calculation of population differentiation statistics. Molecular Ecology Resources, 12(6), 1158-1160.

Wright, S. (1943). Isolation by distance. Genetics, 28(March), 114-138. 


\section{Biosketch}

754 The authors are particularly interested in documenting and explaining spatial patterns of

755 biodiversity at large spatial scales. They try to disentangle the interplay between historical and

756 contemporary factors (including anthropogenic pressures) in shaping patterns of alpha and

757 beta diversities in aquatic populations and communities and value this knowledge to guide

758 conservation strategies of aquatic ecosystems.

\section{Supporting information}

760 Supporting information for this article may be found online.

\section{Data availability}

762 The data and the script used for the analyses are available from the Dryad Digital Repository:

763 https://doi.org/10.5061/dryad.8vb6160. 
Journal of Biogeography

\section{SUPPORTING INFORMATION}

\section{Correlations between broad-scale taxonomic and genetic differentiations suggest a dominant imprint of historical processes on beta diversities}

Marine Robuchon, Boris Leroy, Céline Jézéquel and Bernard Hugueny

Appendix S1 Characteristics of the drainage basins analysed in our study

aet $=$ mean annual actual evapotranspiration; pet $=$ mean annual potential evapotranspiration; tmoy $=$ mean annual temperature ; precsum $=$ mean annual precipitation; runoff = mean annual surface runoff; Surface_area_km = surface area; N_species = number of species with genetic data. See main text for the source of data. Mean and standard deviation (SD) over the 38 basins are given at the end of the table.

\begin{tabular}{|c|c|c|c|c|c|c|c|}
\hline Basins & aet & pet & tmoy & precsum & runoff & Surf_area_km & N_species \\
\hline Acheloos & 640 & 1066.1 & 123.27929 & 924.009 & 557.74899 & 5821.728156 & 1 \\
\hline Agly & 630 & 906.3 & 125.49053 & 770.632 & 116.367 & 1125.200682 & 3 \\
\hline Arachthos & 655 & 1034.7 & 113.31274 & 1004.44 & 742.65767 & 2473.939349 & 1 \\
\hline Aude & 625 & 928.5 & 123.53473 & 781.976 & 130.21899 & 5283.136409 & 1 \\
\hline Axios & 493 & 986.3 & 101.52936 & 601.732 & 154.31825 & 24583.23488 & 3 \\
\hline Charente & 644 & 911.6 & 120.03306 & 867.967 & 233.5864 & 9561.56072 & 1 \\
\hline Churchill & 398 & 582 & -23.90383 & 475.655 & 118.85188 & 304248.866 & 1 \\
\hline Danube & 574 & 850.7 & 87.342907 & 750.564 & 295.57456 & 802142.8624 & 16 \\
\hline Delaware & 813 & 991.2 & 91.341375 & 1148.11 & 623.8048 & 28618.74225 & 1 \\
\hline Dordogne & 682 & 935.2 & 111.27602 & 886.614 & 350.67982 & 24113.64285 & 1 \\
\hline Elbe & 507 & 721.7 & 79.989063 & 623.004 & 178.65205 & 143864.5137 & 16 \\
\hline Evinos & 629 & 1068.6 & 124.6515 & 898.565 & 462.55499 & 1105.990108 & 1 \\
\hline Evros & 525 & 994.7 & 112.64752 & 622.026 & 233.69195 & 53005.94877 & 1 \\
\hline Garonne & 653 & 932 & 111.66166 & 822.437 & 258.36741 & 55217.94818 & 2 \\
\hline Glomma & 404 & 469.2 & 8.6601708 & 730.294 & 415.933 & 41930.43322 & 4 \\
\hline Grande.USA & 333 & 1517.8 & 163.21044 & 395.802 & 11.279145 & 480465.5835 & 2 \\
\hline Guadalupe & 714 & 1510 & 198.33098 & 844.73 & 31.73177 & 15777.64583 & 1 \\
\hline Hudson & 756 & 924.8 & 71.827872 & 1118.13 & 526.25893 & 34795.07612 & 1 \\
\hline Loire & 602 & 854.6 & 105.10719 & 750.497 & 196.85747 & 116661.6899 & 2 \\
\hline Louros & 663 & 1121.3 & 145.51997 & 1040.27 & 713.57898 & 1080.177613 & 1 \\
\hline Mackenzie & 329 & 521.7 & -43.57659 & 392.294 & 160.29758 & 1680044.211 & 1 \\
\hline Meuse & 588 & 732.3 & 91.633783 & 886.959 & 285.14163 & 32856.16342 & 1 \\
\hline Mississippi & 618 & 1096.6 & 95.416708 & 759.456 & 222.75135 & 3017672.487 & 4 \\
\hline Nelson & 418 & 726 & 12.974033 & 492.429 & 95.228112 & 1019864.883 & 1 \\
\hline Odra & 489 & 737.8 & 81.363189 & 581.098 & 155.37879 & 118991.636 & 17 \\
\hline Pearl & 1119 & 1437.3 & 178.64183 & 1495.1 & 483.74908 & 21790.63225 & 1 \\
\hline
\end{tabular}




\begin{tabular}{lrrrrrrr} 
Po & 635 & 788.2 & 92.085106 & 1020.21 & 519.70202 & 73831.63159 & 5 \\
Rhine & 588 & 738.1 & 82.161385 & 872.964 & 475.19941 & 163633.2382 & 16 \\
Rhone & 629 & 802.8 & 85.285926 & 1019.07 & 479.94488 & 96827.05122 & 10 \\
Rihios & 414 & 1063.9 & 139.98324 & 484.53 & 1.7229 & 2088.952236 & 2 \\
Saint.Jean.USA & 635 & 762.6 & 36.171725 & 1049.03 & 608.68723 & 54888.62971 & 1 \\
Saint.Laurent & 629 & 811.7 & 49.93017 & 884.414 & 343.00659 & 1056005.322 & 6 \\
Sakarya & 421 & 1033.3 & 106.13612 & 497.924 & 62.963135 & 70666.64849 & 2 \\
Santee & 985 & 1322.8 & 155.71445 & 1239.84 & 132.91453 & 39531.78697 & 1 \\
Seine & 559 & 811.4 & 101.43787 & 690.465 & 173.8974 & 75984.27645 & 3 \\
Strymon & 459 & 957.1 & 104.39717 & 545.061 & 93.719109 & 16826.18541 & 1 \\
Susurluk.Cayi & 578 & 1056.4 & 120.13898 & 727.301 & 111.40774 & 23768.99736 & 4 \\
Tagus & 459 & 1097.2 & 136.86304 & 565.262 & 214.13121 & 71216.07416 & 1 \\
& & & & & & & 257588.6 \\
Mean & 591.9 & 942.2 & 97.9 & 796.3 & 288.8 & 2.6 & 3.6 \\
SD & 158.5 & 237.6 & 50.0 & 245.9 & 204.0 & 584802.5 & 4.8 \\
\hline
\end{tabular}


Appendix S2 Descriptive statistics of the datasets used for analyses

$\mathrm{N} \_$basins_genet $=$number of basins with genetic data analysed; $\mathrm{N}$ basins_native $=$ number of basins where the species is recoreded as native; Prop_basins_genet/native $=$ proportion of basins with genetic data analysed over basins where the species is recorded as native; $\mathrm{N} \_$indiv_tot $=$ total number of individuals; $N$ indiv_mean = mean number of individuals by basin; $N$ indiv_min = minimum number of individuals in a basin; $\mathrm{N} \_$indiv_max $=$maximum number of individuals in a basin. Mean and standard deviation (SD) over the 22 species are given at the end of the table.

\begin{tabular}{|c|c|c|c|c|c|c|c|}
\hline Species & N_basins_genet & N_basins_native & Prop_basins_genet/native & N_indiv_tot & N_indiv_mean & N_indiv_min & N_indiv_max \\
\hline Abramis brama & 4 & 8 & 0.500 & 46 & 12 & 6 & 16 \\
\hline Alburnoides bipunctatus & 5 & 5 & 1.000 & 31 & 6 & 4 & 13 \\
\hline Alburnus alburnus & 5 & 8 & 0.625 & 43 & 9 & 3 & 18 \\
\hline Barbatula barbatula & 4 & 4 & 1.000 & 55 & 14 & 5 & 22 \\
\hline Campostoma anomalum & 4 & 6 & 0.667 & 30 & 8 & 5 & 15 \\
\hline Chondrostoma nasus & 4 & 5 & 0.800 & 71 & 18 & 5 & 35 \\
\hline Esox lucius & 11 & 16 & 0.688 & 97 & 9 & 3 & 15 \\
\hline Gobio gobio & 7 & 8 & 0.875 & 71 & 10 & 3 & 22 \\
\hline Lampetra planeri & 4 & 6 & 0.667 & 27 & 7 & 3 & 10 \\
\hline Leuciscus aspius & 4 & 5 & 0.800 & 34 & 9 & 3 & 17 \\
\hline Leuciscus leuciscus & 4 & 5 & 0.800 & 47 & 12 & 4 & 19 \\
\hline Lota lota & 5 & 7 & 0.714 & 37 & 7 & 5 & 13 \\
\hline Notropis atherinoides & 4 & 4 & 1.000 & 25 & 6 & 4 & 11 \\
\hline Phoxinus phoxinus & 4 & 4 & 1.000 & 234 & 59 & 5 & 207 \\
\hline Rhinichthys atratulus & 5 & 5 & 1.000 & 28 & 6 & 3 & 11 \\
\hline Rhinichthys cataractae & 4 & 5 & 0.800 & 39 & 10 & 5 & 17 \\
\hline Rutilus rutilus & 6 & 11 & 0.545 & 58 & 10 & 3 & 17 \\
\hline Scardinius erythrophthalmus & 4 & 11 & 0.364 & 26 & 7 & 3 & 10 \\
\hline Squalius cephalus & 11 & 16 & 0.688 & 87 & 8 & 3 & 21 \\
\hline Telestes pleurobipunctatus & 4 & 6 & 0.667 & 20 & 5 & 3 & 9 \\
\hline Thymallus thymallus & 6 & 7 & 0.857 & 41 & 7 & 4 & 11 \\
\hline Tinca tinca & 5 & 7 & 0.714 & 32 & 6 & 3 & 13 \\
\hline Mean & 5.2 & 7.2 & 0.762 & 53.6 & 11.0 & 3.9 & 24.6 \\
\hline SD & 2.1 & 3.4 & 0.175 & 45.3 & 11.0 & 1.0 & 41.1 \\
\hline
\end{tabular}


Appendix S3 Results of the Mantel tests between taxonomic differentiation and genetic differentiation (raw correlations) and between the residuals of taxonomic differentiation and genetic differentiation (residual correlations)

$r$ is the Mantel $r$ coefficient; mean and standard deviation (SD) over the 22 species are given at the end of the table

\begin{tabular}{lrrrr}
\hline & \multicolumn{3}{r}{ Raw correlations } & \multicolumn{2}{c}{ Residual correlations } \\
Species & r & pval & r & pval \\
\hline Abramis brama & 0.539 & 0.167 & 0.949 & 0.042 \\
Alburnoides bipunctatus & 0.963 & 0.100 & 0.885 & 0.008 \\
Alburnus alburnus & -0.098 & 0.333 & -0.781 & 0.975 \\
Barbatula barbatula & 0.327 & 0.458 & 0.716 & 0.083 \\
Campostoma anomalum & 0.333 & 0.250 & -0.857 & 1.000 \\
Chondrostoma nasus & 0.841 & 0.042 & 0.784 & 0.042 \\
Esox lucius & 0.685 & 0.077 & 0.040 & 0.406 \\
Gobio gobio & 0.586 & 0.174 & 0.112 & 0.354 \\
Lampetra planeri & -0.306 & 0.583 & 0.900 & 0.083 \\
Leuciscus aspius & 0.448 & 0.167 & 0.825 & 0.042 \\
Leuciscus leuciscus & 0.511 & 0.167 & -0.989 & 1.000 \\
Lota lota & 0.918 & 0.050 & 0.793 & 0.008 \\
Notropis atherinoides & 0.725 & 0.208 & 0.221 & 0.375 \\
Phoxinus phoxinus & -0.049 & 0.708 & 0.802 & 0.042 \\
Rhinichthys atratulus & 0.488 & 0.033 & 0.682 & 0.025 \\
Rhinichthys cataractae & 0.099 & 0.625 & -0.588 & 1.000 \\
Rutilus rutilus & 0.918 & 0.006 & 0.724 & 0.008 \\
Scardinius erythrophthalmus & 0.970 & 0.250 & 0.978 & 0.042 \\
Squalius cephalus & 0.103 & 0.304 & -0.004 & 0.507 \\
Telestes pleurobipunctatus & -0.464 & 0.750 & 0.798 & 0.042 \\
Thymallus thymallus & 0.799 & 0.001 & 0.730 & 0.008 \\
Tinca tinca & 0.187 & 0.217 & 0.618 & 0.017 \\
\hline Mean & & & & \\
\hline SD & 0.433 & 0.258 & 0.379 & 0.278 \\
\hline & 0.420 & 0.229 & 0.641 & 0.376 \\
\hline
\end{tabular}


Appendix S4. Tests of the overall correlation (over the 22 species) between taxonomic differentiation and genetic differentiation for (a) the raw correlations and (b) the residual correlations (i.e. the correlations between the residuals of the multiple regressions). The $\mathrm{p}$-values associated to these tests were obtained by comparing the mean observed p-value over the species to a null distribution of $\mathrm{p}$-values. Dashed vertical lines in test plots show the mean observed p-value over the species.

(a) Raw correlations between

taxonomic differentiation and genetic differentiation

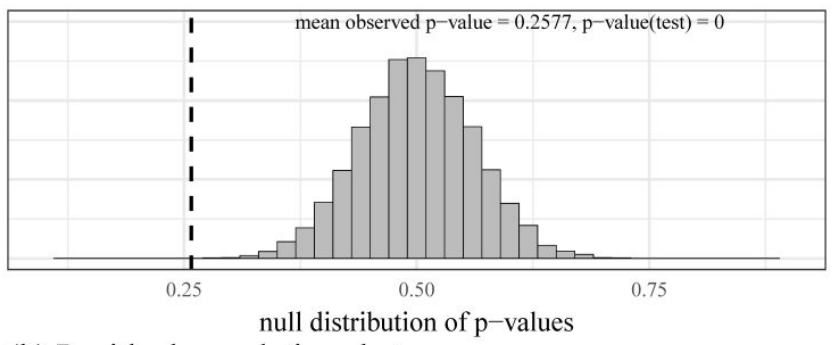

(b) Residual correlations between

taxonomic differentiation and genetic differentiation

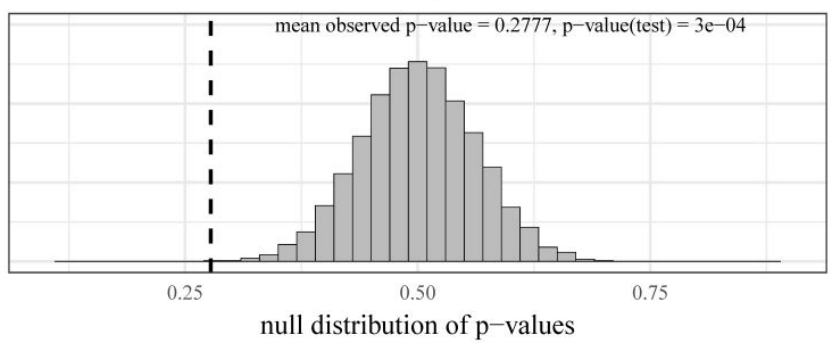


Appendix S5 Results of multiple regressions on taxonomic differentiation

All the coefficients are standardised partial regression coefficients; R2 is the total variance explained by the multiple regression; mean and standard deviation (SD) over the 22 species are given at the end of the table.

\begin{tabular}{|c|c|c|c|c|c|c|c|c|c|c|}
\hline Species & Intercept & pval.Intercept & Geo & pval.Geo & Env & pval.Env & Area & pval.Area & $\mathbf{R 2}$ & pval.R2 \\
\hline Abramis brama & 0.659 & 0.701 & 0.521 & 0.398 & 0.475 & 0.298 & -0.202 & 0.360 & 0.521 & 0.624 \\
\hline Alburnoides bipunctatus & 2.261 & 0.207 & 0.338 & 0.207 & -0.084 & 0.550 & -0.763 & 0.207 & 0.784 & 0.020 \\
\hline Alburnus alburnus & 2.194 & 0.199 & 0.416 & 0.079 & -0.669 & 0.813 & -0.670 & 0.164 & 0.388 & 0.367 \\
\hline Barbatula barbatula & 0.659 & 0.628 & 0.521 & 0.326 & 0.475 & 0.138 & -0.202 & 0.323 & 0.521 & 0.624 \\
\hline Campostoma anomalum & 0.672 & 0.882 & 0.305 & 0.461 & 0.570 & 0.329 & 0.324 & 0.700 & 0.797 & 0.288 \\
\hline Chondrostoma nasus & 0.659 & 0.705 & 0.521 & 0.406 & 0.475 & 0.301 & -0.202 & 0.366 & 0.521 & 0.624 \\
\hline Esox lucius & 0.317 & 0.092 & 0.558 & 0.090 & 0.073 & 0.267 & 0.410 & 0.989 & 0.702 & 0.000 \\
\hline Gobio gobio & 1.402 & 0.445 & 0.150 & 0.331 & 0.015 & 0.438 & -0.711 & 0.099 & 0.602 & 0.001 \\
\hline Lampetra planeri & 1.962 & 0.844 & 0.470 & 0.387 & 0.195 & 0.503 & -0.389 & 0.330 & 0.978 & 0.032 \\
\hline Leuciscus aspius & -0.253 & 0.908 & -0.333 & 0.540 & 0.641 & 0.460 & 0.083 & 0.464 & 0.085 & 0.975 \\
\hline Leuciscus leuciscus & 0.659 & 0.618 & 0.521 & 0.326 & 0.475 & 0.126 & -0.202 & 0.331 & 0.521 & 0.624 \\
\hline Lota lota & 0.421 & 0.794 & 0.770 & 0.233 & 0.568 & 0.142 & 0.036 & 0.628 & 0.853 & 0.007 \\
\hline Notropis atherinoides & 0.605 & 0.710 & 0.101 & 0.461 & 0.426 & 0.379 & -0.303 & 0.369 & 0.594 & 0.542 \\
\hline Phoxinus phoxinus & 0.659 & 0.629 & 0.521 & 0.375 & 0.475 & 0.131 & -0.202 & 0.332 & 0.521 & 0.624 \\
\hline Rhinichthys atratulus & 0.344 & 0.859 & 0.061 & 0.510 & -0.287 & 0.684 & 0.513 & 0.791 & 0.314 & 0.488 \\
\hline Rhinichthys cataractae & -9.883 & 0.373 & -4.072 & 0.882 & 4.147 & 0.079 & 1.821 & 0.830 & 0.576 & 0.563 \\
\hline Rutilus rutilus & 1.819 & 0.391 & 0.312 & 0.164 & -0.132 & 0.559 & -0.875 & 0.089 & 0.873 & 0.000 \\
\hline Scardinius erythrophthalmus & -0.590 & 0.748 & -0.385 & 0.662 & -0.219 & 0.670 & -0.712 & 0.167 & 0.789 & 0.299 \\
\hline Squalius cephalus & 0.034 & 0.956 & -0.025 & 0.527 & 0.228 & 0.196 & -0.044 & 0.423 & 0.052 & 0.434 \\
\hline Telestes pleurobipunctatus & -87.769 & 0.253 & -1.617 & 0.829 & 1.548 & 0.171 & 0.086 & 0.423 & 0.867 & 0.192 \\
\hline Thymallus thymallus & 1.903 & 0.715 & 0.215 & 0.368 & -0.089 & 0.542 & -0.654 & 0.120 & 0.353 & 0.172 \\
\hline Tinca tinca & 7.394 & 0.550 & 0.839 & 0.397 & -0.389 & 0.603 & -1.071 & 0.196 & 0.802 & 0.016 \\
\hline Mean & -3.358 & 0.600 & 0.032 & 0.407 & 0.405 & 0.381 & -0.178 & 0.395 & 0.592 & 0.342 \\
\hline SD & 19.067 & 0.254 & 1.051 & 0.204 & 0.956 & 0.214 & 0.617 & 0.250 & 0.249 & 0.288 \\
\hline
\end{tabular}


Appendix S6 Results of multiple regressions on genetic differentiation

All the coefficients are standardised partial regression coefficients; R2 is the total variance explained by the multiple regression; mean and standard deviation (SD) over the 22 species are given at the end of the table.

Table S6.1 Results when genetic differentiation is measured with G' ${ }_{\text {ST }}$

\begin{tabular}{|c|c|c|c|c|c|c|c|c|c|c|}
\hline Species & Intercept & pval.Intercept & Geo & pval.Geo & Env & pval.Env & Area & pval.Area & $\mathbf{R 2}$ & pval.R2 \\
\hline Abramis brama & -7.853 & 0.142 & -1.278 & 0.954 & 0.630 & 0.089 & 1.047 & 1.000 & 0.286 & 0.847 \\
\hline Alburnoides bipunctatus & 1.667 & 0.375 & 0.156 & 0.349 & 0.045 & 0.496 & -0.760 & 0.204 & 0.739 & 0.035 \\
\hline Alburnus alburnus & 0.928 & 0.791 & 0.034 & 0.619 & -0.084 & 0.442 & -0.694 & 0.359 & 0.448 & 0.280 \\
\hline Barbatula barbatula & 2.138 & 0.562 & 0.224 & 0.343 & 0.030 & 0.457 & -0.854 & 0.174 & 0.466 & 0.682 \\
\hline Campostoma anomalum & 3.536 & 0.001 & 1.136 & 0.000 & -0.347 & 0.902 & -0.042 & 0.310 & 0.931 & 0.101 \\
\hline Chondrostoma nasus & -0.458 & 0.952 & -0.165 & 0.582 & 0.650 & 0.167 & 0.463 & 0.671 & 0.417 & 0.731 \\
\hline Esox lucius & 1.025 & 0.097 & 1.021 & 0.097 & -0.103 & 0.627 & -0.138 & 0.335 & 0.927 & 0.000 \\
\hline Gobio gobio & 5.610 & 0.120 & 0.768 & 0.132 & -0.335 & 0.848 & -0.511 & 0.144 & 0.737 & 0.000 \\
\hline Lampetra planeri & 2.266 & 0.286 & 0.552 & 0.000 & -0.742 & 1.000 & 0.397 & 1.000 & 0.335 & 0.806 \\
\hline Leuciscus aspius & -1.954 & 0.658 & -0.992 & 0.711 & 0.147 & 0.437 & -0.460 & 0.314 & 0.545 & 0.598 \\
\hline Leuciscus leuciscus & -2.365 & 1.000 & -0.210 & 0.511 & 0.944 & 0.162 & 0.725 & 0.671 & 0.962 & 0.056 \\
\hline Lota lota & 0.710 & 0.476 & 0.884 & 0.216 & 0.295 & 0.236 & -0.094 & 0.507 & 0.757 & 0.028 \\
\hline Notropis atherinoides & -0.801 & 0.833 & -0.255 & 0.594 & 0.500 & 0.244 & -0.685 & 0.163 & 0.999 & 0.001 \\
\hline Phoxinus phoxinus & 1.527 & 0.751 & 0.047 & 0.468 & -0.304 & 0.754 & -0.870 & 0.218 & 0.725 & 0.382 \\
\hline Rhinichthys atratulus & -1.992 & 0.417 & -0.723 & 0.839 & 0.867 & 0.159 & 0.171 & 0.572 & 0.234 & 0.633 \\
\hline Rhinichthys cataractae & -1.374 & 0.198 & -3.698 & 1.000 & 3.493 & 0.000 & 1.875 & 1.000 & 0.380 & 0.766 \\
\hline Rutilus rutilus & 0.772 & 0.679 & 0.039 & 0.505 & 0.327 & 0.292 & -0.682 & 0.130 & 0.872 & 0.000 \\
\hline Scardinius erythrophthalmus & -0.167 & 1.000 & -0.275 & 0.523 & -0.331 & 0.499 & -0.799 & 0.242 & 0.929 & 0.105 \\
\hline Squalius cephalus & 3.345 & 0.024 & 0.848 & 0.011 & 0.069 & 0.383 & 0.222 & 0.760 & 0.813 & 0.000 \\
\hline Telestes pleurobipunctatus & 99.964 & 0.175 & 1.305 & 0.000 & -0.826 & 1.000 & 0.275 & 0.825 & 0.657 & 0.467 \\
\hline Thymallus thymallus & 2.520 & 0.570 & 0.255 & 0.330 & 0.175 & 0.378 & -0.742 & 0.069 & 0.639 & 0.009 \\
\hline Tinca tinca & 1.026 & 0.877 & 0.092 & 0.470 & -0.054 & 0.496 & 0.131 & 0.591 & 0.036 & 0.972 \\
\hline Mean & 5.003 & 0.499 & -0.011 & 0.420 & 0.229 & 0.457 & -0.092 & 0.466 & 0.629 & 0.341 \\
\hline SD & 21.381 & 0.334 & 1.060 & 0.305 & 0.865 & 0.293 & 0.713 & 0.308 & 0.271 & 0.350 \\
\hline
\end{tabular}


Table S6.2 Results when genetic differentiation is measured with $\mathrm{F}_{\mathrm{ST}}$

\begin{tabular}{|c|c|c|c|c|c|c|c|c|c|c|}
\hline Species & Intercept & pval.Intercept & Geo & pval.Geo & Env & pval.Env & Area & pval.Area & $\mathbf{R 2}$ & pval.R2 \\
\hline Abramis brama & 0.808 & 0.810 & 0.170 & 0.481 & -0.633 & 0.778 & -0.813 & 0.277 & 0.698 & 0.416 \\
\hline Alburnoides bipunctatus & -1.278 & 0.198 & -0.268 & 1.000 & 0.228 & 0.000 & 0.113 & 0.655 & 0.044 & 0.961 \\
\hline Alburnus alburnus & -3.214 & 0.108 & -0.621 & 0.902 & 1.165 & 0.144 & 0.723 & 0.906 & 0.599 & 0.118 \\
\hline Barbatula barbatula & -4.092 & 0.543 & -0.765 & 0.718 & 0.205 & 0.379 & 1.140 & 0.803 & 0.324 & 0.816 \\
\hline Campostoma anomalum & 1.264 & 0.706 & -0.093 & 0.530 & -0.702 & 0.797 & -0.207 & 0.627 & 0.675 & 0.446 \\
\hline Chondrostoma nasus & -0.127 & 0.870 & -0.098 & 0.532 & 0.722 & 0.180 & 0.191 & 0.619 & 0.469 & 0.679 \\
\hline Esox lucius & 0.230 & 0.357 & -0.119 & 0.571 & -0.155 & 0.726 & 0.051 & 0.538 & 0.038 & 0.578 \\
\hline Gobio gobio & 1.649 & 0.540 & 0.183 & 0.298 & -0.276 & 0.789 & -0.120 & 0.338 & 0.047 & 0.839 \\
\hline Lampetra planeri & -4.038 & 0.379 & -1.397 & 0.699 & 1.337 & 0.343 & 0.033 & 0.419 & 0.944 & 0.082 \\
\hline Leuciscus aspius & -1.608 & 0.309 & -1.292 & 1.000 & 0.829 & 0.113 & -0.268 & 0.340 & 0.380 & 0.766 \\
\hline Leuciscus leuciscus & -2.876 & 0.398 & -0.536 & 0.763 & 0.103 & 0.326 & -0.043 & 0.502 & 0.308 & 0.829 \\
\hline Lota lota & 0.661 & 0.263 & 1.058 & 0.196 & 0.309 & 0.214 & -0.275 & 0.262 & 0.971 & 0.000 \\
\hline Notropis atherinoides & -1.436 & 0.958 & -0.390 & 0.505 & 0.609 & 0.495 & -0.626 & 0.493 & 0.963 & 0.055 \\
\hline Phoxinus phoxinus & 15.134 & 0.169 & 1.609 & 0.169 & -0.234 & 0.792 & -2.050 & 0.123 & 0.986 & 0.021 \\
\hline Rhinichthys atratulus & 2.101 & 0.398 & 0.640 & 0.219 & -0.560 & 0.778 & -0.278 & 0.242 & 0.172 & 0.748 \\
\hline Rhinichthys cataractae & 0.363 & 0.865 & -0.235 & 0.553 & 0.169 & 0.443 & 0.630 & 0.756 & 0.282 & 0.850 \\
\hline Rutilus rutilus & -1.722 & 0.109 & -0.469 & 0.991 & 1.028 & 0.033 & 0.102 & 0.603 & 0.582 & 0.019 \\
\hline Scardinius erythrophthalmus & 6.458 & 0.254 & 0.950 & 0.000 & -0.552 & 1.000 & 0.458 & 0.747 & 0.605 & 0.530 \\
\hline Squalius cephalus & 0.188 & 0.808 & -0.038 & 0.565 & -0.065 & 0.511 & 0.019 & 0.453 & 0.010 & 0.913 \\
\hline Telestes pleurobipunctatus & 100.388 & 0.339 & 1.331 & 0.159 & -0.821 & 0.749 & 0.261 & 0.497 & 0.683 & 0.436 \\
\hline Thymallus thymallus & 3.549 & 0.310 & 0.529 & 0.222 & -0.608 & 0.855 & -0.340 & 0.218 & 0.171 & 0.543 \\
\hline Tinca tinca & -0.616 & 0.847 & -0.148 & 0.586 & 0.652 & 0.148 & -0.214 & 0.375 & 0.512 & 0.202 \\
\hline Mean & 5.081 & 0.479 & 0.000 & 0.530 & 0.125 & 0.481 & -0.069 & 0.490 & 0.476 & 0.493 \\
\hline SD & 21.673 & 0.277 & 0.774 & 0.295 & 0.648 & 0.310 & 0.623 & 0.209 & 0.324 & 0.333 \\
\hline
\end{tabular}


Appendix S7. Tests of the overall effects (over the 22 species) of geographic distance, environmental distance and difference in area on (a) taxonomic differentiation, (b) genetic differentiation measured with G"' ${ }_{\text {ST }}$ and (c) genetic differentiation measured with $\mathrm{F}_{\mathrm{ST}}$. The p-values associated to these tests were obtained by comparing the mean observed p-value over the species associated to each effect to a null distribution of $p$-values. Dashed vertical lines in test plots show the mean observed p-value over the species.

(a) Multiple regressions on taxonomic differentiation

Geographic distance

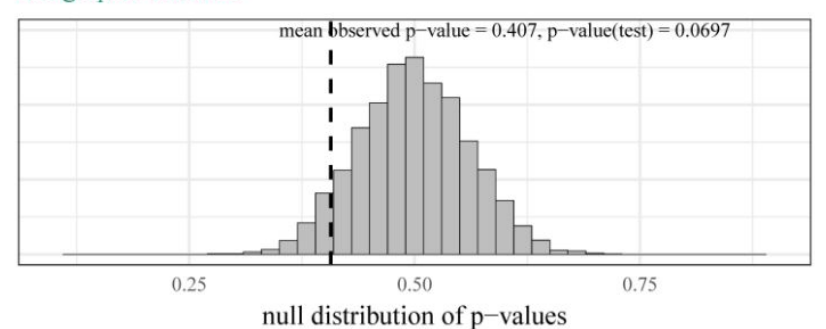

Environmental distance

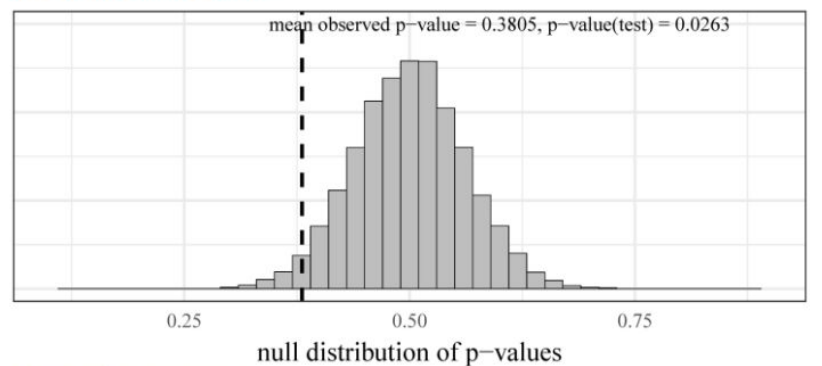

Harmonic mean area

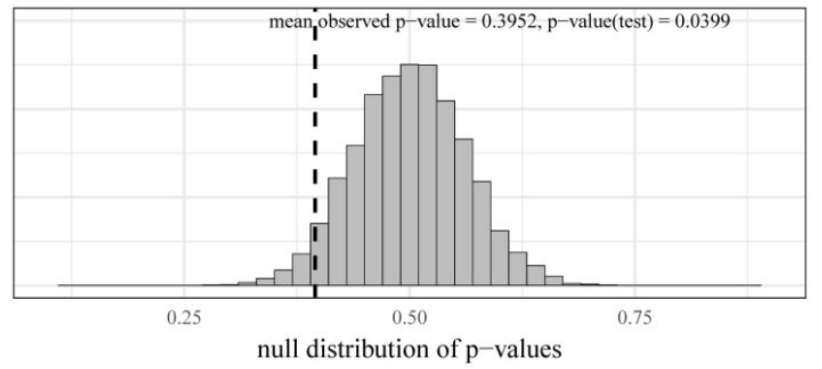

(b) Multiple regression on genetic differentiation ( $\left.G^{\prime \prime}{ }_{S T}\right)$ Geographic distance

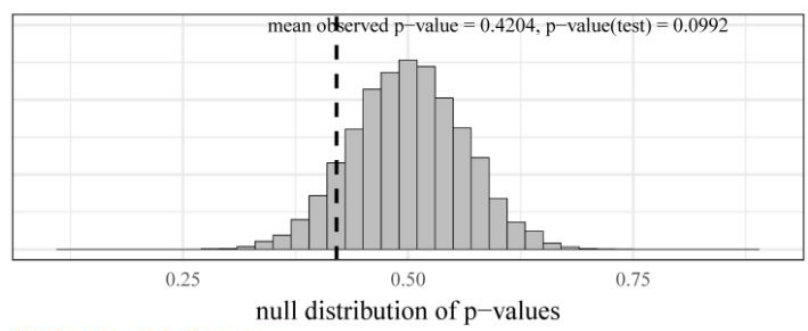

Environmental distance

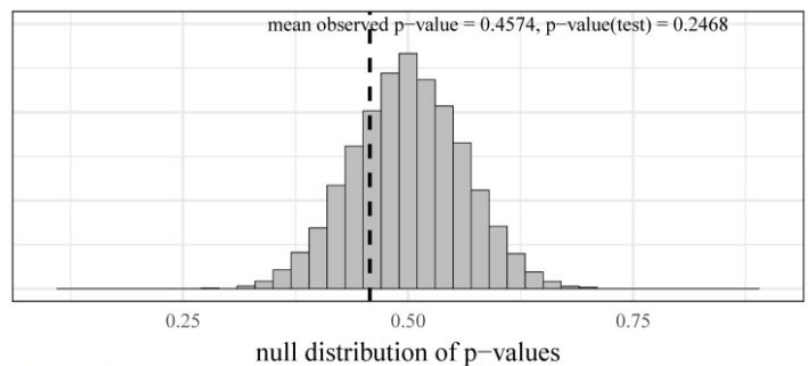

Harmonic mean area

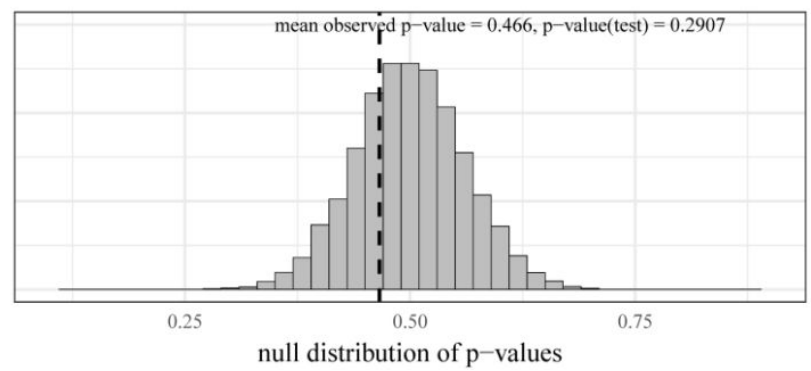


(c) Multiple regressions on genetic differentiation $\left(\mathrm{F}_{\mathrm{ST}}\right)$

Geographic distance

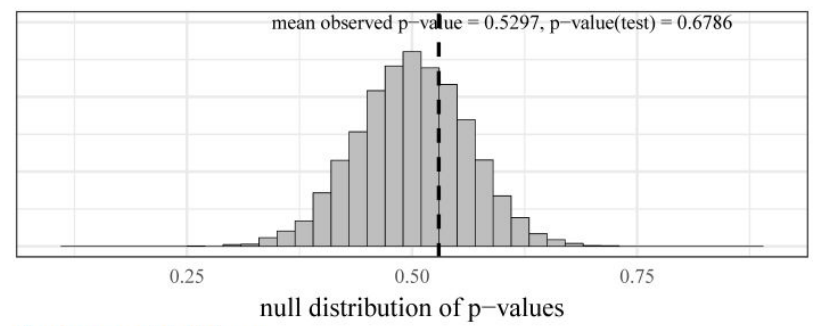

Environmental distance

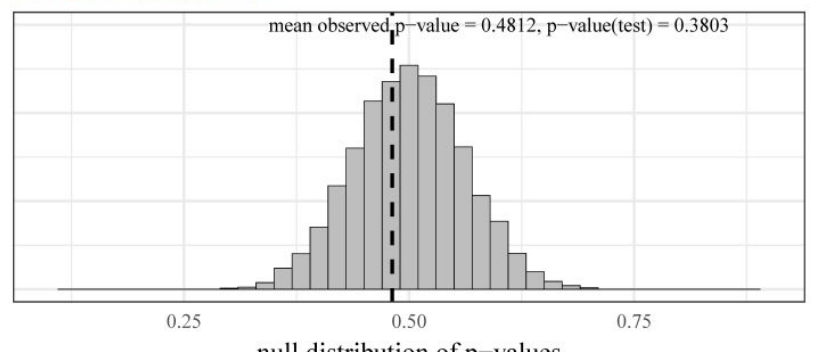

null distribution of $\mathrm{p}$-values

Harmonic mean area

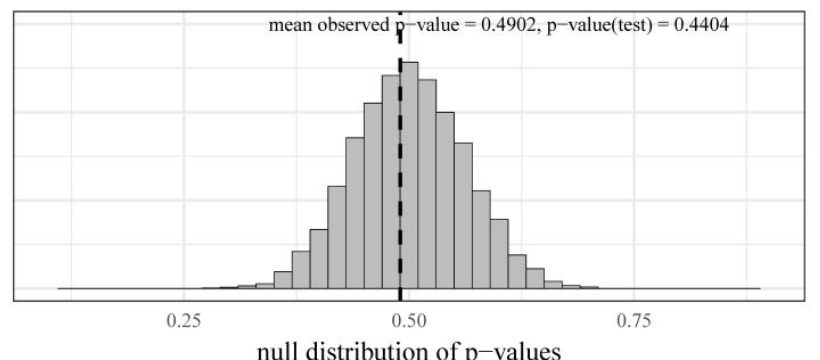


Appendix S8. Variations of the residual correlation coefficient between taxonomic differentiation and genetic differentiation (r) according to different species traits: (a) length, (b) dispersal ability, (c) longevity in the wild, (d) vulnerability, (e) use in aquaculture, (f) use as baits, (g) use in aquarium and (h) habitat.

(a) Length

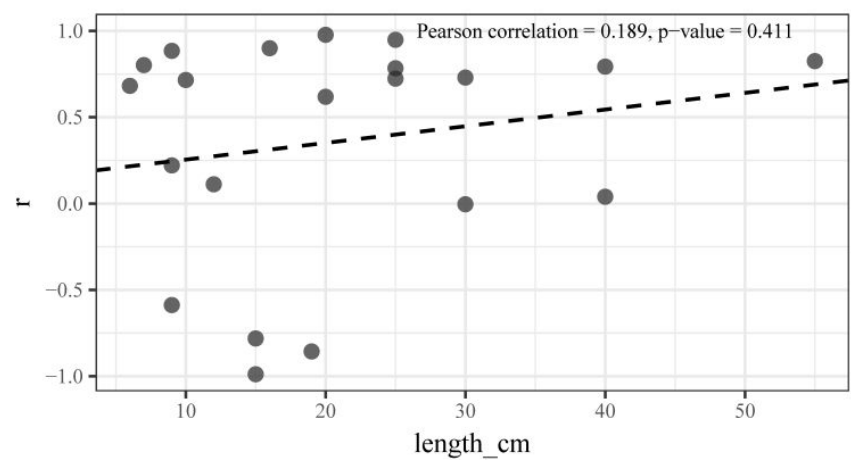

(c) Longevity in the wild

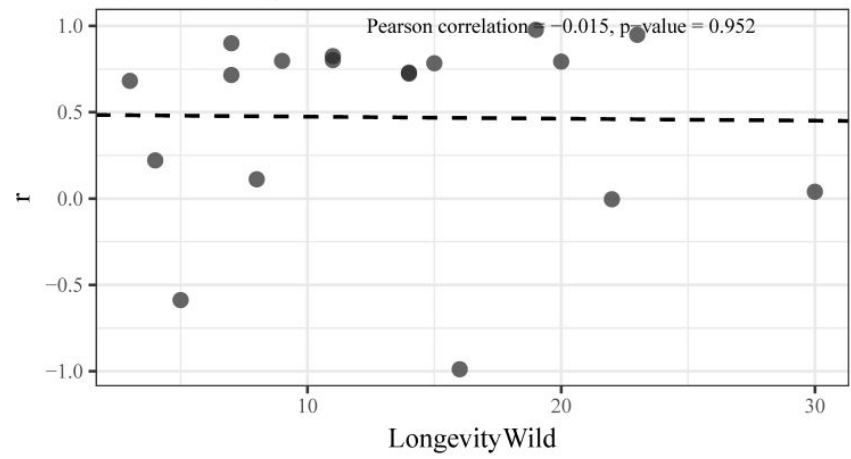

(e) Used for aquaculture

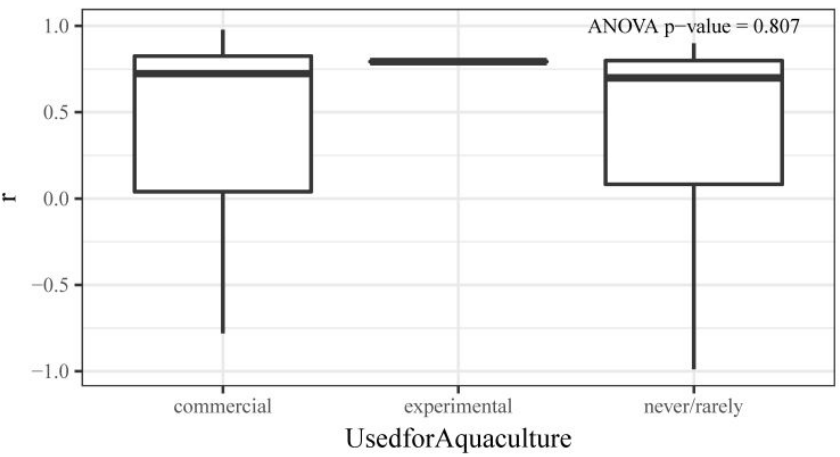

(g) Used in aquarium

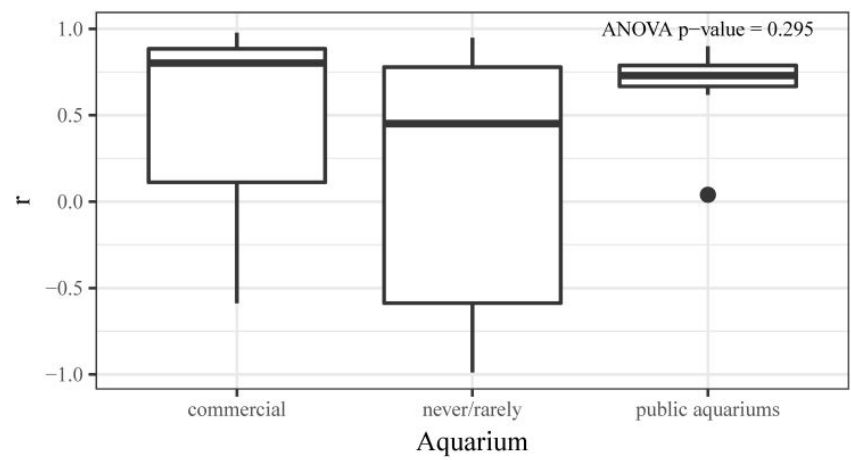

(b) Dispersal ability

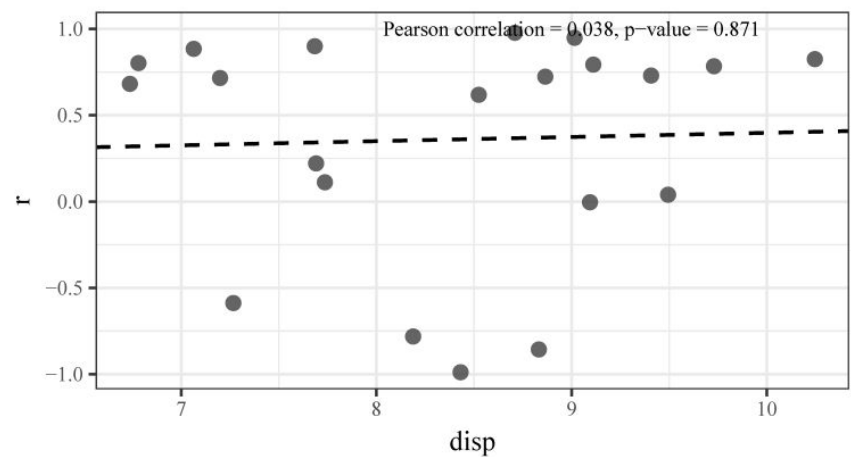

(d) Vulnerability

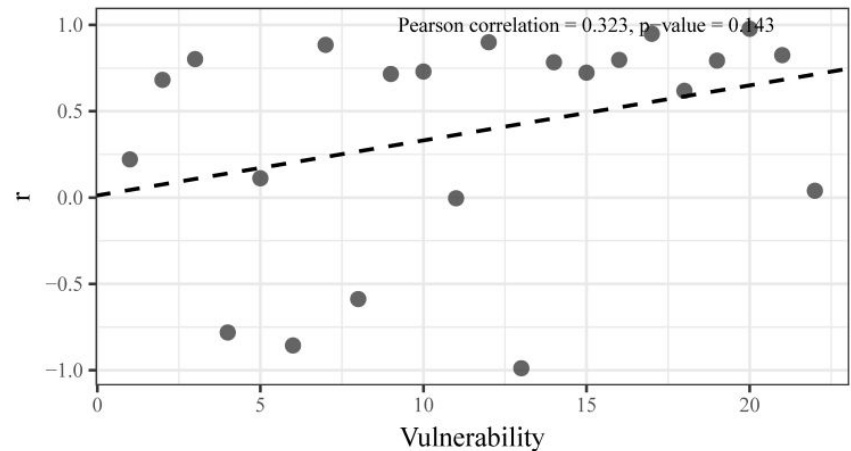

(f) Used as bait

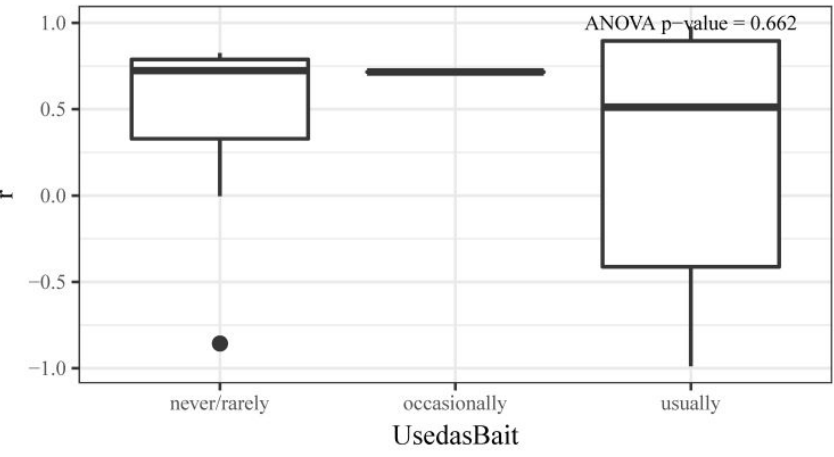

(h) Habitat

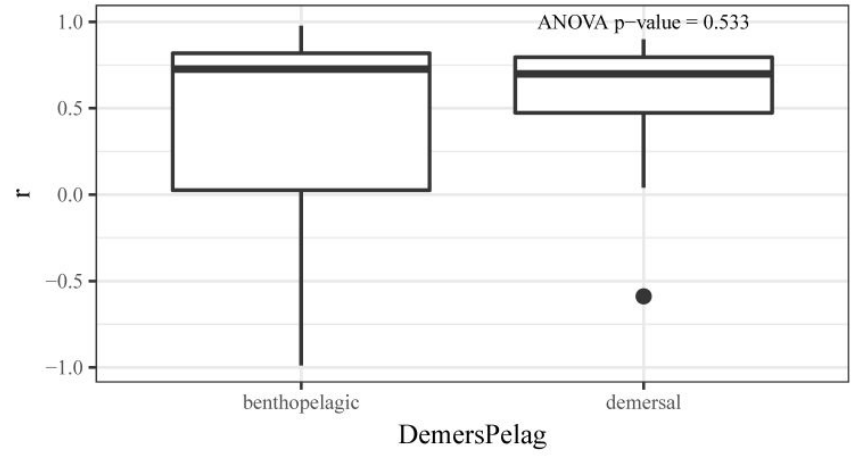



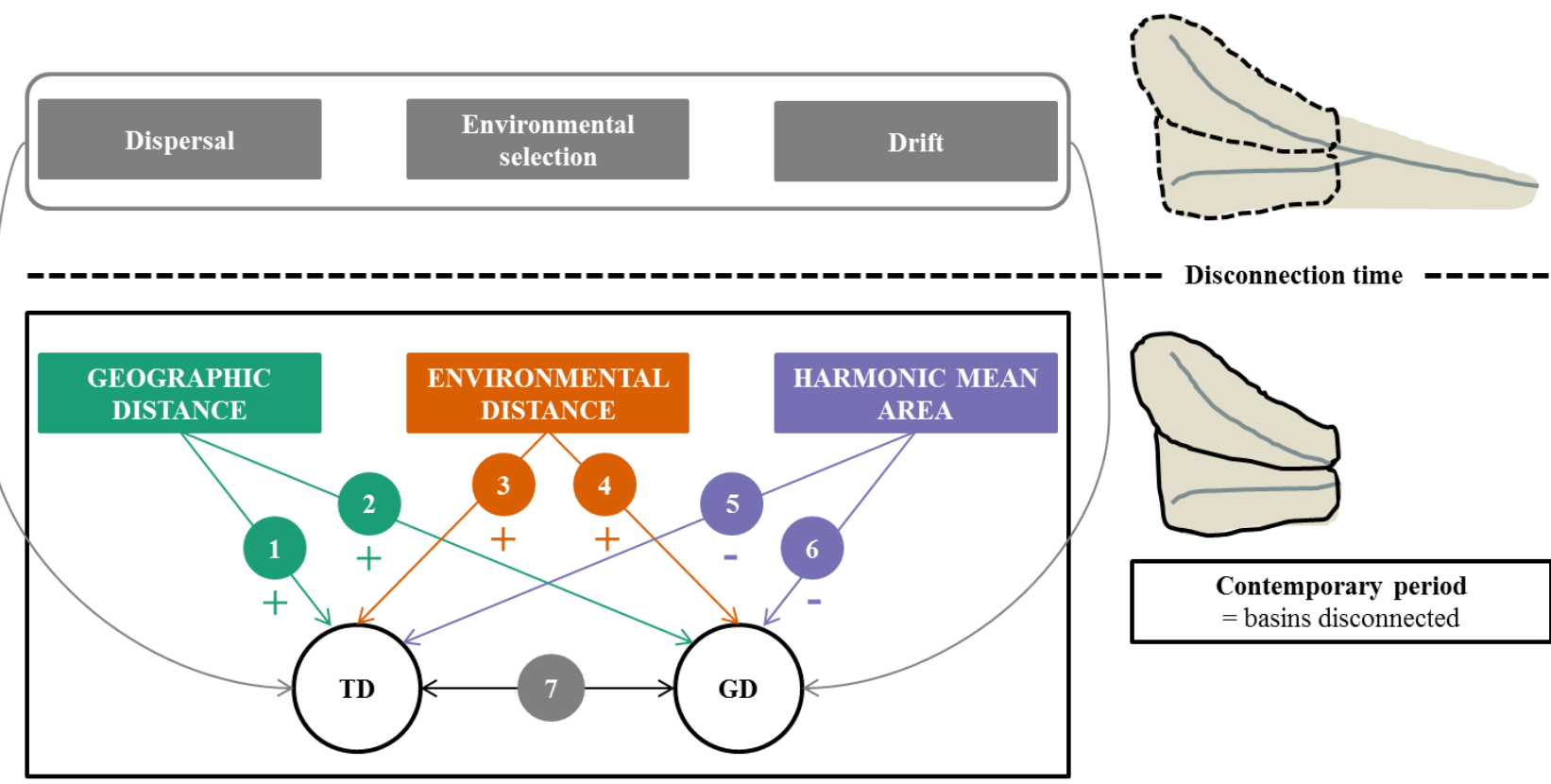

\section{Disconnection time}

1 Taxonomic differentiation is expected to increase with geographical distance because of dispersal limitation

3 Taxonomic differentiation is expected to increase with environmental distance because of environmental selection

Taxonomic differentiation is expected to increase with drift which decreases with harmonic mean area

\section{Journal of Biogeography}

2 Genetic differentiation is expected to increase with geographical distance because of dispersal limitation

4 Genetic differentiation is expected to increase with environmental distance because of environmental selection

6 Genetic differentiation is expected to increase with drift which decreases with harmonic mean area

Contemporary period $=$ basins disconnected

Residual correlation due to unmeasured processes including

those depending on the historical connectivity of basins 
(a) Multiple regressions on taxonomic differentiation

(b) Multiple regressions on genetic differentiation

Page 95 of 97 untypeset proof

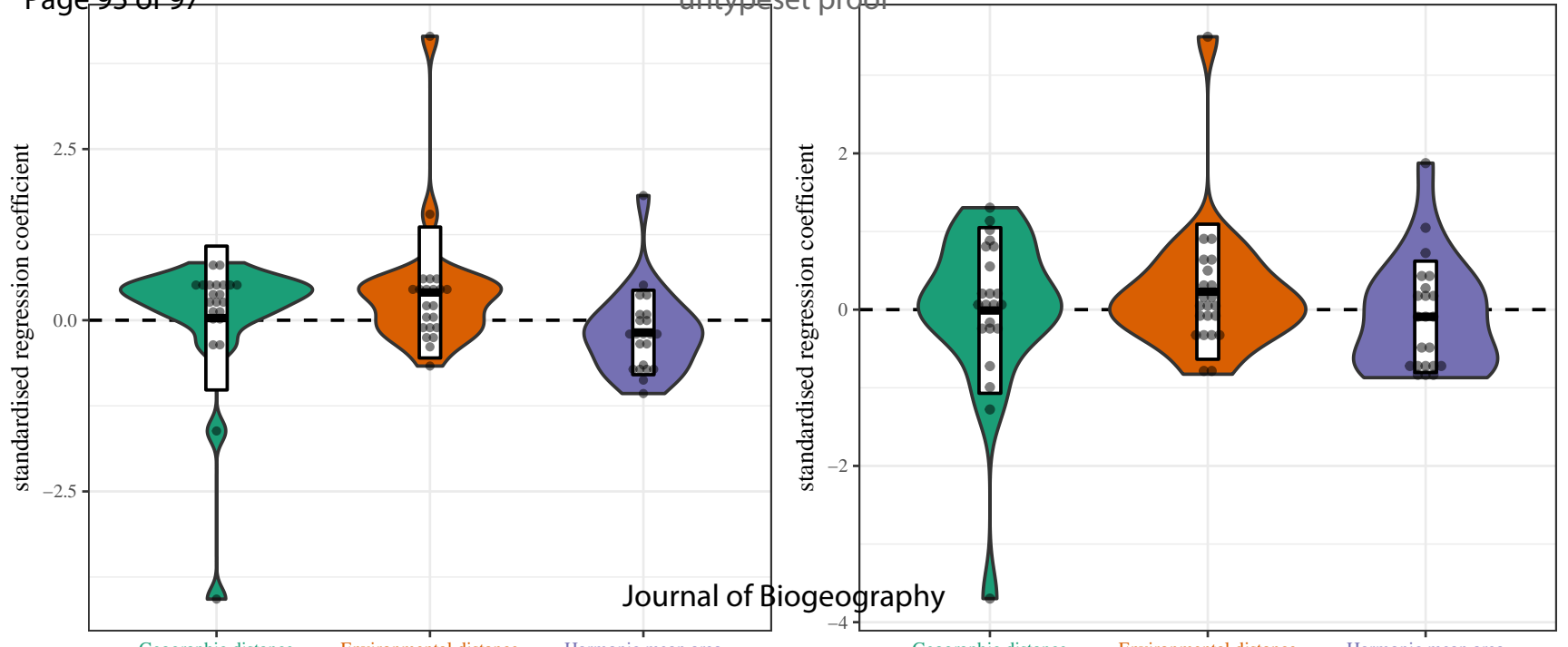


GEOGRAPHIC DISTANCE
ENVIRONMENTAE DISTANCE

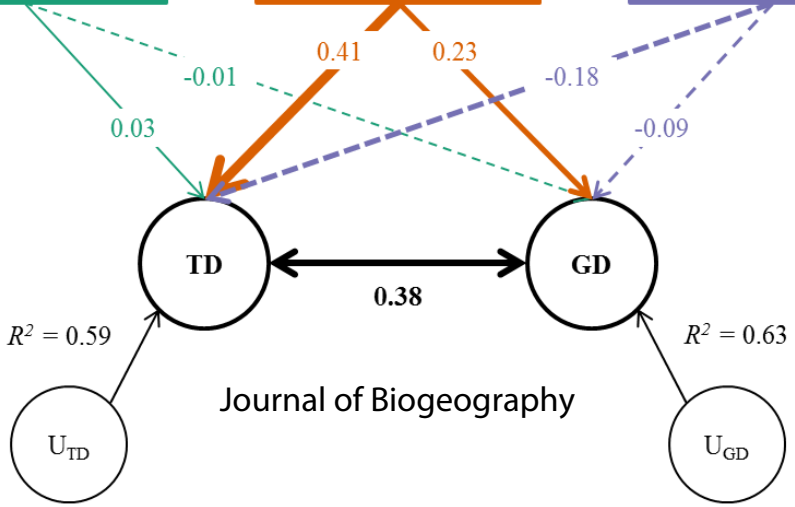


